NBER WORKING PAPER SERIES

\title{
POLITICAL ECONOMY OF SOVEREIGN DEBT: A THEORY OF CYCLES OF POPULISM AND AUSTERITY
}

\author{
Alessandro Dovis \\ Mikhail Golosov \\ Ali Shourideh \\ Working Paper 21948 \\ http://www.nber.org/papers/w21948
NATIONAL BUREAU OF ECONOMIC RESEARCH
1050 Massachusetts Avenue
Cambridge, MA 02138
January 2016

We thank Andy Abel, Mark Aguiar, Manuel Amador, V. V. Chari, Pablo D'Erasmo, Joao Gomes, Emmanuel Farhi, Larry Jones, Tasos Karantounias, Patrick Kehoe, Juan Pablo Nicolini and Chris Phelan and seminar participants at Carnegie Mellon, EUI, Ohio State, Princeton, Rochester, UPenn, Wharton, 2014 Pizzanomics Conference, SED, Minnesota Workshop in Macroeconomic Theory, Stony Brook Workshop in Political Economy, ITAM-PIER conference, NBER conference on macroeconomics within and across borders for valuable comments. We thank Gaston Chaumont for valuable research assistance. Golosov thanks the National Science Foundation for financial support. Shourideh thanks the Rodney White Center for Financial Research for support. The views expressed herein are those of the authors and do not necessarily reflect the views of the National Bureau of Economic Research.

NBER working papers are circulated for discussion and comment purposes. They have not been peerreviewed or been subject to the review by the NBER Board of Directors that accompanies official NBER publications.

(C) 2016 by Alessandro Dovis, Mikhail Golosov, and Ali Shourideh. All rights reserved. Short sections of text, not to exceed two paragraphs, may be quoted without explicit permission provided that full credit, including $\odot$ notice, is given to the source. 
Political Economy of Sovereign Debt: A Theory of Cycles of Populism and Austerity Alessandro Dovis, Mikhail Golosov, and Ali Shourideh

NBER Working Paper No. 21948

January 2016

JEL No. E60,F30,F34

\begin{abstract}
$\underline{\text { ABSTRACT }}$
We study optimal fiscal and redistributive policies in an open economy without commitment. Due to its redistributive motives, the government's incentive to default on its external debt is affected by inequality. We show that in equilibrium the economy endogenously fluctuates between two regimes. In the first regime, the government borrows from abroad, spends generously on transfers and keeps the inequality low. In the second regime, it implements austerity-like policies by cutting transfers, reducing foreign debt and increasing the inequality. The equilibrium dynamics resembles the populist cycles documented in many developing countries.
\end{abstract}

Alessandro Dovis

Department of Economics

Pennsylvania State University

615 Kern Graduate Building

University Park, PA 16802

and NBER

aledovis@gmail.com

Mikhail Golosov

Department of Economics

Princeton University

111 Fisher Hall

Princeton, NJ 08544

and NBER

golosov@princeton.edu
Ali Shourideh

University of Pennsylvania

Wharton School

shouride@wharton.upenn.edu 


\section{Introduction}

Fiscal policies in many developing countries often follow boom-bust fluctuations, sometimes called "populist cycles". During the boom phase of the cycle, a country borrows from abroad, runs a current account deficit, and spends generously on direct and indirect transfers such as welfare programs, pensions, compensation packages in state sector. The boom is followed by a bust phase characterized by debt crisis, current account surplus, a reversal in redistributive policies, and an implementation of drastic austerity measures. ${ }^{1}$ The rationale for these cycles in fiscal and redistributive policies is not well-understood.

In this paper, we study the interaction between external borrowing and redistribution in a neoclassical model with political frictions, and show that populist cycles can arise endogenously in such settings. We develop a tractable heterogeneous-agent overlapping generations framework where government's redistributive motives determine fiscal policies. Our framework has three types of agents. First, there are households that are heterogeneous with respect to their labor productivity when they are young; they decide how much to work and how much to save. Second, there are foreign creditors who lend to the government and have an opportunity cost of lending given by the international interest rate. Third, there is a government that imposes taxes on labor income and wealth, provides transfers to young and old households, and issues domestic and external debt. The government is benevolent and cares about a weighted average of utilities of agents in the current, and possibly future, generations. The key assumption is that the government cannot commit to future policies.

When the government lacks commitment, it faces ex-post incentives to default on external debt, increase wealth taxes and reduce inequality. To formally analyze these incentives, we study a repeated game between the government, households, and foreign lenders. In this setting, future governments' incentive to deviate from equilibrium strategies are captured by sustainability constraints, which specify that the payoff to the government at each point in time must be above a certain level. These incentives increase in both external debt and inequality that future governments inherit.

We show that despite the complexity and various degrees of heterogeneity in our model, it is possible to write the optimal policy problem recursively in terms of two aggregate variables: the stock of external debt for the government and the level of wealth inequality among the current old. This recursive formulation allows us to characterize the dynamics of policies and allocations in terms of trade-offs between external debt and inequality implied by our framework.

\footnotetext{
${ }^{1}$ Dornbusch and Edwards (1991) and Sachs (1989) documented extensively populist cycles in the context of Latin American economies. The recent experiences of some of the Southern European economies show a similar cyclical pattern. We discuss this evidence in section 6.
} 
In our setup, inequality and external debt contribute to financing spending for the government. Evidently, external debt increases resources currently available. Additionally, to incentivize young agents to work, the current government wants to keep current labor taxes and future wealth taxes relatively low. This results in wealth inequality among the future old. The future governments, on the other hand, have incentives to increase wealth taxes and to redistribute this wealth inequality and default on external debt.

The key insight of our model is that the current and future governments disagree on the composition of inequality and external debt, and that this disagreement gives rise to cyclical dynamics. The current government prefers to finance any given level of current consumption with a higher level of debt and lower inequality than the future government does. The reason is that delivering a unit of consumption via borrowing is cheaper than via production, since it does not incur the disutility of effort (as well as inequality in consumption and leisure). The future government, however, prefers that consumption be financed with lower debt and higher inequality. This is because the future government does not incur the leisure cost of production and the cost of inequality of consumption and leisure.

The main result of our paper regarding cycles follows from this conflict of interest. In fact, the dynamics of the economy can be characterized by how future values of inequality and debt respond to changes in the current value of debt. There are two regimes: first, when inherited external debt is low, in which case the sustainability constraint is slack; second, when inherited external debt is high, in which case the sustainability constraint is binding.

In the first regime, the current government does not face any constraint imposed by reoptimization of the future government. In this regime, a government that starts a period with higher external debt rolls over more external debt into the future and keeps transfers lower (and thus inequality higher) to service higher gross interest payment.

In the second regime, the current government is constrained by re-optimization incentives by the future government. In this regime, an increase in inherited debt tightens this constraint. As a result, once future sustainability constraints bind, the composition of debt and inequality has to be realigned with future governments' preferences: external debt needs to be cut which in part is accomplished by lowering transfers and increasing inequality. The larger is the debt level when a country enters this regime, the bigger is the re-alignment. This implies that future debt issuance is a decreasing function of the current debt in the second regime.

The fact that future debt decreases in current debt has two implications. First, it shows that debt dynamics is generally cyclical. The larger is the amount of external debt accumulated prior to entering the state of the world in which this adjustment occurs, the larger is the amplitude of the fiscal cycle. Second, the cut in the external debt in the sec- 
ond regime is achieved in part by a large decrease in transfers, leading to an increase in inequality. This resembles austerity.

Thus, the economy typically fluctuates between two phases. It experiences a period of low external debt that leads to expansion of transfer programs and the welfare state. This period is then followed by one in which external debt is low, and the government reduces transfers and encourages production. Hence, it exhibits cycles of austerity and populism as documented by Dornbusch and Edwards (1991) and Sachs (1989).

We first illustrate our main insight in a simple deterministic economy in which the government's objective is given by a weighted average of utilities of all currently and future households, and policies are constrained so that utility of future governments cannot fall below an exogenous threshold. When international interest rate is lower than government's discount rate across generations, the economy's unique steady state is in the constrained region. Convergence to this steady state occurs via endogenous fluctuations in fiscal policy.

We then extend this analysis to a probabilistic voting model as in Lindbeck and Weibull (1987). We characterize various equilibria of this game: the best subgame perfect equilibrium in the spirit of Chari and Kehoe (1990) and the Markov equilibrium in the spirit of Eaton and Gersovitz (1981). As in the basic setup, we show that the conflict of interest regarding the mixture of inequality and external debt in these equilibria yields cyclical policy dynamics.

We also study an extension of our baseline model to a stochastic setting by introducing shocks to terms of trade. An important feature of this extension is that cycles of populism and austerity recur in the long-run. In fact, in the stochastic steady state of the model, a one-time temporary shock to terms of trade, can lead to oscillatory dynamics in fiscal policy. Finally, due to the implementation of austerity measures, current account surplus can be positive even in bad times in contrast with models with a representative agent.

In the last section of the paper, we discuss the historical evidence regarding the cyclical pattern of fiscal policy and external debt. We provide evidence from Argentina and Chile where the policy dynamics is in line with fluctuations implied by our model. We also show how the experience of Southern European countries in the last two decades is consistent with the predictions of our model.

Literature Review. Our paper contributes to several strands of the literature in macroeconomics, public finance, and international economics.

Our work is mostly related to the large literature in macroeconomics and international economics that analyzes government's choices of fiscal and debt policy over time and business cycles (e.g., Lucas and Stokey (1983), Chari and Kehoe (1999), Aiyagari et al. (2002), Arellano (2008), Aguiar and Amador (2014), among many others). This strand of literature is mainly silent on issues pertaining to redistribution and inequal- 
ity. While recently inequality and redistributive policies have been introduced for the study of macroeconomic policies (e.g., Werning (2007), and Bhandari et al. (2013)), their open economy consequences are primarily unexplored. This is of particular interest given that a large fraction of government outlays is spent on transfers, such as, social transfers and public pensions. As we show, redistributive considerations significantly change the implications on optimal policies regarding external debt and can explain the cyclicality in fiscal and external debt policies in developing economies. In this regard, our paper is closely related to Werning (2007), who considered a closed economy with infinitely lived households.

Our paper is also related to the recent literature on optimal policy and social insurance in heterogeneous agent economies in the absence of commitment (e.g., Sleet and Yeltekin (2006), Farhi et al. (2012), and Scheuer and Wolitzky (2014)). Similar to these authors, we consider an intergenerational setting with overlapping generations where policies are chosen by governments that cannot commit to future policies (or via a political economy model of voting). While this literature is mainly interested in the shape of the optimal tax functions and the long-run behavior of inequality, we focus on the dynamics of debt and inequality over time and business cycles. Furthermore, we exogenously impose restrictions on the tax function. This allows us to develop a tractable framework for the analysis of the trade-offs between inequality and external debt and its determinants over time.

Two recent papers address some of the issues related to this trade-off: First, D'Erasmo and Mendoza (2013) consider a closed economy with heterogeneous agents in which the government does not have access to asset taxes and it can issue debt and default on it. The authors show that in order to explain the level of domestic debt observed in Europe, government's objective must feature a political bias towards government's creditors. Second, Ferriere (2014) argues that when the government can change the progressivity of the tax code, progressive taxes can be used to mitigate the cost of default and borrowing. Similar to these papers, our model implies that wealth inequality negatively affects government's ability to borrow. However, our novel result is that due to the interactions between inequality and external debt, it is optimal to drastically decrease external debt when highly indebted and thus policies resemble austerity.

Since Eaton and Gersovitz (1981), a large literature in international economics has analyzed the determinants of sovereign debt based on theories involving a government that cannot commit to repay its external creditors. Aguiar and Amador (2014) and Aguiar et al. (2009), for example, using the contracting framework of Thomas and Worrall (1994), consider an economy where accumulated external debt affects the ability of a sovereign to invest due to its incentives for expropriation. Such constraints on investment imply that external debt is gradually adjusted over time, while investment is gradually increased. This is in sharp contrast with the implication of our model that external debt adjustment 
is not gradual, that is, future external debt is inversely related to current external debt. Our result, thus, provides a rationale for the observed austerity measures that are often used in episodes following debt crises.

The rest of the paper is organized as follows. Section 2 describes the model. Section 3 characterizes the optimal policies chosen by a planner without commitment. Section 4 extends the result to a setup with probabilistic voting. Section 5 describes a stochastic version of the basic model, Section 6 provides historical evidence in support for our results, and Section 7 concludes.

\section{Model Setup}

In this section, we describe the basic framework in which we analyze the determinants of government policies. We consider an overlapping-generations small open economy populated by a continuum of heterogeneous households and the government.

Households. Time, $t$, is discrete and $t=0,1, \cdots$. At the beginning of each period, a generation of households are born and live for two periods. Each generation born at $t$ consists of a continuum of households who draw a productivity type $\theta_{t}$ when they are born. They work, consume, and save when they are young and consume when they are old. We assume that $\theta \in\left\{\theta^{1}<\cdots<\theta^{N}\right\}$ and that $\operatorname{Pr}\left(\theta_{t}=\theta^{i}\right)=\mu^{i}$ where the average value of $\theta^{i}$ is normalized to 1 (i.e., $\sum_{i=1}^{N} \mu^{i} \theta^{i}=1$ ). We refer to households with productivity type $\theta^{i}$ as households of type $i$. Households value consumption and labor supply according to the following preferences:

$$
u_{t, 0}^{i}=\log c_{t, 0}^{i}+\psi \log \left(1-\frac{y_{t}^{i}}{\theta^{i}}\right)+\beta \log \left(c_{t, 1}^{i}\right)
$$

where $c_{t, 0}^{i}, c_{t, 1}^{i}$ are consumption when young and old, respectively, while $y_{t}^{i}$ is the effective hours worked or income when households are young. In the above expression, $u_{t, 0}^{i}$ represents the utility of a young household born at time $t$, and $u_{t-1,1}^{i}=\log \left(c_{t-1,1}^{i}\right)$ is the utility of an old household. Our assumption on the form of the utility function is purely for simplicity of analysis and can be extended to more general utility functions at the cost of further complications (see the discussion in section 3.4.1 and Appendix for an extension of our results to more general preferences).

A young household of type $i$ has wealth $a_{t}^{i}$ at the end of the period. Finally, there is an initial old generation at $t=0$ whose wealth distribution is given by $\left\{a_{-1}^{\mathfrak{i}}\right\}_{i=1, \cdots, N}$ and consumption by $c_{-1,1}^{i}$.

Technology. Labor is the only input for production, and the total output in the economy is given by $Y_{t}=\sum_{i} \mu^{i} y_{t}^{i}$. 
Government. The government provides transfers to households when they are young (i.e., $T_{t}$ ) and pensions to households when they are old (i.e., $P_{t}$ ), and pays for $G_{t}$, which is government purchases net of any other source of revenue for the government, such as revenue from selling commodities. The government finances these expenses with revenues raised from taxing labor income and taxing assets saved for retirement, as well as borrowing from abroad. Given the structure of government finances, the government budget constraint is given by

$$
B_{t}^{d}+\delta_{t} B_{t}+T_{t}+P_{t}+G_{t}=\tau_{l, t} Y_{t}+\tau_{a, t} \sum_{i} \mu^{i} a_{t-1}^{i}+q_{t} B_{t+1}+q_{t}^{d} B_{t+1}^{d}
$$

where $B_{t}^{d}$ and $B_{t}$ are the face value of government's domestic and external debt, respectively; $T_{t}$ is transfers to the young; $P_{t}$ is public pensions for the old; $\tau_{l, t}$ is the tax rate on earnings; $\tau_{a, t}$ is the tax rate on assets (private pensions); $q_{t}$ is the price of external debt; and $q_{t}^{d}$ is the price of domestic government debt. In addition, $\delta_{t} \in[0,1]$ is the fraction of the external debt that is repaid in each period. Since the government can impose asset taxes on domestic holdings of its debt, it is without loss of generality to assume that all domestic debt is repaid.

Given the above government policies, we can write households' budget constraint as

$$
\begin{aligned}
c_{t, 0}^{i}+q_{t}^{d} a_{t}^{i} & \leqslant y_{t}^{i}\left(1-\tau_{l, t}\right)+T_{t} \\
c_{t, 1}^{i} & \leqslant a_{t}^{i}\left(1-\tau_{a, t+1}\right)+P_{t+1} .
\end{aligned}
$$

In addition, the initial old households simply consume their after-tax asset income and pensions, or $c_{-1,1}^{i}=a_{-1}^{i}\left(1-\tau_{a, 0}\right)+P_{0}$.

Note that we have assumed that the government is the only domestic entity that can borrow and lend in international credit markets. While extreme, this assumption is without loss of generality when the government has the ability to impose capital controls (differential taxes between domestic and foreign asset income). With capital controls, taxes on foreign transactions can be imposed in such a way that domestic households have no incentive to trade with the rest of the world and only hold domestic debt.

Markets. The feasibility of allocations requires that goods and domestic asset markets clear. That is, if $C_{t, 0}$ and $C_{t, 1}$ are the aggregate consumption of the young and, respectively, the old in each period, we must have that

$$
\begin{aligned}
C_{t, 0}+C_{t-1,1}+G_{t} & =Y_{t}+q_{t} B_{t+1}-\delta_{t} B_{t} \\
\sum_{i} \mu^{i} a_{t}^{i} & =B_{t+1}^{d} .
\end{aligned}
$$


Moreover, the price of external government debt must satisfy the no-arbitrage condition for the international lenders:

$$
\mathrm{q}_{\mathrm{t}}=\frac{\delta_{\mathrm{t}+1}}{1+\mathrm{r}}
$$

where $r$ is the international risk-free interest rate.

Competitive Equilibrium with Taxes. As it is standard in the Ramsey approach, the above market structure and households optimization put a constraint on the set of allocations that can be achieved by the government. Before describing the determination of these policies, our notion of competitive equilibrium makes precise the type of restriction the above market structure puts on government's choice:

Definition 1. Given a sequence of government policies $\left\{B_{t}, B_{t}^{d}, \tau_{l, t}, \tau_{a, t}, T_{t}, P_{t}, \delta_{t}\right\}_{t=0}^{\infty}$, as well as the international interest rate, $r$, a competitive equilibrium with taxes is given by allocations $\left\{c_{t, 0}^{i}, c_{t, 1}^{i}, y_{t}^{i}, a_{t}^{i}\right\}_{t=0}^{\infty}$ together with prices $\left\{q_{t}, q_{t}^{d}\right\}_{t=0}^{\infty}$, where $(i) c_{t, 0}^{i}, c_{t, 1}^{i}, y_{t}^{i}, a_{t}^{i}$ maximizes (1) subject to (3) and (4); (ii) external government debt price, $q_{t}$, is given by (7); and (iii) domestic bond price, $q_{t}^{d}$, adjusts so that domestic credit markets clear, that is, (5) holds.

\subsection{Characterizing the set of Competitive Equilibria}

Our assumption about the utility function allows us to provide a very simple characterization of the allocations that can constitute a competitive equilibrium with taxes. The following lemma states this result:

Lemma 1. Suppose that households' preferences are given by (1). Given the initial asset distribution for the initial old, $\left\{\mathrm{a}_{0}^{i}\right\}_{i=1, \ldots, \mathrm{N}^{\prime}}$ and an initial foreign government debt, $\mathrm{B}_{0}$, an allocation can be supported as a competitive equilibrium with taxes if and only if the sequence of aggregate allocations $\left\{\mathrm{C}_{\mathrm{t}, 0}, \mathrm{C}_{\mathrm{t}-1,1}, \mathrm{Y}_{\mathrm{t}}, \mathrm{B}_{\mathrm{t}}\right\}_{\mathrm{t}=0}^{\infty}$ satisfies (5) and there exists a vector of market weights $\left\{\Phi_{\mathrm{t}}=\left(\varphi_{\mathrm{t}}^{\mathrm{i}}\right)_{\mathrm{i} \in\{1, \cdots, \mathrm{N}\}}\right\}_{\mathrm{t}=-1}^{\infty}$ where $\sum_{\mathrm{i}} \mu^{i} \varphi_{\mathrm{t}}^{\mathrm{i}}=1$ such that

$$
\begin{aligned}
c_{t, 0}^{i} & =\varphi_{t}^{i} C_{t, 0}, \quad c_{t, 1}^{i}=\varphi_{t}^{i} C_{t, 1}, \quad \theta^{i}-y_{t}^{i}=\varphi_{t}^{i}\left(1-Y_{t}\right), \forall t \geqslant 0 \\
c_{-1,1}^{i} & =\varphi_{-1}^{i} C_{-1,1},
\end{aligned}
$$

while the market weights satisfy

$$
\begin{aligned}
\varphi_{\mathrm{t}}^{\mathrm{i}} & =1+\frac{\psi}{1+\psi+\beta} \frac{\theta^{i}-1}{1-Y_{\mathrm{t}}}, \forall \mathrm{t} \geqslant 0, \\
\varphi_{-1}^{i} & =\frac{\mathrm{a}_{-1,1}^{\mathrm{i}}}{\mathrm{C}_{-1,1}} .
\end{aligned}
$$


The above lemma states that competitive equilibria are characterized by aggregate allocations that need only satisfy the aggregate budget constraint (5) together with a representation of the distribution of individual allocations, or inequality. This distribution is captured by market weights $\varphi_{\mathrm{t}}^{\mathrm{i}}$. Furthermore, the linearity of the tax function implies that inequality is related to aggregate allocations through equation (10). This relationship captures the equity versus efficiency trade-off that is central to our analysis. As GDP, $Y_{t}$, rises, the distribution of $\varphi_{t}^{i}$ becomes more dispersed, that is, increases according to second order stochastic dominance. This captures the idea that an increase in GDP must be accompanied by a decline in taxes, which leads to higher inequality. We thus refer to $\Phi_{t}$ as inequality and refer to the right side of $(10)$ as $\hat{\varphi}^{i}\left(Y_{t}\right)$.

Welfare. The novelty of our approach allows us to provide a simple and tractable framework to study the optimal policy in the presence of heterogeneity. A stark implication of our formulation is the simplicity of welfare analysis. To see this, consider the welfare associated with an arbitrary point on the Pareto frontier for a particular generation represented by Pareto weights $\left\{\alpha^{i}\right\}$. We can then write welfare as

$$
\log C_{t, 0}+\psi \log \left(1-Y_{t}\right)+\beta \log C_{t, 1}+(1+\psi+\beta) \underbrace{\sum_{i} \alpha^{i} \mu^{i} \log \left(\hat{\varphi}^{i}\left(Y_{t}\right)\right)}_{-H\left(Y_{t}\right)} .
$$

The first three terms represent the planner's value from aggregate allocations, while $H\left(Y_{t}\right)$ is a convex and increasing function that represents the disutility of inequality. Preferences for redistribution imply that the Pareto weights must satisfy the following assumption:

Assumption 1. (Redistributive Motives) The Pareto weights $\left\{\alpha^{i}\right\}$ are weakly decreasing in i.

Assumption 1 implies that $\mathrm{H}(\mathrm{Y})$ is increasing in $\mathrm{Y}$. Intuitively, higher output means that inequality in consumption and income is higher in the sense of mean-preserving spread, which lowers social welfare.

Our approach to study optimal taxation is an adoption of the so-called primal approach, following Lucas and Stokey (1983) to an environment with heterogeneity of workers. We focus on allocations that arise in any competitive equilibrium with taxes. Policies (e.g., taxes, transfers, and debt) are then determined in order to support a particular allocation. For example, an increase in output must be accompanied by a decline in labor income taxes and transfers, which in turn leads to an increase in inequality. The disutility function $H(Y)$ captures this effect. 


\section{A Planning Problem}

In this section, we establish the main result of our paper. We show that without commitment, the optimal policy has the feature that an increase in the current value of external debt can lead to a decline in its future value. Hence, allocations exhibit cyclical dynamics, that is, convergence of allocations to their steady state value is cyclical. Thus, under lack of commitment, the optimal policy exhibits cycles that involve an increase in borrowing together with an increase in transfers and pensions, followed by a downward readjustment of government's external debt and decline in transfers and pensions.

Our main assumption regarding the determination of policies is that they are chosen sequentially; thus, at each point in time, the government cannot commit to future paths of choices of taxes, transfers, and repayments of debt. In this section, we start with the simplest form of this problem in the spirit of Chari and Kehoe (1990)'s sustainable plans: at each point in time, governments maximize a weighted average of households' utilities. We assume that within a generation, welfare weights are as described before in Assumption 1 , while across generations, we have geometric discounting at rate $\hat{\beta}$.

Formally, as in Chari and Kehoe (1990), policies are determined in a repeated game between a continuum of households, a long-lived government, and a continuum of foreign lenders. We consider subgame perfect equilibria of this game supported by trigger strategies to autarky. In the Appendix, we show that allocations arise from such equilibria if and only if they satisfy the competitive equilibrium conditions described in Lemma 1 where feasibility is given $b^{2}$

$$
C_{t, 0}+C_{t-1,1}=Y_{t}+\frac{1}{1+r} B_{t+1}-B_{t}
$$

and the following sustainability constraint:

$$
\frac{\beta}{\hat{\beta}} \sum_{i} \alpha^{i} \mu^{i} u_{t-1,1}^{i}+\sum_{s=t}^{\infty} \hat{\beta}^{s-t} \sum_{i} \alpha^{i} \mu^{i} u_{s}^{i} \geqslant \underline{W} .
$$

Here, $\underline{W}$ is the value of a one-shot deviation by the government involving full redistribution of wealth among the current old and default on external debt. This is followed by government being in full financial autarky, from domestic households and foreign lenders. Thus the value $\underline{W}$ is associated with an allocation where there is no inequality

\footnotetext{
${ }^{2}$ Note that we have imposed $\delta_{t}=1$ in our feasibility constraint. This is without loss of generality. As has been noted by many authors (for example by Grossman and Van Huyck (1988), Kehoe and Perri (2004), Kehoe and Levine (2009), and Dovis (2013)), the allocations described above can be decentralized via non-stage contingent debt and default as well as state contingent debt and no default. While our model's implications about default are worth exploring, our main goal is to characterize the dynamics of aggregate quantities: debt (external and domestic), output, inequality, etc. We leave this for future work.
} 
among the initial old, the young do not save, the old only consume the pensions received from the government, and the economy is in financial autarky with respect to the rest of the world. The government thus gains from equalizing consumption among the old and not paying its external debt, while the cost of this deviation is the disruption in domestic asset markets, which in turn reduces government's ability to redistribute. ${ }^{3}$

The sustainability constraint points to the two main sources of time-inconsistency in the determination of policies: First, if the government is a net external debtor, it has an incentive to default on its external debt payments so that it can increase domestic consumption and leisure. Second, at each period, since there is a non-degenerate distribution of wealth among the old households and the government is inequality-averse, it has an incentive to expropriate all the wealth via a 100 percent tax on wealth and redistribute it equally among the old. The key trade-off is that the inequality among the old is necessary to provide incentive to produce when young, while it is costly ex-post once labor supply decisions are made. As it becomes clear, the interaction between these two incentives drives most of our results.

Using the above restrictions, we can thus define the best sustainable equilibrium as an allocation that satisfies the conditions in Lemma 1 and (14), and maximizes social welfare at time 0 . In our analysis, we assume the following:

Assumption 2. (Impatience) $\hat{\beta}(1+r) \leqslant 1$.

In section 5, we discuss why in an environment with shocks and a continuum of countries, it is natural to have the market clearing interest rate satisfy Assumption 2 with strict inequality.

\subsection{A Recursive Formulation}

The problem associated with the best sustainable equilibrium has a natural two-dimensional state variable: external debt and output in the previous period, since inequality among the current old depends only on output in the previous period. Let $V\left(B_{t}, Y_{t-1}\right)$ be the social welfare associated with the best sustainable equilibrium at $t$. Since the objective function is additively separable between inequality and other variables, we have that $\mathrm{V}\left(\mathrm{B}, \mathrm{Y}_{-}\right)=\mathrm{W}(\mathrm{B})-\frac{\beta}{\hat{\beta}} \mathrm{H}\left(\mathrm{Y}_{-}\right)$where $\mathrm{W}(\cdot)$ is given by $(\mathrm{P} 1)$ :

$$
W(B)=\max _{C_{0}, C_{1}, Y, B^{\prime}} \frac{\beta}{\hat{\beta}} \log C_{1}+\log C_{0}+\psi \log (1-Y)-(1+\psi+\beta) H(Y)+\hat{\beta} W\left(B^{\prime}\right)
$$

\footnotetext{
${ }^{3}$ Given the disruption in domestic financial markets following a default, it is possible for the government to support a positive amount of foreign debt.
} 
subject to

$$
\begin{aligned}
& C_{0}+C_{1}+B+G \leqslant \frac{B^{\prime}}{1+r}+Y \\
& W\left(B^{\prime}\right)-\frac{\beta}{\hat{\beta}} H(Y) \geqslant \underline{W}
\end{aligned}
$$

where in the above formulation we have used the characterization of aggregate allocations in a competitive equilibrium with taxes in Lemma 1 and the definition of $\mathrm{H}(\mathrm{Y})$ in (12). Therefore, $W(B)$ is the value for the planner excluding the disutility of inequality of the current old. The constraint (15) is the aggregate resource constraint for the economy which enters period $t$ with external debt $B$, while (16) is the sustainability constraint at $t+1$.

The recursive problem in (P1) is non-standard in the sense that the value function appears in the constraint set. As a result, the functional equation in (P1) might have multiple solutions. Nevertheless, we are able to show that the set of solutions to (P1) is non-empty and the one with the highest value among these solutions solves the optimal policy problem. We do so by focusing on the dual of the functional equation in (P1) (with promised utility as state variable) and use standard dynamic programming techniques. All of our results are stated for this solution to (P1).

The following proposition connects the solution of (P1) to the best sustainable equilibrium:

Proposition 1. Consider the best solution to (P1), $W^{*}$. If an allocation is associated with the best sustainable equilibrium, then the allocations for $t \geqslant 1$ must be generated from the policy functions associated with $\mathrm{W}^{*}$.

Conversely, if an allocation is generated from the policy function associated with $\mathrm{W}^{*}$ and satisfies

$$
\lim \sup _{t \rightarrow \infty} \hat{\beta}^{t} W^{*}\left(B_{t}\right)=0
$$

then it must be associated with the best sustainable equilibrium.

Proposition 1 is similar to the standard principle of optimality (see Theorems 4.2 and 4.3 in Stokey et al. (1989)). We provide the proof in the Appendix.

The following lemma establishes the basic properties of the best value function $W^{*}(B)$ :

Lemma 2. The value function $\mathrm{W}^{*}(\mathrm{~B})$ is strictly decreasing, strictly concave, and differentiable.

The proof resorts to the duality property stated above and uses standard dynamic programming techniques (see Appendix for details). 


\subsection{Cyclicality of External Debt}

In this section, we provide our main result by characterizing the dynamics of external debt over time.

The problem in (P1) can be simplified. Note that the ratio between consumption of the old and the young households is constant. Using that observation and rearranging the terms in (P1), the optimization problem boils down to the following simple problem:

$$
\max _{B^{\prime}, Y} U\left(\frac{B^{\prime}}{1+r}+Y-B-G, Y\right)+\hat{\beta} V\left(B^{\prime}, Y\right)
$$

subject to

$$
\mathrm{V}\left(\mathrm{B}^{\prime}, \mathrm{Y}\right) \geqslant \underline{\mathrm{W}}
$$

where $U(C, Y)=(1+\beta / \hat{\beta}) \log C+\psi \log (1-Y)-(1+\psi) H(Y)$. Our previous discussion implies that $V\left(B, Y_{-}\right)$is decreasing in both $B$ and $Y_{-}$.

The program in (P2) is the central problem in our paper in that it captures the model's key trade-off: the tension between external debt and inequality from the current government's perspective compared to future government's perspective. The function $U(C, Y)$ represents the social welfare of the currently alive people and includes the cost of inequality. The function $V\left(B^{\prime}, Y\right)$ represents the value from future external debt and inequality for the future government. Due to the equity-efficiency trade-off, higher output today can only be achieved with higher inequality. Hence, the function $V\left(B^{\prime}, Y\right)$ is decreasing in $Y$. Note that the standard representative agent models of borrowing and lending without commitment are a special case of the problem in (P2), where the value function $\mathrm{V}(\mathrm{B}, \mathrm{Y})$ is independent of $Y$.

The first-order conditions associated with (P2) are given by

$$
\begin{array}{r}
\mathrm{u}_{\mathrm{C}}+(\hat{\beta}+\lambda) \mathrm{v}_{\mathrm{B}^{\prime}}=0 \\
\mathrm{u}_{\mathrm{C}}+\mathrm{U}_{\mathrm{Y}}+(\hat{\beta}+\lambda) \mathrm{V}_{\mathrm{Y}}=0,
\end{array}
$$

where $\lambda$ is the Lagrange multiplier on (17). Since an increase in output is costly for the current government, $\mathrm{U}_{Y}<0$, the two first order conditions above imply that

$$
0>V_{Y}>V_{B^{\prime}}
$$

The above inequality captures the key tension between the current and future government's perspectives. The future government would like to equate the marginal cost of debt and inequality. However, from current government's perspective, inequality is costly, due to disutility of effort and inequality. Hence, from future government's per- 
spective, there is too little inequality and too much external debt. In other words, a reduction in government's external debt and an increase in output of the same size lead to an increase in the value of the future government while current consumption remains unchanged.

The following theorem is a direct result of this conflict of interest, and it describes its effect on the shape of policy functions in (P2):

Theorem 1. The policy function $\mathrm{B}^{\prime}(\mathrm{B})$ in the programming problem (P2) is hump-shaped: for small values of $\mathrm{B}$, the sustainability constraint is slack and $\mathrm{B}^{\prime}(\mathrm{B})$ is increasing; for large values of $\mathrm{B}$, the sustainability constraint is binding and $\mathrm{B}^{\prime}(\mathrm{B})$ is decreasing. The policy function $\mathrm{Y}(\mathrm{B})$ is increasing.

Proof. We provide the idea of the proof here and leave the details to the Appendix:

Suppose that the sustainability constraint is slack. Then we can ignore the constraint (17) in (P2). Since the objective function is supermodular in $\left(B, B^{\prime}\right)$ and concave, then standard monotone comparative statics results imply that the policy function $\mathrm{B}^{\prime}$ (B) must be increasing. Furthermore, due to the income effect, $\mathrm{Y}(\mathrm{B})$ must be increasing.

Suppose that the sustainability constraint is binding. This constraint implies a mapping from $B^{\prime}$ to $Y$. The inequality (20) implies that this mapping has a slope that is less than $-\frac{1}{1+r}$. We can then use this map to substitute for $Y$ in terms of $B^{\prime}$ in the objective function in (P2). The resulting objective function for this simplified problem is submodular in $\left(B, B^{\prime}\right)$ and hence $B^{\prime}(B)$ is decreasing while $Y(B)$ is increasing.

Consider the comparative statics with respect to B. When B is low, the sustainability constraint (17) is slack. Hence, an increase in current external debt should be accompanied by an increase in future external debt for standard consumption smoothing reasons. Furthermore, an increase in external debt increases the interest payment to the foreign lenders, which in turn leads to an increase in output and inequality. In other words, from the current government's perspective, equality (inverse of inequality) is a normal good.

When $B$ is sufficiently high, the sustainability constraint is binding. Due to the sustainability constraint (17), both $\mathrm{B}^{\prime}$ and $Y$ cannot be increased in response to an increase in B. Since there is too little inequality from future government's perspective (i.e., inequality (20) holds), the cost of an increase in inequality is lower. Therefore, in response to an increase in $B, Y$ must increase and $B^{\prime}$ must decrease.

Intuitively, an increase in external debt, B, increases the effective weight on the utility of the future government. Since there is too little inequality from the future government's perspective, it always prefers a decline in external debt and an increase in future inequality. Therefore, when current external debt increases, the allocation of future debt and inequality tilts in favor of the future government, which implies that $\mathrm{B}^{\prime}$ must decrease and inequality must increase. 

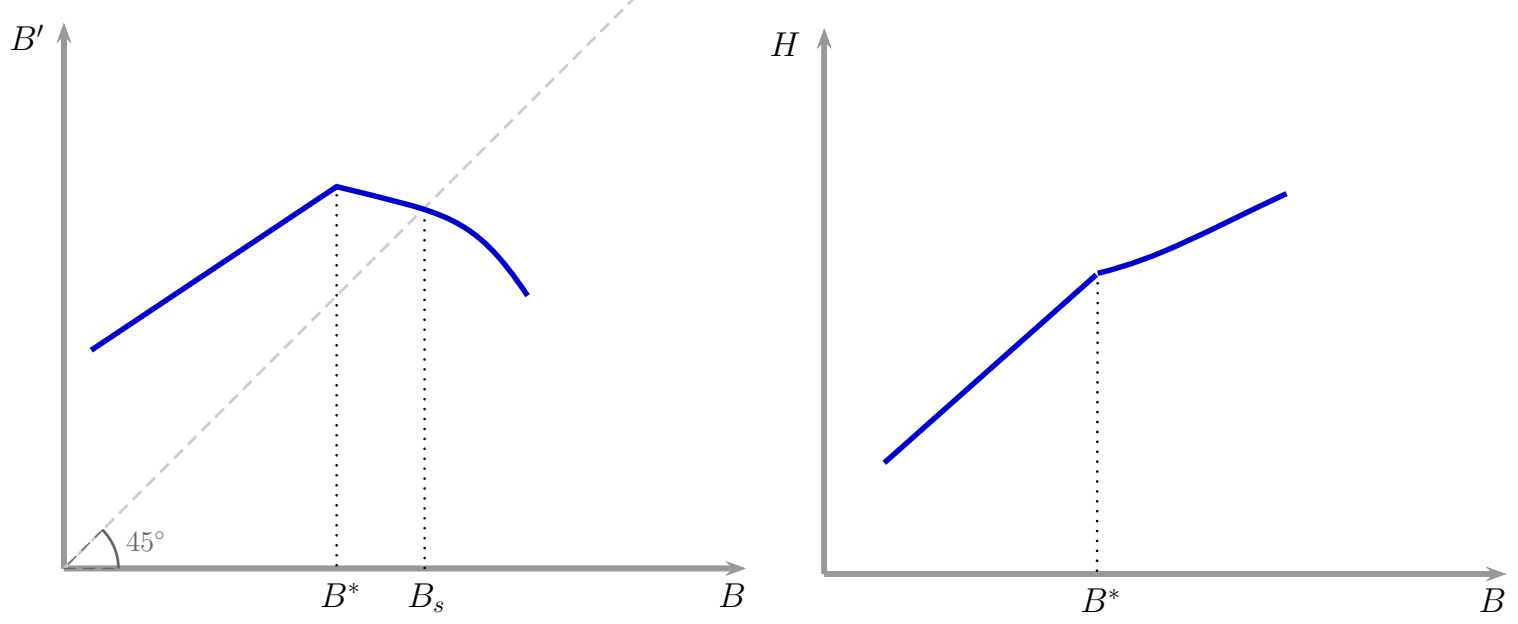

Figure 1: Policy Functions for external debt and inequality

Figure 1 depicts the policy functions associated with future debt and current inequality $(H=H(Y)$ is the disutility from inequality) for the case where $\hat{\beta}(1+r)<1$. When $B$ is below $B^{*}$, the sustainability constraint is slack, $B^{\prime}(B)$ is increasing, and $B^{\prime}(B)>B$. For values of $B$ higher than $B^{*}$, the sustainability constraint is binding and $B^{\prime}(B)$ is decreasing. The steady state level of external debt is given by $B_{s}$ and is in the region where $B^{\prime}(B)$ is decreasing.

When debt is above its steady state value, $B_{s}$, it is reduced below the steady state level and vice versa. We call this feature of the model overshooting. This implies that the convergence to the steady state is cyclical. Therefore, the country goes through cycles with two phases. In the first phase, inherited external debt is below its steady state value and the current inequality is low. Low inequality is generated by a high value of transfers and pensions, and borrowing from the rest of the world (i.e., future debt is high). In the second phase, both inherited external debt and inequality are high. High inequality is generated by a low value of transfers and pensions, and a reduction of external debt. In this sense, during the second phase, the country goes through a period that resembles austerity.

The following corollary states the cyclical pattern of external debt:

Corollary 1. Suppose that $\hat{\beta}(1+r)<1$. Then, the dynamic system implied by $\mathrm{B}^{\prime}(\mathrm{B})$ eventually exhibits oscillatory dynamics. That is, for all $\mathrm{t}$ large enough, if $\mathrm{B}_{\mathrm{t}} \neq \mathrm{B}_{\mathrm{s}},\left(\mathrm{B}_{\mathrm{t}}-\mathrm{B}_{\mathrm{s}}\right)\left(\mathrm{B}_{\mathrm{t}+1}-\mathrm{B}_{\mathrm{s}}\right)<$ 0 . In addition, optimal allocations, $C_{t, 0}, C_{t-1,1}, Y_{t}$, feature the same dynamics.

As it can be seen in problem (P2), an increase in $\mathrm{G}$ is equivalent to an increase in $\mathrm{B}$. This implies that a high enough unexpected shock to $G$ reduces the value of outstanding external debt and thus the country goes through a period resembling austerity. This period will 
be followed by a cyclical convergence to the steady state. In section 5 , we formally analyze a version of our model with shocks to $G$, and describe how cycles between populism and austerity do not dissipate in the long run. This dynamic contrasts most models of international borrowing and lending (see for example Thomas and Worrall (1994), Aguiar et al. (2009), and Aguiar and Amador (2011)), where future outstanding external debt is increased in response to an increase in current external debt or government spending.

\subsection{Dynamics of Taxes, Transfers and Debt}

Our previous analysis has focused on allocations. From Lemma 1, there must exist taxes, transfers, pensions, and domestic debt policies that support such allocation as a competitive equilibrium. In this section, we describe a competitive equilibrium which supports the optimal allocations and has a recursive structure that follows those of the allocations. Hence, policies depend on external debt. We resolve the indeterminacy in transfers and debt holdings by considering a decentralization in which the lowest productivity type hold zero assets, $a^{1}=0$. The following proposition describes how one set of such policies depend on the state.

Proposition 2. The optimal allocations generated from policy functions for problem (P2) are supported by government policies where domestic debt is $V$-shaped in $\mathrm{B}$; $\mathrm{B}^{\mathrm{d}}$ is decreasing in $\mathrm{B}$ when $\mathrm{B}<\mathrm{B}^{*}$ and increasing in $\mathrm{B}$ when $\mathrm{B} \geqslant \mathrm{B}^{*}$; labor income tax, $\tau_{l}$, is increasing in $\mathrm{B}$, and transfers are decreasing in $\mathrm{B}$.

Figure 2 describes the behavior of policies in response to changes in external debt. As external debt increases, interest payments to foreign lenders increase; the government finances this increase by a decline in transfers and pensions and an increase in labor income taxes. When the sustainability constraint is binding, the change in transfers and pensions is more pronounced, while the change in taxes is less pronounced, since the trade-off between inequality and external debt is tilted towards more inequality. ${ }^{4}$ In addition, a reduction of external debt is partly financed by issuing domestic debt and, hence, domestic debt issuance is a V-shaped function of external debt. ${ }^{5}$

\footnotetext{
${ }^{4}$ In general, we cannot prove that promised pensions are a V-shaped function of external debt since there are two opposite forces at play. In our decentralization, promised pensions are given by $\mathrm{P}^{\prime}(\mathrm{B})=$ $\varphi^{1}(\mathrm{Y}(\mathrm{B})) \frac{1-K}{K} \mathrm{C}\left(\mathrm{B}^{\prime}(\mathrm{B})\right)$. For low level of debt, when the sustainability constraint is slack, both the consumption share of lowest productivity type and the promised aggregate consumption are decreasing in $\mathrm{B}$ and therefore so are promised pensions. For high level of debt, when the sustainability constraint is binding, the consumption share of lowest productivity type is decreasing in B while the promised aggregate consumption is increasing in B. However, in all of our numerical simulations, promised pensions are increasing in debt in this region.

${ }^{5}$ This implies that during fiscal consolidations the share of total government debt held domestically increases. This fact is well documented for the recent European debt crisis. For instance, Broner et al. (2014) document that the share of government debt held by residents increases in Italy, Spain, Portugal, Ireland,
} 

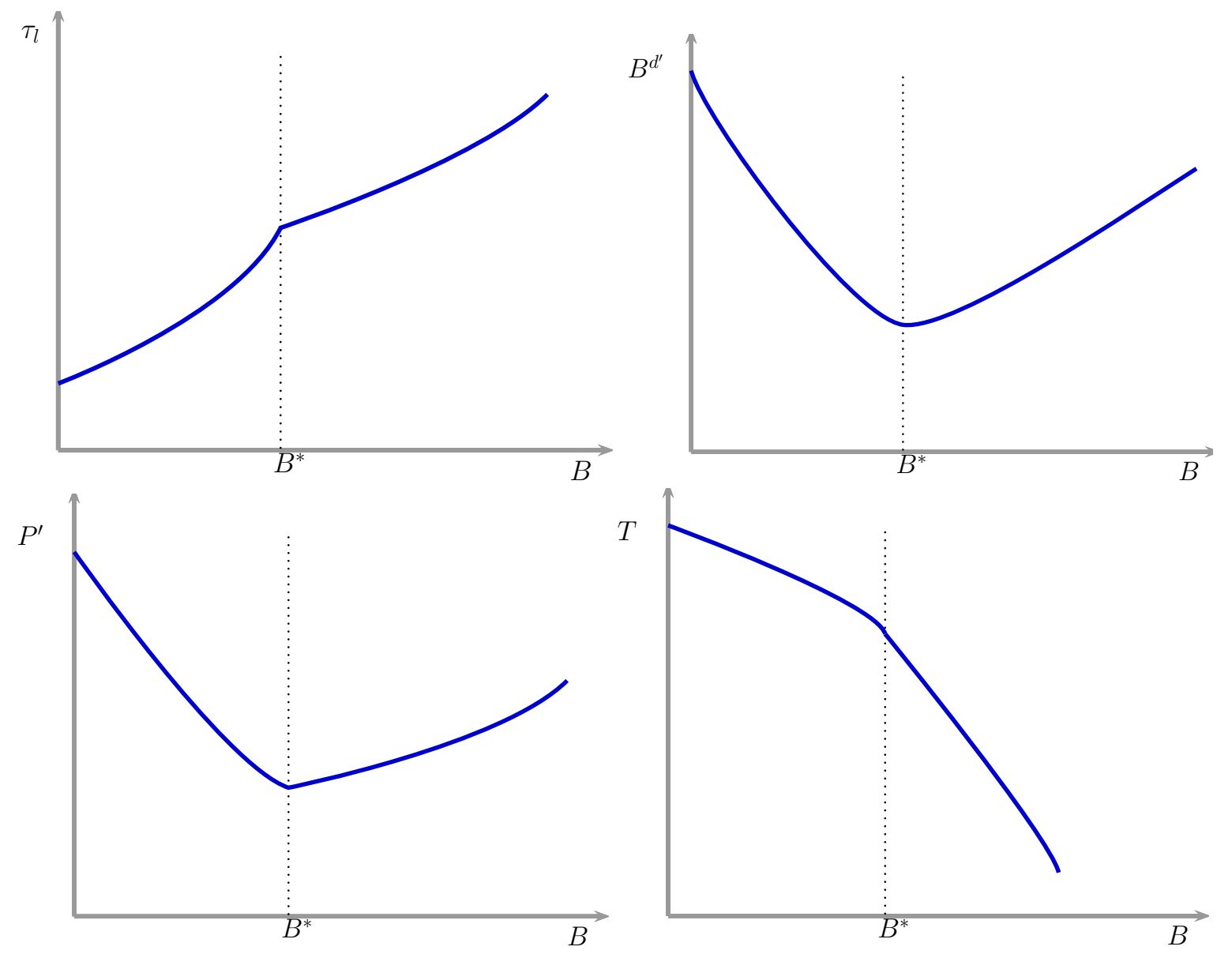

Figure 2: Policy Functions for external debt and inequality

\subsection{Robustness of Cycles}

\subsubsection{Role of Preferences}

In our analysis above, the key property that generates a hump-shape in future external debt policy function and upward sloping inequality is the fact that equality is a normal good. That is, as countries become richer, their demand for equality increases. Log preferences create a direct relationship between inequality and output, and normality of equality implies that output must also increase in response to an increase in external debt. With other preferences, the relationship between inequality and output is not as straightforward. In the Appendix, we extend our analysis to GHH (given by $\left.\log \left(c_{0}-v(l)\right)+\beta \log c_{1}\right)$ and BGP preferences. For all such preferences, equality is a normal good and thus the policy functions for future external debt and inequality satisfy the same property as in Figure 1. With these preferences, however, the direct relationship be-

and Greece (and to a less extent in France) while in Germany the share of debt held domestically continues a long-run downward trend. (see Figure 4 in their paper) 
tween output and inequality does not hold, and the output can decline as debt increases as it is the case with GHH preferences where the wealth effect is absent. Note that the insights from section 3.3 hold for these alternative specifications of the utility function.

\subsubsection{Three-Period Generations}

Another key assumption in our formulation is that individuals only live for two periods. In the Appendix, we relax this assumption by considering a setting for which each generation lives for three periods. In this extension, the state of the economy is summarized by three variables: external debt, and inequality among the past two generations. It can be shown that the same conflict of interest between the current and the future government gives rise to overshooting. That is, future debt is a hump-shaped function of current debt. The existence of cycles is, however, not guaranteed since past level of inequality also affect the policy functions. Nevertheless, we show, by way of numerical simulations, that this economy also exhibits cyclical dynamics.

\section{Political Economy Model}

So far, we have considered an environment in which policies are chosen by a fictitious planner that lacks commitment and cares about all the future generations. In this section, we extend this insight to a model where policies are determined according to the probabilistic model of Lindbeck and Weibull $(1987)^{6}$ and show that our main results extend to this environment. We sketch the political game here and leave the formal development to the Appendix.

We consider a game where in each period, two political parties propose policy platforms that include all the contemporaneous policy variables introduced in section 3 . The young and old individuals evaluate such policies based on preferences in 1 with the addition of a political bias shock toward each party. When the additive political bias shocks are distributed uniformly, the symmetric equilibrium of the political game between the two parties is equivalent to the maximization of

$$
\omega \sum_{i} \alpha^{i} \mu^{i} u_{t-1,1}^{i}+\sum_{i} \alpha^{i} \mu^{i} u_{t, 0}^{i}
$$

a weighted sum of the utility of the people alive at $t$. We assume that political bias shocks are distributed so that $\alpha^{i}$ s are weakly decreasing in $i{ }^{7}$

\footnotetext{
${ }^{6}$ See also Song et al. (2012), Farhi et al. (2012) and Scheuer and Wolitzky (2014) for similar applications to other dynamic settings.

${ }^{7}$ In particular, when political bias shocks have the same uniform distribution for all individuals, this
} 
Similar to the game underlying the model in section 3, policies are determined in a dynamic game between foreign creditors, households, and politicians. Our notion of equilibrium in this dynamic game is the standard subgame perfect equilibrium (SPE).

As in section 3, we consider equilibria that involve trigger strategies to autarky. We can thus show that an allocation is the symmetric SPE resulting from such equilibria of the political game if it satisfies the characterization in Lemma 1 and if the following inequality is satisfied:

$$
\omega \sum_{i} \alpha^{i} \mu^{i} u_{t-1,1}^{i}+\sum_{i} \alpha^{i} \mu^{i} u_{t, 0}^{i} \geqslant \underline{V}
$$

where $\underline{\mathrm{V}}$ is defined in a way analogous to $\underline{W}$ in section 3 . We refer to the above constraint as the political sustainability constraint. Intuitively, this constraint requires that at each point in time, the value for the current government in power under the prescribed policy be higher than what it can get in autarky. See the Appendix for a formal characterization of the entire set of these SPE outcomes.

To derive the implications for policies and allocations associated with the political economy game, we need to specify a criterion to select among the set of equilibrium outcomes. We consider two alternatives. First, we consider the SPE outcome that maximizes the same objective function introduced in section 3. We refer to such outcome as best SPE outcome. Second, we consider a selection criterion in the spirit of the canonical Eaton and Gersovitz (1981) model of sovereign default. We refer to this particular SPE as the Eaton-Gersovitz (EG) political equilibrium. We will show that in both cases, with some minor qualifications, the main conclusions derived in section 3 remain valid. In particular, the economy exhibits cyclical dynamics over time.

\subsection{Best SPE}

In this section, we briefly describe the behavior of the best SPE. We rank subgame perfect equilibria according to the welfare function in section 3, which attaches a Pareto weight of $\hat{\beta}^{t} \alpha^{i}$ to an agent of type $i$ born at $t \geqslant 0$. As before, we assume that Assumption 2 holds. The best SPE is, therefore, the solution of a planning problem that maximizes the social welfare as defined in section 3 subject to the constraints imposed by Lemma 1 and the political sustainability constraint (22).

We use a dual approach for the characterization of the planning problem described above. The dual version of the planning problem is one where payoff to the foreign lenders is maximized subject to a given level of utility to current generation and a value of social welfare for all generations, in addition to the constraints imposed by Lemma 1 and (22). This dual problem can be written recursively where the state is given by the

assumption is automatically satisfied. 
average utility for a generation ${ }^{8}$ :

$$
v_{t}=\log C_{t, 0}+\psi \log \left(1-Y_{t}\right)+\beta \log C_{t, 1}-(1+\psi+\beta) H\left(Y_{t}\right)
$$

Under this formulation, the political sustainability constraint becomes

$$
v_{t+1}+\omega \log C_{t, 1}-\omega H\left(Y_{t-1}\right) \geqslant \underline{V}
$$

We defer the formal definition of the recursive dual planning problem to the Appendix. The main result is that the policy function $v^{\prime}(t, v)$, the social welfare associated with future generations, is decreasing in $v$ and thus we have the following proposition:

Proposition 3. Suppose that $\hat{\beta}(1+r)=1$. When the value of initial external debt or inequality is high, the dynamics of $v_{\mathrm{t}}$ in the best SPE is cyclical, that is, $v_{\mathrm{s}}$ exists such that $\forall \mathrm{t}$, $\left(v_{\mathrm{t}}-v_{\mathrm{s}}\right)\left(v_{\mathrm{t}+1}-v_{\mathrm{s}}\right)<0$.

The proof can be found in the Appendix.

The dynamics of the best SPE outcome is then consistent with the cycles we described in section 3. When total indebtedness is low and utility for current generation is high, we observe an increase in government debt, especially when external debt, and income inequality is low. This increase in indebtedness translates into low utility for future generations and high income inequality. As before, the trade-off between average value for the next generation and inequality among the future old is tilted towards inequality. Therefore, an increase in $v$ must be accompanied by a change in favor of the future government towards higher inequality among the old and, as a result, a lower value for the next generation.

\subsection{Eaton-Gersovitz Political Equilibrium}

We turn to analyze the EG political equilibrium. Such an equilibrium satisfies the following two properties. First, strategies are the same after two histories with no default if the inherited external debt, the distribution of domestic assets, and pension payments promised by the previous government are the same. Second, a re-optimization by the government triggers reversion to autarky. In particular, we say that the current government defaults on promises made by previous governments if it does not repay inherited external debt, taxes assets of the initial old above a certain level exogenously specified, or lowers pension payments below what was set by the previous government. Without loss of generality, we set the maximal tax on assets to zero.

\footnotetext{
${ }^{8}$ When $\hat{\beta}(1+r)<1$ the problem is non-stationary and thus time must be part of the state. When $\hat{\beta}(1+r)=1$, the problem is stationary and the state is represented only by $v_{t}$. For simplicity, we focus on the case where $\hat{\beta}(1+r)=1$.
} 
In the Appendix we show that (other than for period zero), we can characterize the EG political equilibrium outcome recursively using a single state variable: the total government debt given by $\hat{B}_{t}=B_{t}+B_{t}^{d}+P_{t}=B_{t}+C_{t-1,1}$. As we show, the optimal policy problem in this equilibrium is equivalent to maximizing the value of one generation that inherits total debt $\hat{B}$ and faces a political sustainability constraint. That is, it solves

$$
w(\hat{B})=\max _{C_{0}, Y, C_{1}, B^{\prime}} \log C_{0}+\psi \log (1-Y)+\beta \log \left(C_{1}\right)-(1+\psi+\beta) H(Y)
$$

subject to

$$
\begin{aligned}
\hat{\mathrm{B}}+\mathrm{C}_{0}+\frac{\mathrm{C}_{1}}{1+\mathrm{r}}+\mathrm{G} & \leqslant \mathrm{Y}+\frac{\hat{\mathrm{B}}^{\prime}}{1+\mathrm{r}} \\
\omega\left[-\mathrm{H}(\mathrm{Y})+\log \left(\mathrm{C}_{1}\right)\right]+w\left(\hat{\mathrm{B}}^{\prime}\right) & \geqslant \underline{\mathrm{V}} .
\end{aligned}
$$

The main result for this section is that the allocations imposed by the above optimization problem feature cycles in total government debt, $\hat{\mathrm{B}}_{\mathrm{t}}$. This follows from the fact that total debt issued today is decreasing in inherited total debt.

Proposition 4. The policy rules associated with the problem in $\left(P^{\prime}\right)$ are such that $\mathrm{Y}(\hat{\mathrm{B}})$ is increasing and $\hat{\mathrm{B}}^{\prime}(\hat{\mathrm{B}})$ is decreasing.

As before, this proposition implies that the equilibrium outcome path exhibits a cyclical behavior in total debt. When inherited obligations, $\hat{B}_{t}$, are above their steady state value, $\hat{\mathrm{B}}_{s}$, the next period they are below $\hat{\mathrm{B}}_{s}$. The opposite happens when $\hat{\mathrm{B}}_{\mathrm{t}}<\hat{\mathrm{B}}_{s}$. The intuition for this dynamic is similar to the one in section 3. An increase in total debt leads to a tilt in the trade-off between inequality and total debt in favor of the future government, which, together with the binding sustainability constraint, implies that inequality must increase while total debt must decrease.

While we are able to show that there are cycles in total government debt (i.e., a measure of government debt that includes external and domestic debt and pensions), the dynamics of the domestic and the dynamics of the foreign components depend on parameters. Solving the model numerically, we find that external government debt decreases in total debt if $\omega$ is sufficiently large, but external debt may increase if $\omega$ is small enough. See Figure 4.2 for an illustration. ${ }^{9}$ Intuitively, when $\omega$ is high, the future government is concerned about the average consumption of the future old, and thus the decline in future total debt coincides with an increase in $C_{1}$. This implies that external debt $B^{\prime}=\hat{B}-C_{1}$ must decline as current total debt increases. Therefore, the dynamics of external and total

\footnotetext{
${ }^{9}$ Parameters other than $\omega$ used in the simulation are: $\beta=.96^{25}, \hat{\beta}=1 /(1+r)=.99^{25}, \alpha^{i}=1$ for all $i$, $\psi=1, \Theta=\{1,1.1,5\}$ with $\left\{\mu^{i}\right\}=\{.1, .8, .1\}$.
} 

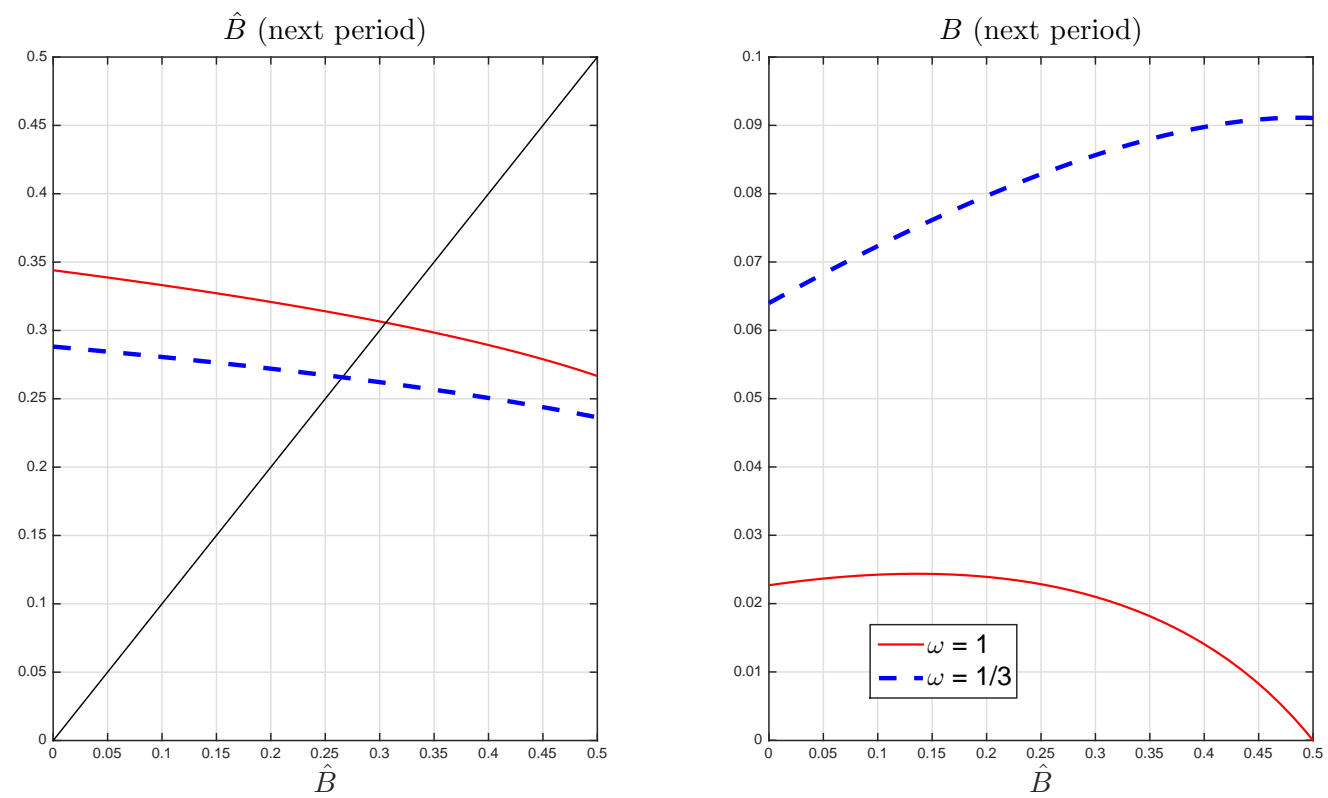

Figure 3: Policy Functions EG Political Equilibrium: High and Low $\omega$

government debt are aligned. When $\omega$ is small, this could be reversed, and hence external debt is not a monotone function of total debt.

\section{Stochastic Economy}

In this section, we extend the model to allow for shocks to terms of trade. This formulation allows to draw parallels with the experiences of Latin American economies where the price of commodities is extremely important for the country's current account and public finances. We show that all of our results in the deterministic model hold in this extension.

Much of the model setup is similar to that presented in section 2. Therefore, we skip many of the details, as they remain unchanged, and describe the changes made to the model.

In each period, there is a realization of a stochastic event $s_{t} \in S=\{s(1)<\cdots<s(K)\} \subset$ $\mathbb{R}$ that is independently and identically distributed according to the distribution $\pi(s)$. The history of shocks is denoted by $s^{t}=\left(s_{0}, \cdots, s_{t}\right) \in S^{t+1}$. With a slight abuse of notation, we represent the probability distribution of $s^{t}$ by $\pi\left(s^{t}\right)=\prod_{\tau=0}^{t} \pi\left(s_{\tau}\right)$. The random variable $s_{t}$ directly affects net government purchases given by $G\left(s_{t}\right)$ where $G$ is an decreasing function of $s_{t}$; that is, $s(1)$ is the state with the highest net government spending while $s(\mathrm{~K})$ is the state with the lowest net government spending. We think of net government spending as the difference between government expenditures and revenues that the 
government receives by selling its endowment of commodities. Hence a lower value for $\mathrm{G}$ is associated with a positive shock to the terms of trade (high commodity price). We let average value of net government spending to be $\bar{G}$. Given this representation of histories, allocations are represented by functions of the history of shocks, $s^{t}$.

In line with Lucas and Stokey (1983) and Werning (2007), we assume that asset markets are complete and young individuals and the government can trade a complete set of arrow securities in each state $s^{t}$ at prices given by $\left\{q_{t+1}^{d}\left(s^{t+1}\right)\right\}_{s^{t+1} \succsim s^{t}}$. In addition, the government can issue full state contingent debt in international markets at prices given by $\left\{q_{t+1}\left(s^{t+1}\right)\right\}_{s^{t+1} \succsim^{t}}$.

We make the following assumptions about the price of government debt in international markets:

Assumption 3. Prices $\left\{\mathrm{q}_{\mathrm{t}+1}\left(\mathrm{~s}^{\mathrm{t}+1}\right)\right\}_{\mathrm{s}^{\mathrm{t}+1 \succsim \mathrm{s}^{\mathrm{t}}}}$ satisfy the following properties:

1. (Stationarity) There exists an interest rate $r$ such that $\mathrm{q}_{\mathrm{t}+1}\left(\mathrm{~s}^{\mathrm{t}+1}\right)=\pi_{\mathrm{t}+1}\left(\mathrm{~s}^{\mathrm{t}+1} \mid \mathrm{s}^{\mathrm{t}}\right) \frac{1}{1+\mathrm{r}}=$ $\pi\left(s_{t}\right) \frac{1}{1+r}$, where $\pi_{t+1}\left(s^{t+1} \mid s^{t}\right)$ is the probability of $s^{t+1}$ conditional on $s^{t}$.

2. (Impatience) $\hat{\beta}(1+r)<1$.

In the Appendix, we show that when the world economy consists of identical countries subject to government spending shocks, stationarity implies that there must exist a constant interest rate. See Kehoe and Levine (1993) and Alvarez and Jermann (2000) for a similar result. Furthermore, since an unconstrained country prices a state contingent security, the first relationship must be satisfied. Finally, since countries would like to avoid binding sustainability constraints in the future, the supply of saving is higher than that of unconstrained steady state; therefore, interest rates must be lower than the discount rate. We can then think of this stochastic economy as justifying our relative impatience assumption in section 3 .

As in section 3, we focus on a planning problem without commitment. An allocation is, then, said to be sustainable if it satisfies

$$
\frac{\beta}{\hat{\beta}} \sum_{i} \alpha^{i} \mu^{i} u_{t-1,1}^{i}\left(s^{t}\right)+\sum_{\tau=t}^{\infty} \hat{\beta}^{\tau-t} \sum_{s^{\tau} \succsim s^{t}} \pi_{\tau}\left(s^{\tau} \mid s^{t}\right) \sum_{i} \alpha^{i} \mu^{i} u_{\tau}^{i}\left(s^{\tau}\right) \geqslant \underline{W}\left(s_{t}\right) .
$$

where as before, $\underline{W}\left(s_{t}\right)$ is the highest value to the government when government and households are in financial autarky defined in a way analogous to (14). As before, the associated Bellman equation can be written as

$W(\hat{B})=\max _{C_{0}, C_{1}, Y_{,} B^{\prime}} \frac{\beta}{\hat{\beta}} \log C_{1}+\log C_{0}+\psi \log (1-Y)-(1+\psi+\beta) H(Y)+\hat{\beta} \sum \pi\left(s^{\prime}\right) W\left(\hat{B}^{\prime}\left(s^{\prime}\right)\right)$ 
subject to

$$
\begin{aligned}
C_{0}+C_{1}+(1+r) \hat{B} & =\sum \pi\left(s^{\prime}\right) \hat{B}^{\prime}\left(s^{\prime}\right)-\frac{\bar{G}}{1+r}+Z Y \\
-\frac{\beta}{\hat{\beta}} H(Y)+W\left(\hat{B}^{\prime}\left(s^{\prime}\right)\right) & \geqslant \underline{W}\left(s^{\prime}\right)
\end{aligned}
$$

where $\hat{B}$ is the sum of government's external debt and net government purchases during the next period. In other words, $\hat{B}_{t}=B_{t}+\frac{G_{t}}{1+r}$. It represents government's obligation excluding those to domestic households. Focusing on $\hat{B_{t}}$ greatly simplifies the recursive formulation of the problem, as it allows us to record only one state variable.

The decision rules have the same properties as in the deterministic case as shown in the following proposition:

Proposition 5. Let $W^{*}$ be the best solution to the Bellman equation in (26). Then its associated policy functions satisfy the following properties:

1. $\mathrm{Y}(\hat{\mathrm{B}})$ is decreasing in $\hat{\mathrm{B}}, \mathrm{C}_{0}(\hat{\mathrm{B}})$ and $\mathrm{C}_{1}(\hat{\mathrm{B}})$ are increasing in $\hat{\mathrm{B}}$;

2. $\hat{\mathrm{B}}^{\prime}\left(\hat{\mathrm{B}}, \mathrm{s}^{\prime}\right)$ is hump-shaped; there exists $\mathrm{B}^{*}\left(\mathrm{~s}^{\prime}\right)$, such that $\hat{\mathrm{B}}^{\prime}\left(\hat{\mathrm{B}}, \mathrm{s}^{\prime}\right)$ is increasing for all $\hat{\mathrm{B}}<$ $\mathrm{B}^{*}\left(\mathrm{~s}^{\prime}\right)$ and decreasing for all $\hat{\mathrm{B}}>\mathrm{B}^{*}\left(\mathrm{~s}^{\prime}\right)$;

3. $\mathrm{B}^{*}\left(\mathrm{~s}^{\prime}\right)$ is increasing in $\mathrm{s}^{\prime}$.

The main result here is that the policy function for debt is hump-shaped in inherited debt. The intuition is the same as in the deterministic case: When the sustainability constraint is binding, an increase in future debt must be accompanied by a fall in inequality and, thus, a fall in output. At the optimum, this fall in output has to be larger than the increase in debt, since output is a costlier instrument to raise funds than debt is. For high values of current external debt, borrowing further cannot increase current consumption. Hence, when the government is highly indebted and values current consumption more, it is willing to make a drastic downward adjustment and sacrifice equality to increase current aggregate consumption.

Figure 4 depicts the policy functions implied by (26) for an example with two values of shocks $(K=2)$. In line with proposition 5 , policy functions are inverted $V$-shaped in external debt and decreasing with respect to future government spending, $G\left(s^{\prime}\right)$.

The typical equilibrium dynamics is a follows. Suppose a country starts with a low level of debt $\hat{B}$. Over time, it accumulates debt since the equilibrium interest rates are less than the discount factor. During this time, the government keeps transfers high and inequality low, corresponding to the boom phase of the cycle. Eventually its debt gets into the region in which sustainability constraints bind (decreasing portion of the policy function), precipitating austerity, cut in transfers and net outflow of resources. 

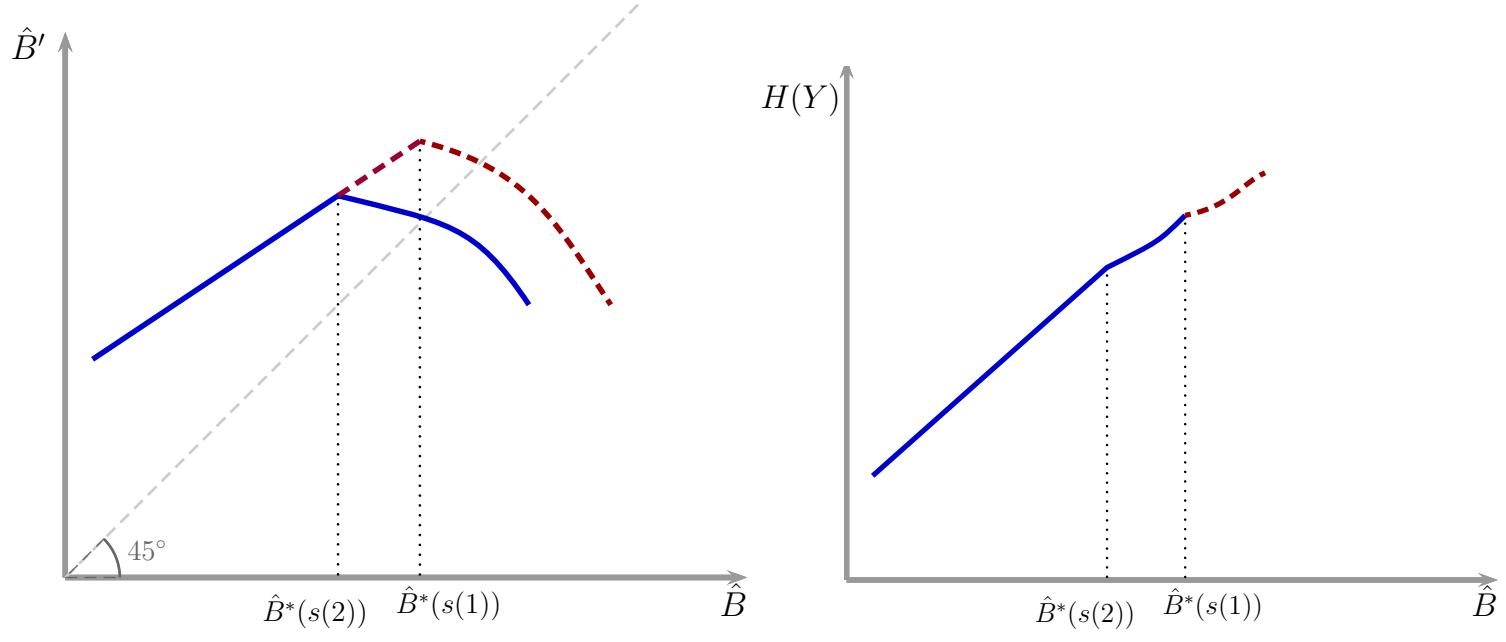

Figure 4: Policy functions for future external debt and inequality in the stochastic economy

As can be seen from Figure 4, populist cycles do not die out over time, as in the case of the deterministic economy in Section 3, and continue to exist in the invariant distribution. ${ }^{10}$ The cycles decline in amplitude over time as long as the country experiences the same realization of $\mathrm{G}\left(\mathrm{s}^{\prime}\right)$. A new shock amplifies the oscillatory dynamics and re-starts the cycle.

It is important to notice a difference between our model and a standard representative agent model with lack of commitment that has been used to analyze international capital flows (see for instance Aguiar et al. (2009)). In a representative agent framework, downward adjustment in external debt happens only when the economy draws a low government spending shocks. In contrast, in our model downward adjustments together with a positive current account also occurs in bad fiscal times. This is consistent with the empirical observation that countries are often forced to repay their debts even in adverse economic conditions.

\section{Historical Evidence}

In this section, we confront the implications of our model with the accounts of various historical episodes for the evolution of fiscal and external debt policies in several developing economies.

Cyclicality of fiscal policy and austerity. The equilibrium dynamics of our model is consistent with the populist cycles in macroeconomic policies first identified by Sachs (1989) and Dornbusch and Edwards (1991). In particular, Dornbusch and Edwards (1991) in

\footnotetext{
${ }^{10}$ In the Appendix, we show the existence of an invariant distribution for this economy.
} 
their study of economic policies in Latin American countries argue that the dynamics of fiscal policy involves two main phases: a populist phase and a consolidation phase. In the populist phase, redistributive policies supporting low and middle-income workers ${ }^{11}$ are implemented. In this phase, government finances worsen as the government runs large primary deficits. Additionally the country's net foreign asset position deteriorates (typically involving a reduction of foreign exchange reserves). A common starting point of the populist phase is the presence of a previous stabilization program that would have generally improved the country's fiscal and external budget at the expense of a highly uneven income distribution. This inequality typically presents a serious political and economic challenge for the governments, and provides the appeal for a radically different fiscal programs (see Dornbusch and Edwards (1991)).

The consolidation (austerity) phase that follows the populist phase attempts to address the fiscal imbalances. In this phase, austerity measures are implemented, and the government reduces its primary deficits and its external debt position. This phase also typically involves the intervention of foreign organizations such as the IMF.

These two phases neatly map into the dynamics predicted by our model. The populist phase corresponds to instances in our model when external debt values are low, and the government borrows heavily externally and expands its redistributive programs. This phase coincides with a primary deficit for the government in combination with a current account deficit. For high enough values of inherited external debt, transfers are reduced and external debt is repaid in an effort to minimize the output distortion in the economy and maximize the amount of resources available. As a result the government runs a primary surplus while the economy runs a current account surplus. Such behavior closely resembles the consolidation phase.

Two particular examples of these populist cycles are worth further consideration: Chile under Allende and Argentina under Perón. Prior to Allende, in the three years leading to 1970, the conditions of the Chilean public finances were favorable, mainly due to an increase in the price of copper, the country's main export product. Upon winning the election in 1971, the Allende government implemented various populist policies such as redistribution of land, nationalization of industries, and increase of minimum wages; for example, the real minimum wages for blue collar workers were increased by 56 percent in the first quarter of 1971. These policies had a positive effect on the income distribution at the cost of reducing the efficiency in the economy and deteriorating the public finance conditions. For instance, Ffrench-Davis (2002) writes that the period in which Allende was in power "shows a distributive improvement but within a deteriorated economy: a less con-

\footnotetext{
${ }^{11}$ Although part of their focus is on the real appreciation of the currency and its effect on import prices and wages in the non-tradable sector, many of the episodes identified also involve labor policies involving low and middle-income workers.
} 
centrated distribution of a smaller cake." Moreover, the average change in the public external debt net of international reserves was 14.2 percent of the GDP, and the primary deficit averaged 13.4 percent of the GDP, reaching a maximal level of 22.5 percent of the GDP in 1973. ${ }^{12}$ This populist phase was followed by the advent of Pinochet and a reversal of the social and economic reforms enacted by Allende and sizable primary surplus ( 3.74 percent from 1973 to 1982). This resulted in a reduction in the external net government debt between 1975 and 1981. In particular, the net external government debt as a fraction of the GDP fell from approximately 52 percent to 2.2 percent over five years. Not surprisingly, this coincided with a primary surplus of around 5 percent of the GDP.

Another emblematic case of populist policies that turned into a large fiscal consolidation is the experience of Argentina in 1945-1948, what Mallon and Sourrouille (1975) call "Perón's period of assault." As secretary of labor, Perón introduced various pro-labor policies including an increase in minimum wages and a substantial increase in pension benefits, and established a close relationship with the labor unions, with these policies continuing when he came to power in 1946. During the same episode, Argentina experienced a decline in its current account (from 1.99 billion pesos in 1946 to -610 million pesos in 1949; see Taylor (1998)) as well as a decline in foreign reserve holdings (from 1.1 billion dollars in 1946 to 258 million dollars in 1948). By the early 1950s there are signs of moves towards austerity measures. In a speech in 1952 Perón stated - as reproduced in Mallon and Sourrouille (1975):

The justicialista [i.e. Peronist] economy asserts that the production of the economy should first satisfy the needs of its inhabitants and only export the surplus; the surplus, nothing more. With this theory the boys here, of course, eat more every day and consume more, so that the surplus is smaller. But these poor guys have been submerged for fifty years; for this reason I have let them spend and eat and waste everything they wanted to for five years... but now we undoubtedly must begin to reorder things so as not to waste any more.

In 1952, the government introduced wage freezes, subsidized exports, and implemented import restrictions. As a result, the current account increased to 7.761 billion pesos in 1953 (2.1 billion pesos in 1954). See Dornbusch and Edwards (1991).

The predictions of our model are also consistent with the experience of several Southern European countries in the current economic crisis. In fact, in the aftermath of the favorable economic climate following the establishment of the euro, the governments of Southern European countries significantly increased public debt (particularly external debt in the case of Portugal and Greece) and government expenditures (with particular

\footnotetext{
${ }^{12}$ The numbers are based on the authors' calculations on data provided by the Central Bank of Chile.
} 
increase in transfers in the form of pensions, social transfers, and compensation of government employees) before 2007. Following the financial crisis of 2007, those countries had to implement drastic austerity measures in an effort to reduce their debt. Among other measures, those countries reduced transfers (especially pensions) and compensation of government employees.

For example, consider the case of Portugal. The run-up in government debt from 1999 to the current crisis is accompanied by an increasing trend in the share of total government expenditures associated with social protection from 12 percent of the GDP in 1999 to about 18 percent in 2009. ${ }^{13}$ The advent of the crisis is associated with dramatic changes in public finances and the trade balance. From 2010 to 2014, the primary surplus relative to the GDP improved from -8.2 percent to 0.5 percent, and the trade balance relative to the GDP improved from -7.1 percent to 1.1 percent. The total government expenditures associated with social protection declined by about 73 billion euro from 2010 to 2012. See Reis (2015) for further discussion.

Similarly, in Greece, the remuneration of public sector employees, a form of transfer, grew by 25 percent from 2000 to 2009, this figure being less than 7 percent on average for the the euro-area (see OECD (2013) Figure 6). These policies reversed after the crisis onset, with the reduction in wages of government employees and the reduction in pensions being the key components of the austerity measures. ${ }^{14}$ See Ioannides and Pissarides (2015) for more details.

Inequality and Incentive to Default. The cycles in our model arise because countries with high wealth inequality (or, equivalently, countries that had high income inequality) can support a lower amount of external public debt. Berg and Sachs (1988) find support for this mechanism. They document that higher income inequality is a significant predictor of the probability that a country will reschedule its external debt and of the interest rate spreads of the bond price in the secondary market. The authors consider a sample of emerging economies and find that income distribution, measured as the ratio of household income of top 20 percentiles over bottom 20 percentiles, is a significant predictor of the probability of rescheduling once controlling for other variables such as outward orientation of trade policies, share of agriculture in GNP, level of per capita GDP, and changes in the terms of trade. ${ }^{15}$ More recently, Aizenman and Jinjarak (2012) find a

\footnotetext{
${ }^{13}$ Source: Eurostat (2014)

${ }^{14}$ For instance, "a single salary grid was introduced and then extended to the whole civil service in November 2012, which rationalized the pay structure and reduced average pay levels by nearly $20 \%$ " (OECD (2013)).

${ }^{15}$ Since most of the countries that rescheduled and have high spreads are in Latin America and since such economies are characterized by extreme income inequality, one may think that high income inequality is just picking up a "Latin American" fixed effect. Interestingly enough, Berg and Sachs (1988) show that introducing a dummy variable for Latin America does not change the result: income inequality is still an important predictor of rescheduling. They find similar result when considering the effect of income
} 
positive association between sovereign default risk (measured by the CDS spread) and inequality.

Relatedly, Tomz (2004) analyzes a public opinion survey administered in Argentina during the debt crisis of 2001-2002. He finds that on average, poor, unemployed, and public sector employees are more favorable to a sovereign default, consistently with our model predictions. See the survey in Tomz and Wright (2013) for references to other works with similar findings.

\section{Conclusion}

The political economy and unequal effect of consolidations are important features of sovereign debt crises. In this paper, we develop a framework to analyze the interactions of inequality and external debt in an economy without commitment. As we have shown, our model can account for why various developing countries go through low-frequency cycles in external debt. In explaining these cycles, our theory points toward weak institutions as the main culprit behind this seemingly puzzling observation. According to our theory, the key difference between these economies and more stable and developed economies is institutions' inability to tie the government's hand in changing policies, in other words, lack of commitment.

We believe that our tractable framework is rich enough for more general analysis of government policy in open economies when the government is concerned about redistribution. Some examples are worth discussing: First, our analysis focuses on an overlapping generations economy without capital. This is partly to separately identify the conflict between current and future governments regarding the trade-off between inequality and external debt, as well as the tractability of the repeated game between the government, households, and foreign creditors. With capital, we conjecture that the conflict that we identify is present but the analysis becomes much more complicated, since the value associated with the worst equilibrium depends on the value of capital and is harder to characterize. Second, we have stayed silent on default and have focused solely on allocations. One can of course, decentralize the allocations discussed above in a setup where government defaults on its debt. These are natural extensions of our framework and are worth exploring in future research.

inequality on the spreads. 


\section{References}

Abreu, D. (1988): "On the Theory of Infinitely Repeated Games with Discounting," Econometrica, 56, 383-396. 57

Abreu, D., D. Pearce, And E. Stacchetti (1990): “Toward a Theory of Discounted Repeated Games with Imperfect Monitoring," Econometrica: Journal of the Econometric Society, 1041-1063. 46

Aguiar, M. And M. Amador (2011): "Growth in the Shadow of Expropriation," Quarterly Journal of Economics, 126. 16

_ (2014): “Fiscal Policy in Debt Constrained Economies," NBER Working Paper. 4, 5

Aguiar, M., M. AMADOR, AND G. GOPINATH (2009): “Investment cycles and sovereign debt overhang," The Review of Economic Studies, 76, 1-31. 5, 16, 25

Aiyagari, S. R., A. Marcet, T. J. SARgent, AND J. Seppälä (2002): “Optimal Taxation without State-Contingent Debt," Journal of Political Economy, 110, 1220-1254. 4

AizenMAN, J. AND Y. JinJARAK (2012): “Income Inequality, Tax Base and Sovereign Spreads," NBER Working Paper. 28

Alvarez, F. AND U. J. Jermann (2000): “Efficiency, Equilibrium, and Asset Pricing with Risk of Default," Econometrica, 68, 775-797. 23

Arellano, C. (2008): “Default Risk and Income Fluctuations in Emerging Economies," The American Economic Review, 98, 690-712. 4

BERG, A. AND J. SACHS (1988): “The Debt Crisis: Structural Explanations of Country Performance," Journal of Development Economics, 29, 271-306. 28

Bhandari, A., D. Evans, M. Golosov, And T. J. Sargent (2013): “Taxes, Debts, and Redistributions with Aggregate Shocks," NBER Working Paper. 5

Broner, F., A. Erce, A. Martin, AND J. Ventura (2014): "Sovereign debt markets in turbulent times: Creditor discrimination and crowding-out effects," Journal of Monetary Economics, 61, 114-142. 16

Chari, V. And P. J. Kehoe (1990): "Sustainable Plans," The Journal of Political Economy, 98, 783-802. 4, 10, 57

Chari, V. V. And P. J. Kehoe (1999): “Optimal Fiscal and Monetary Policy," Handbook of macroeconomics, 1, 1671-1745. 4 
D'ERAsmo, P. And E. G. MendozA (2013): “Distributional Incentives in an Equilibrium Model of Domestic Sovereign Default," NBER Working Paper. 5

Dornbusch, R. AND S. EdWARDS (1991): The Macroeconomics of Populism in Latin America, University of Chicago Press. 2, 4, 25, 26, 27

Dovis, A. (2013): “Efficient Sovereign Default," Working Paper, Pennsylvania State University. 10

DUNFORD, N. AND J. T. SCHWARTZ (1958): “Linear operators, vol. I," Interscience, New York, 1963. 54

EAton, J. AND M. Gersovitz (1981): “Debt with Potential Repudiation: Theoretical and Empirical Analysis," The Review of Economic Studies, 289-309. 4, 5, 19

EUROSTAT (2014): “Government Statistics, General Government Expenditure by Function," http://ec.europa.eu/eurostat/web/government-finance-statistics/data/ database. 28

FARHI, E., C. SleEt, I. Werning, AND S. YELteKIN (2012): “Non-Linear Capital Taxation Without Commitment," The Review of Economic Studies, 79, 1469-1493. 5, 18

FERRIERE, A. (2014): “Sovereign Default, Inequality, and Progressive Taxation," Working Paper, European University Institute. 5

FFRENCH-DAVIS, R. (2002): Economic Reforms in Chile: from Dictatorship to Democracy, University of Michigan Press. 26

Grossman, H. I. AND J. B. VAn HuycK (1988): “Sovereign Debt as a Contingent Claim: Excusable Default, Repudiation, and Reputation," American Economic Review, 78, 10881097. 10

Hardy, G. H., J. E. LitTlewOOd, AND G. PÓlya (1952): Inequalities, Cambridge university press. 37

IOANNIDES, Y. M. AND C. A. Pissarides (2015): "Is the Greek Debt Crisis One of Supply or Demand?" Brookings Papers on Economic Activity. 28

KeHOE, P. J. AND F. PERRI (2004): “Competitive Equilibria with Limited Enforcement," Journal of Economic Theory, 119, 184-206. 10

KeHOE, T. J. And D. K. Levine (1993): “Debt-Constrained Asset Markets," The Review of Economic Studies, 60, 865-888. 23 
(2009): "Bankruptcy and Collateral in Debt Constrained Markets," Macroeconomics in the Small and the Large: Essays on Microfoundations, Macroeconomic Applications and Economic History in Honor of Axel Leijonhufoud, 99-115. 10

LindBeCK, A. AND J. W. Weibull (1987): “Balanced-Budget Redistribution as the Outcome of Political Competition," Public choice, 52, 273-297. 4, 18

Lucas, R. E. And N. L. Stokey (1983): “Optimal Fiscal and Monetary Policy in an Economy Without Capital," Journal of Monetary Economics, 12, 55-93. 4, 9, 23

Mallon, R. D. AND J. V. Sourrouille (1975): Economic Policymaking in a Conflict Society, Harvard University Press. 27

OECD (2013): “OECD Economic Surveys: Greece," Organization for Economic Co-operation and Development. 28

REIS, R. (2015): “Looking for a Success: The Euro Crisis Adjustment Programs,” Brookings Papers on Economic Activity. 28

RudiN, W. (1991): Functional Analysis, McGraw-Hill, Inc., New York. 54

SACHS, J. D. (1989): "Social Conflict and Populist Policies in Latin America," NBER Working Paper. 2, 4, 25

SCheuer, F. AND A. WolitzKy (2014): “Capital Taxation under Political Constraints," NBER Working Paper. 5, 18

SleEt, C. AND Ş. Yeltekin (2006): “Credibility and Endogenous Societal Discounting," Review of Economic Dynamics, 9, 410-437. 5

Song, Z., K. Storesletten, AND F. Zilibotti (2012): “Rotten Parents and Disciplined Children: A Politico-Economic Theory of Public Expenditure and Debt," Econometrica, 80, 2785-2803. 18

StOkey, N., R. LuCAS, AND E. PRescotT (1989): Recursive Methods in Economic Dynamics, Harvard University Press. 12, 36, 49

TAYLOR, A. M. (1998): "Argentina and the World Capital Market: Saving, Investment, and International Capital Mobility in the Twentieth Century," Journal of Development Economics, 57, 147-184. 27

THOMAS, J. AND T. WORRALL (1994): “Foreign direct investment and the risk of expropriation," The Review of Economic Studies, 81-108. 5, 16 
TOMZ, M. (2004): "Interests, Information, and the Domestic Politics of International Agreements," Unpublished manuscript, Stanford. 29

TOMZ, M. AND M. L. WRIGHT (2013): “Empirical Research on Sovereign Debt and Default," Annual Review of Economics, 5, 247-272. 29

Werning, I. (2007): “Optimal Fiscal Policy with Redistribution," The Quarterly Journal of Economics, 122, 925-967. 5, 23, 65

\section{Proofs}

\subsection{Proof of Lemma 1}

Consider an allocation that constitutes a competitive equilibrium with taxes. For any such allocation, the necessary first order conditions with log-log preferences are

$$
\begin{aligned}
q_{t}^{d} \frac{1}{c_{t, 0}^{i}} & =\beta\left(1-\tau_{a, t+1}\right) \frac{1}{c_{t, 1}^{i}} \\
\frac{1-\tau_{l, t}}{c_{t, 0}^{i}} & =\psi \frac{1}{\theta^{i}-y_{t}^{i}}
\end{aligned}
$$

Therefore

$$
\frac{c_{t, 0}^{i}}{c_{t, 0}^{j}}=\frac{c_{t, 1}^{i}}{c_{t, 1}^{j}}=\frac{\theta^{i}-y_{t}^{i}}{\theta^{j}-y_{t}^{j}}
$$

If we define $\varphi_{t}^{i}=c_{t, 0}^{i} / C_{t, 0}$, then the above equations yield

$$
\begin{aligned}
c_{0, \mathrm{t}}^{i} & =\varphi_{\mathrm{t}}^{i} \mathrm{C}_{0, \mathrm{t}} \\
\mathrm{c}_{1, \mathrm{t}}^{i} & =\varphi^{i} \mathrm{C}_{1, \mathrm{t}} \\
\theta^{i}-y_{\mathrm{t}}^{i} & =\varphi_{\mathrm{t}}^{i}\left(1-Y_{\mathrm{t}}\right)
\end{aligned}
$$

where we have used the fact that $\sum \mu^{i} \theta^{i}=1$ and assumed that all allocations are interior. ${ }^{16}$ Note that the above together with (89) imply that

$$
\frac{1-\tau_{l, t}}{C_{t, 0}}=\psi \frac{1}{1-Y_{t}}, q_{t}^{d} \frac{1}{C_{t, 0}}=\beta\left(1-\tau_{a, t+1}\right) \frac{1}{C_{t, 1}}
$$

\footnotetext{
${ }^{16}$ Since our preferences do not satisfy Inada condition for hours worked at 0 hours, we need to make assumption about the dispersion of productivities so that everyone works positive hours. When we allow for hours worked to be zero, all of our results will go through while they involve more extensive and cumbersome algebra and are available upon request.
} 
We can combine the budget constraints (3) and (4) to obtain

$$
c_{t, 0}^{i}+\frac{q_{t}^{d}}{\left(1-\tau_{a, t+1}\right)} c_{t, 1}^{i}=y_{t}^{i}\left(1-\tau_{l, t}\right)+T_{t}+\frac{q_{t}^{d}}{\left(1-\tau_{a, t+1}\right)} P_{t+1}
$$

Using (35) in the above equation we obtain

$$
c_{t, 0}^{i}+\frac{\beta C_{t, 0}}{C_{t, 1}} c_{t, 1}^{i}=y_{t}^{i} \frac{\psi C_{t, 0}}{1-Y_{t}}+T_{t}+\frac{q_{t}^{d}}{\left(1-\tau_{a, t+1}\right)} P_{t+1}
$$

This can be written as

$$
\frac{1}{C_{t, 0}} c_{t, 0}^{i}-\frac{\psi}{1-Y_{t}} y_{t}^{i}+\beta \frac{1}{C_{t, 1}} c_{t, 1}^{i}=\hat{T}_{t} .
$$

for some constant $\hat{T}_{t}$. Replacing from (32)-(34), we have

$$
\begin{aligned}
& \frac{1}{C_{t, 0}} \varphi_{t}^{i} C_{t, 0}-\frac{\psi}{1-Y_{t}}\left[\theta^{i}-\varphi_{t}^{i}\left(1-Y_{t}\right)\right]+\beta \frac{1}{C_{t, 1}} \varphi_{t}^{i} C_{t, 1}=\hat{T}_{t} . \\
& (1+\psi+\beta) \varphi_{\mathrm{t}}^{\mathrm{i}}-\frac{\psi \theta^{\mathrm{i}}}{1-Y_{\mathrm{t}}}=\hat{\mathrm{T}}_{\mathrm{t}}
\end{aligned}
$$

Taking averages across i's, we have

$$
\begin{aligned}
(1+\psi+\beta) \sum_{i} \mu^{i} \varphi_{t}^{i}-\sum_{i} \frac{\psi \mu^{i} \theta^{i}}{1-Y_{t}} & =\hat{T}_{t} \\
(1+\psi+\beta)-\frac{\psi}{1-Y_{t}} & =\hat{T}_{t}
\end{aligned}
$$

Hence,

$$
(1+\psi+\beta) \varphi_{\mathrm{t}}^{\mathrm{i}}-\frac{\psi \theta^{\mathrm{i}}}{1-Y_{\mathrm{t}}}=(1+\psi+\beta)-\frac{\psi}{1-Y_{\mathrm{t}}}
$$

or

$$
\varphi_{\mathrm{t}}^{\mathrm{i}}=1+\frac{\psi}{1+\psi+\beta} \frac{\theta^{i}-1}{1-Y_{\mathrm{t}}}
$$

This implies that any allocation that constitutes a competitive equilibrium with taxes must satisfy (8) and (10). The equations (9) and (11) are satisfied from the definition of initial assets.

To prove the reverse claim, consider aggregate allocations together with the $\varphi_{t}^{i}$ s that satisfy (8)-(11) as well as the feasibility constraint (5). We construct labor income taxes, $\tau_{l, t}$, and bond prices, $q_{t}^{d}$ using equation (35) - we set asset taxes to 0 . We choose transfers, $T_{t}$, and pensions, $P_{t+1}$ so that present value of government transfers to generation $t, T_{t}+$ $q_{t}^{d} P_{t+1}$ is given by (36).

By definition of $\tau_{l, t}$, the first order conditions (29) and (30) are satisfied if $c_{t, i}=\varphi_{t}^{i} C_{t, 0}$, 
$c_{t+1, i}=\varphi_{t}^{i} C_{t, 1}$ and $y_{t, i}=\theta^{i}-\varphi_{t}^{i}\left(\bar{\theta}-Y_{t}\right)$. Since equation (36) is satisfied, this individual allocation satisfies the budget constraint. Therefore, concavity of the problem implies that this allocation solves the optimization problem for households of type $i$. Since feasibility constraint as well as the budget constraints of the households are satisfied, Walras' law implies that government's budget constraint is satisfied. Thus the constructed allocations and policies constitute a competitive equilibrium with taxes.

Q.E.D.

\subsection{Proof of Proposition 1}

To prove the proposition, we first analyze the recursive dual problem given by

$$
\hat{B}(V)=\max Y-C_{0}-C_{1}-G+\frac{\hat{B}\left(V^{\prime}\right)}{1+r}
$$

subject to

$$
\begin{aligned}
\frac{\beta}{\hat{\beta}} \log C_{1}+\left[\log C_{0}+\psi \log (1-Y)-(1+\psi+\beta) H(Y)\right]+\hat{\beta} V^{\prime} & \geqslant V \\
V^{\prime}-\frac{\beta}{\hat{\beta}} H(Y) & \geqslant \underline{W}
\end{aligned}
$$

where $V_{t}$ is the value for the government at $t$ excluding the cost of inequality for the current old.

The transformation associated with the right hand side of (37) is a contraction and thus the above functional equation has a unique solution. Standard arguments from dynamic programming can be used to show that the value function $\hat{B}(\mathrm{~V})$ must be the value of the planning problem associated with the dual of the problem associated with the best sustainable equilibrium. Furthermore, it is straightforward to show that $\hat{B}(V)$ is strictly decreasing and that the promise keeping constraint, (38) is binding. Hence, it must be invertible. We let the inverse of this function be given by $W^{*}(B)$ - a strictly decreasing function. In what follows, we show that $W^{*}(B)$ is a solution to the functional equation (P1).

To see this, consider the following optimization problem

$$
\max _{C_{0}, C_{1}, Y, B^{\prime}} \frac{\beta}{\hat{\beta}} \log C_{1}+\log C_{0}+\psi \log (1-Y)-(1+\psi+\beta) H(Y)+\hat{\beta} W^{*}\left(B^{\prime}\right)
$$


subject to

$$
\begin{array}{r}
C_{0}+C_{1}+B+G \leqslant \frac{B^{\prime}}{1+r}+Y \\
W^{*}\left(B^{\prime}\right)-\frac{\beta}{\hat{\beta}} H(Y) \geqslant \underline{W}
\end{array}
$$

Evidently, the above value must be at least as high as $W^{*}(B)$. This is because we can just use the associated policy functions in (37) for the arguments and guarantee a value of $W^{*}(B)$. Suppose that for some value of $B$, the value of the above is strictly higher than $W^{*}(\mathrm{~B})$ and let $\left\{\tilde{\mathrm{C}}_{0}, \tilde{\mathrm{C}}_{1}, \tilde{\mathrm{Y}}, \tilde{\mathrm{B}}^{\prime}\right\}$ be an allocation that delivers such a value. Now, consider the allocation $\left\{\tilde{C}_{0}-\varepsilon, \tilde{C}_{1}, \tilde{Y}, W^{*}\left(\tilde{B}^{\prime}\right)\right\}$. This allocation satisfies (39) while the utility that it delivers is higher than $W^{*}(B)$ - for a small and positive value of $\varepsilon$. Finally, this allocation satisfies

$$
\begin{aligned}
\tilde{Y}-\tilde{C}_{0}+\varepsilon-\tilde{C}_{1}-G+\frac{\hat{B}\left(W^{*}\left(\tilde{B}^{\prime}\right)\right)}{1+r} & =\tilde{Y}-\tilde{C}_{0}+\varepsilon-\tilde{C}_{1}-G+\frac{\tilde{B}^{\prime}}{1+r} \\
& >B+\varepsilon>\hat{B}\left(W^{*}(B)\right)
\end{aligned}
$$

The above inequality is a contradiction since $\hat{B}\left(W^{*}(B)\right)$ is the highest value achieved by any allocation that delivers utility higher than $W^{*}(B)$ and satisfies the sustainability constraint (39). This implies that the value of the objective in (P1) must be equal to $W^{*}(B)$. Therefore, $W^{*}$ (B) must be a solution to the functional equation in (P1). Now, suppose that there exists another solution of (P1) that delivers a higher value than $W^{*}(B)$. This implies that an allocation must exists that is sustainable and feasible and delivers a value higher than $\hat{B}\left(W^{*}(B)\right)$ which is a contradiction. Thus, $W^{*}(B)$ is the largest solution of $(P 1)$. The rest of the claim in the proposition can be shown using the standard argument for the principle of optimality.

Q.E.D.

\subsection{Proof of Lemma 2}

We prove that the value function $\hat{B}(V)$ is concave and decreasing. This implies that its inverse $W^{*}$ (B) must also be concave. The proof of monotonicity (as well differentiability) is standard and follows the same techniques from Stokey et al. (1989). In order to show concavity of the value function, it is sufficient to show that the constraint set is convex and the rest of the proof follows from Stokey et al. (1989). 
Note that given lemma 1, the constraint set is given by

$$
\begin{aligned}
\frac{\beta}{\hat{\beta}} \log C_{1}+\log C_{0}+\psi \log (1-Y)-(1+\psi+\beta) H(Y)+\hat{\beta} V^{\prime} & =V \\
V^{\prime}-\frac{\beta}{\hat{\beta}} H(Y) & \geqslant \underline{W}
\end{aligned}
$$

where

$$
H(Y)=-\sum_{i} \alpha^{i} \mu^{i} \log \left(1+\frac{\psi}{1+\psi+\beta} \frac{\theta^{i}-1}{1-Y}\right) .
$$

Since $\log$ is a concave function, in order to prove the convexity of the constraint set, it is sufficient to show that $\mathrm{H}(\mathrm{Y})$ is convex. We have

$$
H^{\prime}(Y)=-\frac{1}{1-Y} \sum_{i=1}^{N} \mu^{i} \frac{\alpha^{i}}{1+\frac{\psi}{1+\psi+\beta} \frac{\theta^{i}-1}{1-Y}} \frac{\psi}{1+\psi+\beta} \frac{\theta^{i}-1}{1-Y}
$$

From assumption $1, \alpha^{i}$ is decreasing in $i$ and so is $\frac{1}{1+\frac{\psi}{1+\psi+\beta} \frac{\theta^{i}-1}{1-Y}}$. Hence, $\frac{\alpha^{i}}{1+\frac{\psi}{1+\psi+\beta} \frac{\theta^{i}-1}{1-Y}}$ is decreasing in $i$ while $\frac{\psi}{1+\psi+\beta} \frac{\theta^{i}-1}{1-Y}$ is increasing in $i$. Therefore, from Chebyshev's sum inequality (see Hardy et al. (1952)), we must have

$$
\begin{aligned}
\sum_{i=1}^{N} \mu^{i} \frac{\alpha^{i}}{1+\frac{\psi}{1+\psi+\beta} \frac{\theta^{i}-1}{1-Y}} \frac{\psi}{1+\psi+\beta} \frac{\theta^{i}-1}{1-Y} & <\sum_{i=1}^{N} \mu^{i} \frac{\alpha^{i}}{1+\frac{\psi}{1+\psi+\beta} \frac{\theta^{i}-1}{1-Y}} \sum_{i=1}^{N} \mu^{i} \frac{\psi}{1+\psi+\beta} \frac{\theta^{i}-1}{1-Y} \\
& =\sum_{i=1}^{N} \mu^{i} \frac{\alpha^{i}}{1+\frac{\psi}{1+\psi+\beta} \frac{\theta^{i}-1}{1-Y}} \frac{\psi}{(1+\psi+\beta)(1-Y)}\left(\sum \mu^{i} \theta^{i}-1\right) \\
& =0
\end{aligned}
$$

This establishes that $\mathrm{H}(\mathrm{Y})$ is strictly increasing in $\mathrm{Y}$.

Furthermore, we have

$$
H^{\prime \prime}(Y)=-\frac{H^{\prime}(Y)}{1-Y}-\frac{1}{1-Y} \sum \mu^{i} \alpha^{i} \frac{\frac{\psi}{1+\psi+\beta}\left(\theta^{i}-1\right)}{\left(1-Y+\frac{\psi}{1+\psi+\beta}\left(\theta^{i}-1\right)\right)^{2}}
$$

Note that in the expression above, the first term is positive while a similar application of Chebyshev's sum inequality implies that the second term is also positive and hence, $H(Y)$ must be strictly convex. This concludes the proof.

Q.E.D. 


\subsection{Proof of Theorem 1}

In light of the proof of proposition 1, we again focus on the functional equation (37). It is sufficient to show that the policy function $V^{\prime}(V)$ resulting from (37) is hump-shape. As the above results establish, we have $B^{\prime}(B)=B\left(V^{\prime}\left(W^{*}(B)\right)\right)$. Since both $B$ and $W^{*}$ are decreasing functions, the hump-shape of $\mathrm{V}^{\prime}$ implies a U-shape for $\mathrm{B}^{\prime}(\cdot)$ and this establishes our claim.

Since, we have shown that the value function is differentiable, we can take first order conditions from (37). There are two possibilities:

1. The sustainability constraint is slack.

In this case, we have the following FOC

$$
1-\lambda\left[\frac{\psi}{1-Y}+(1+\psi+\beta) H^{\prime}(Y)\right]=0
$$

where $\lambda$ is the Lagrange multiplier associated with the promise keeping constraint. Furthermore, from envelope condition for (37), we must have

$$
\hat{\mathrm{B}}^{\prime}(\mathrm{V})=-\lambda
$$

Since $\hat{B}(V)$ is concave, the above condition implies that $\lambda$ is increasing in $V$. We can then write the FOC associated with $Y$ as

$$
\frac{1}{\lambda}=\frac{\psi}{1-Y}+(1+\psi+\beta) H^{\prime}(Y)
$$

Since $\mathrm{H}$ is convex, the right hand side of the above equation is increasing in $\mathrm{Y}$ and the left hand side is decreasing in $\lambda$, it must be that $Y$ decreases as $\lambda$ increases. In other words, $Y$ is a decreasing function of $\mathrm{V}$.

Furthermore, when the sustainability constraint is not binding, the first order condition associated with $V^{\prime}$ together with the envelope condition implies that

$$
\frac{1}{1+r} \hat{B}^{\prime}(V)+\lambda \hat{\beta}=0 \rightarrow \frac{1}{1+r} \hat{B}^{\prime}(V)-\hat{\beta} \hat{B}^{\prime}(V)=0
$$

Since $\hat{B}$ is concave, the above implies that $V^{\prime}$ is an increasing function of $V$.

The above results also imply that the sustainability constraint is slack for high values of $\mathrm{V}$. This is because, the following expression is increasing in $\mathrm{V}$ - under the above assumption

$$
V^{\prime}-\frac{\beta}{\hat{\beta}} H(Y)
$$

Thus there must exists a value $V^{*}$ so that for values of $V$ higher than $V^{*}$, the sustainability 
constraint is slack.

2. Sustainability constraint is binding.

As we show above $\mathrm{V}^{*}$ must exist such that sustainability constraint is binding only if $\mathrm{V}<\mathrm{V}^{*}$. When $\mathrm{V}$ is below $\mathrm{V}^{*}$, sustainability constraint binds and hence, we must have

$$
\mathrm{V}^{\prime}=\underline{W}+\frac{\beta}{\hat{\beta}} H(\mathrm{Y})
$$

Using this relationship, the promise keeping constraint becomes

$$
\frac{\beta}{\hat{\beta}} \log C_{1}+\log C_{0}+\psi \log (1-Y)-(1+\psi) H(Y)+\hat{\beta} \underline{W}=V
$$

while the objective becomes

$$
Y-C_{0}-C_{1}+\frac{1}{1+r} \hat{B}\left(\underline{W}+\frac{\beta}{\hat{\beta}} H(Y)\right)
$$

Using this objective and taking first order conditions with respect to $Y$, we have

$$
1+\frac{\beta}{\hat{\beta}(1+r)} \hat{B}^{\prime}\left(V^{\prime}\right) H^{\prime}(Y)-\lambda\left[\frac{\psi}{1-Y}+(1+\psi) H^{\prime}(Y)\right]=0
$$

where $\mathrm{V}^{\prime}$ is given by (43). As before, the envelope condition implies that $\hat{B}^{\prime}(\mathrm{V})=-\lambda$ and hence, we need to show that $Y$ is a decreasing function of $\lambda$. Consider a small change in $\lambda$, given by $d \lambda$. Let the change in $Y$ and $V^{\prime}$ be defined by $d Y$ and $d V^{\prime}$, respectively. Then, we must have the following relationships - based on (43)

$$
d V^{\prime}=\frac{\beta}{\hat{\beta}} H^{\prime}(Y) d Y
$$

Using the above equation, taking a total derivative from (44) and after manipulations, we can write

$$
\frac{d Y}{d \lambda}=\frac{\frac{\psi}{1-Y}+(1+\psi) H^{\prime}(Y)}{\frac{\beta}{\hat{\beta}(1+r)}\left(\hat{B}^{\prime \prime}\left(V^{\prime}\right)\left(H^{\prime}(Y)\right)^{2} \frac{\beta}{\hat{\beta}}+\hat{B}^{\prime}\left(V^{\prime}\right) H^{\prime \prime}(Y)\right)-\lambda\left[\frac{\psi}{(1-Y)^{2}}+(1+\psi) H^{\prime \prime}(Y)\right]}
$$

Note that $\mathrm{H}^{\prime}>0$ and hence the numerator is a positive number. Furthermore, $\hat{\mathrm{B}}^{\prime \prime}<0$, $\hat{\mathrm{B}}^{\prime}<0, \mathrm{H}^{\prime \prime}>0$ together with $\lambda>0$ imply that the denominator is negative. Hence, $\frac{\mathrm{d} Y}{\mathrm{~d} \lambda}<0$. The claim then follows from the fact that $\frac{d \lambda}{d V}>0$ and $\frac{d V^{\prime}}{d Y}=\frac{\beta}{\hat{\beta}} H^{\prime}(Y)>0$.

We can then relate these results back to the primal problem (P1) to get the desired results.

Q.E.D. 


\subsection{Proof of Proposition 2}

For this proposition, we consider a decentralization in which households with the lowest productivity, $\theta^{1}$, hold zero debt, $\mathrm{a}^{1}=0$.

For simplicity, we will consider the dual version of the problem, (37) introduced in the proof of Theorem 1. Moreover, we will repeatedly use the fact that $Y$ is decreasing in $V$ as established in the proof of Theorem 1.

We start by showing that the income tax rate $\tau_{l}$ is increasing in $B$ or decreasing in V. Consider first the case in which the sustainability constraint is slack. In this case, the optimal allocation satisfies the following FOCs where $\lambda$ is the multiplier on the promise keeping constraint ${ }^{17}$ :

$$
\begin{aligned}
\lambda \frac{\kappa}{\mathrm{C}} & =1 \\
1-\lambda\left[\frac{\psi}{1-\mathrm{Y}^{\prime}}+(1+\psi+\beta) \mathrm{H}^{\prime}\left(\mathrm{Y}^{\prime}\right)\right] & =0
\end{aligned}
$$

Note that from the definition of $k$, the consumption of the young is given by $C / K$ and hence labor income taxes are given by

$$
1-\tau_{l}=\frac{\psi}{1-Y} \frac{C}{\kappa}
$$

Combining (30) and (46) we can write

$$
1-\frac{C}{K}\left[\frac{\psi}{1-Y}+(1+\psi+\beta) H^{\prime}(Y)\right]=0
$$

Using the definition of $\mathrm{H}$ we have

$$
1-\frac{C}{K}\left[\frac{\psi}{1-Y}-\frac{\psi}{1-Y} \sum \alpha^{i} \mu^{i} \frac{\frac{\theta^{i}-1}{1-Y}}{1+\frac{\psi}{1+\psi+\beta} \frac{\theta^{i}-1}{1-Y}}\right]=0
$$

or rearranging and using the definition of $\tau_{l}$ we obtain

$$
\frac{\tau_{l}}{1-\tau_{l}}=-\sum_{i} \alpha^{i} \mu^{i} \frac{\frac{\theta^{i}-1}{1-Y}}{1+\frac{\psi}{1+\psi+\beta} \frac{\theta^{i}-1}{1-Y}}=-\sum_{i} \alpha^{i} \mu^{i} \frac{\theta^{i}-1}{1-Y+\frac{\psi}{1+\psi+\beta}\left(\theta^{i}-1\right)}
$$

\footnotetext{
${ }^{17}$ Here we have used the fact that utility from consumption in (38) can be written as $\kappa \log \mathrm{C}$ where $\mathrm{C}=$ $\mathrm{C}_{0}+\mathrm{C}_{1}$ and $\mathrm{k}=\frac{\hat{\beta}}{\hat{\beta}}+1$. In addition, $\mathrm{C}_{0}=\frac{\hat{\beta}}{\beta+\hat{\beta}} \mathrm{C}$.
} 
Moreover,

$$
\begin{aligned}
\frac{\partial}{\partial Y} \sum \alpha^{i} \mu^{i} \frac{\theta^{i}-1}{1-Y+\frac{\psi}{1+\psi+\beta}\left(\theta^{i}-1\right)} & =\sum \alpha^{i} \mu^{i} \frac{\theta^{i}-1}{\left(1-Y+\frac{\psi}{1+\psi+\beta}\left(\theta^{i}-1\right)\right)^{2}} \\
& =\sum \mu^{i} \frac{\alpha^{i}}{\left(1-Y+\frac{\psi}{1+\psi+\beta}\left(\theta^{i}-1\right)\right)^{2}}\left(\theta^{i}-1\right) \\
& =\operatorname{Cov}\left(\frac{\alpha^{i}}{\left(1-Y+\frac{\psi}{1+\psi+\beta}\left(\theta^{i}-1\right)\right)^{2}}, \theta^{i}\right)<0
\end{aligned}
$$

Hence, the right side of (47) is increasing in $V$ and so must be the left side. Then $\tau_{l}$ is decreasing in $\mathrm{V}$.

When the sustainability constraint binds, the FOC for $\mathrm{Y}$ is

$$
1+\frac{q}{\hat{\beta}} \beta H^{\prime}(Y) \hat{B}^{\prime}\left(\underline{W}+\frac{\beta}{\hat{\beta}} H(Y)\right)-\lambda\left[\frac{\psi}{1-Y}+(1+\psi) H^{\prime}(Y)\right]=0
$$

Combining the equation above with (29), the definition of $1-\tau_{l}$, and $\mathrm{H}$ we obtain

$$
1-\tau_{l}=\frac{1+\frac{q}{\hat{\beta}} \beta H^{\prime}(Y) \hat{B}^{\prime}\left(\frac{W}{h}+\frac{\beta}{\hat{\beta}} H(Y)\right)}{1-\sum \alpha^{i} \mu^{i} \frac{\frac{\theta^{i}-1}{1-Y}}{1+\frac{\psi}{1+\psi+\beta} \frac{\theta^{i}-1}{1-Y}}}=\frac{F_{1}(Y)}{F_{2}(Y)}
$$

We know that $F_{2}(Y)>1$ and it is increasing in $Y$. Moreover,

$$
\begin{aligned}
& F_{1}^{\prime}(Y)=1+\frac{q}{\hat{\beta}} \beta H^{\prime}(Y) \hat{B}^{\prime}\left(\underline{W}+\frac{\beta}{\hat{\beta}} H(Y)\right) \\
& F_{1}^{\prime}(Y)=\frac{q}{\hat{\beta}} \beta H^{\prime \prime}(Y) \hat{B}^{\prime}\left(\underline{W}+\frac{\beta}{\hat{\beta}} H(Y)\right)+q\left(\frac{\beta}{\hat{\beta}}\right)^{2}\left(H^{\prime}(Y)\right)^{2} \hat{B}^{\prime \prime}\left(\underline{W}+\frac{\beta}{\hat{\beta}} H(Y)\right)<0
\end{aligned}
$$

so from (48) we have that

$$
\frac{\partial \tau_{l}}{\partial V}=-\frac{\partial}{\partial Y} \frac{F_{1}(Y)}{F_{2}(Y)} \times \frac{\partial Y}{\partial V}<0,
$$

and so $\tau_{l}$ is decreasing in $V$ (or increasing in $B$ ).

We now turn to show that domestic debt is $V$-shaped, in that $B^{d}$ is increasing for $\mathrm{V}>\mathrm{V}^{*}$ (decreasing in $\mathrm{B}$ for $\mathrm{B}<\mathrm{B}^{*}$ ) and it is decreasing in $\mathrm{V}$ for $\mathrm{V}<\mathrm{V}^{*}$ (increasing in $\mathrm{B}$ for $\mathrm{B}>\mathrm{B}^{*}$ ). Under our decentralization, total domestic debt is given by

$$
\mathrm{B}^{\mathrm{d}}(\mathrm{V})=\sum_{i=2}^{\mathrm{N}} \varphi^{i}(\mathrm{Y}(\mathrm{V})) \mathrm{C}_{1}\left(\mathrm{~V}^{\prime}(\mathrm{V})\right)=\left(1-\varphi^{1}(\mathrm{Y}(\mathrm{V}))\right) \frac{\beta}{\beta+\beta} \mathrm{C}\left(\mathrm{V}^{\prime}(\mathrm{V})\right)
$$


Since $Y$ is decreasing in $V$, then $\left(1-\varphi^{1}(Y(V))\right)$ is decreasing in $V$. Moreover $C$ is increasing in $V$. Let $V<V^{*}$. In this case, $V^{\prime}(V)$ is decreasing and so $B^{d}(V)$ is decreasing. Consider now the case $\mathrm{V}>\mathrm{V}^{*}$. When the sustainability constraint is slack, we can combine the FOC for $V^{\prime}, C$, and the envelope condition to get

$$
\mathrm{C}\left(\mathrm{V}^{\prime}(\mathrm{V})\right) \propto-\mathrm{B}^{\prime}\left(\mathrm{V}^{\prime}(\mathrm{V})\right) \propto \mathrm{C}(\mathrm{V})
$$

Using this and the definition of $\varphi^{1}$ into (49) we obtain

$$
B^{d}(V)=\frac{\psi}{1+\psi+\beta} \frac{1-\theta^{1}}{1-Y(V)} \frac{\beta}{\beta+\beta} C\left(V^{\prime}(V)\right) \propto \frac{C(V)}{1-Y(V)} \propto 1-\tau_{l}(V)
$$

which is increasing as we showed above. Hence $B^{d}(V)$ is increasing in $V$ for $V \geqslant V^{*}$.

Consider now transfers for current young. In our decentralization, these are given by

$$
\begin{aligned}
\mathrm{T}(\mathrm{V}) & =c^{i}(\mathrm{~V})-\left(1-\tau_{l}(\mathrm{~V})\right) y^{i}(\mathrm{~V}) \\
& =\varphi^{i}(\mathrm{~V}) \frac{\hat{\beta}}{\beta+\hat{\beta}} \mathrm{C}(\mathrm{V})-\frac{\hat{\beta}}{\beta+\hat{\beta}} \frac{\psi \mathrm{C}(\mathrm{V})}{1-\mathrm{Y}(\mathrm{V})}\left(\theta^{1}-\varphi^{1}(\mathrm{~V})(1-\mathrm{Y}(\mathrm{V}))\right)
\end{aligned}
$$

where we used the fact that $y^{i}=\theta^{i}-\varphi^{i}(1-Y)$ and that the labor income tax rate equals $\psi C(V) / 1-Y(Y)$. Rearranging the expression above we obtain

$$
\mathrm{T}(\mathrm{V})=\frac{\hat{\beta}}{\beta+\hat{\beta}}\left[\varphi^{i}(\mathrm{~V}) \mathrm{C}(\mathrm{V})\right]\left[1+\psi-\frac{\theta^{1} \psi}{(1-\mathrm{Y}(\mathrm{V})) \varphi^{1}(\mathrm{~V})}\right]
$$

note that both terms in square brackets are positive and increasing in $V$, implying that $\mathrm{T}(\mathrm{V})$ is increasing.

Q.E.D.

\subsection{Proof of Proposition 3}

As described in section 4.1, the sequence problem associated with the best SPE is given by

$$
\max \frac{\beta}{\hat{\beta}} \sum \alpha^{i} \mu^{i} \log c_{-1,1}^{i}+\sum_{t} \hat{\beta}^{t}\left(\log C_{t, 0}+\psi \log \left(1-Y_{t}\right)-(1+\psi+\beta) H\left(Y_{t}\right)+\beta \log C_{t, 1}\right)
$$


subject to

$$
\begin{aligned}
\log C_{t, 0}+\psi \log \left(1-Y_{t}\right)-(1+\psi+\beta) H\left(Y_{t}\right)+\beta \log C_{t, 1} & \\
+\omega\left[\log C_{t-1,1}-H\left(Y_{t}\right)\right] & \geqslant \underline{v} \\
\sum_{t} \frac{1}{(1+r)^{t}}\left[Y_{t}-C_{t, 0}-C_{t-1,1}-G\right] & =B_{0} \\
c_{-1,1}^{i} & =a_{-1}^{i}+P_{0}
\end{aligned}
$$

Its dual is given by

$$
\max \sum_{t} \frac{1}{(1+r)^{t}}\left[Y_{t}-C_{t, 0}-C_{t-1,1}-G\right]
$$

subject to

$$
\begin{aligned}
\sum_{t} \hat{\beta}^{t}\left(\log C_{t, 0}+\psi \log \left(1-Y_{t}\right)-(1+\psi+\beta) H\left(Y_{t}\right)+\beta \log C_{t, 1}\right) & \\
+\frac{\beta}{\hat{\beta}} \sum \alpha^{i} \mu^{i} \log \left(a_{-1}^{i}+P_{0}\right) & =V_{0} \\
\log C_{t, 0}+\psi \log \left(1-Y_{t}\right)-(1+\psi+\beta) H\left(Y_{t}\right)+\beta \log C_{t, 1} & \\
+\omega\left[\log C_{t-1,1}-H\left(Y_{t}\right)\right] & \geqslant \underline{V} C_{-1,1}=\sum_{i} \mu^{i}\left(a_{-1}^{i}+P_{0}\right)
\end{aligned}
$$

We let the above objective be given by $K\left(\left\{a_{-1}^{i}\right\}_{i=1}^{N}, V_{0}\right)$. If we let $\eta$ be the multiplier on promise keeping constraint, then we have

$$
\begin{aligned}
K\left(\left\{a_{-1}^{i}\right\}_{i=1}^{N}, V_{0}\right)= & \min _{\eta} \max \sum_{t} \frac{1}{(1+r)^{t}}\left[Y_{t}-C_{t, 0}-C_{t-1,1}-G\right] \\
& +\eta \sum_{t} \hat{\beta}^{t}\left(\log C_{t, 0}+\psi \log \left(1-Y_{t}\right)-(1+\psi+\beta) H\left(Y_{t}\right)+\beta \log C_{t, 1}\right) \\
& +\eta \frac{\beta}{\hat{\beta}} \sum \alpha^{i} \mu^{i} \log \left(a_{-1}^{i}+P_{0}\right)-\eta V_{0}
\end{aligned}
$$

subject to

$$
\begin{aligned}
\log C_{t, 0}+\psi \log \left(1-Y_{t}\right)-(1+\psi+\beta) H\left(Y_{t}\right)+\beta \log C_{t, 1} & \\
+\omega\left[\log C_{t-1,1}-H\left(Y_{t}\right)\right] & \geqslant \underline{V} C_{-1,1}=\sum_{i} \mu^{i}\left(a_{-1}^{i}+P_{0}\right)
\end{aligned}
$$


Our approach for solving the above problem is a two stage approach in which we first solve a recursive problem given $\eta$ and for allocations for periods 1 and onward. We then solve the problem of allocating initial period's allocations. The recursive formulation for the problem for periods 1 and onward for a given value of $\eta$ is given by

$$
k(v ; \eta)=\max Y-C_{0}-\frac{1}{1+r} C_{1}-G+\frac{1}{1+r} k\left(v^{\prime} ; \eta\right)+\eta v
$$

subject to

$$
\begin{array}{r}
\log C_{0}+\psi \log (1-Y)-(1+\psi+\beta) H(Y)+\beta \log C_{1}=v \\
\omega\left[\log C_{1}-H(Y)\right]+v^{\prime} \geqslant \underline{V}
\end{array}
$$

We prove the claim in the proposition by first showing that when the sustainability constraint is binding, the policy function $v^{\prime}(v ; \eta)$ is decreasing in $v$. To show this, we first show the following lemma:

Lemma 3. The value function, $\mathrm{k}(v ; \eta)$ is strictly concave and differentiable. Furthermore, $\mathrm{k}_{v}(v ; \eta) \rightarrow$ $\eta>0$ as $v \rightarrow-\infty$ while $k_{v}(v ; \eta) \rightarrow-\infty$ as $v \rightarrow \infty$.

Proof. The proof of strict concavity and differentiability of $k(v ; \eta)$ is standard. To show the rest of the claim, let $\mathrm{C}_{0}^{\text {AUT }}, \mathrm{C}_{1}^{\text {AUT }}, \mathrm{Y}^{\text {AUT }}$ be the aggregate allocations associated with autarky and $v^{\text {AUT }}$ be its associated value. Define $\hat{C}_{0}(v)$ be defined by

$$
\log \hat{C}_{0}(v)+\psi \log \left(1-\gamma^{\text {AUT }}\right)-(1+\psi+\beta) H\left(Y^{\text {AUT }}\right)+\beta \log C_{1}^{\text {AUT }}=v
$$

Furthermore, let $k_{1}(v ; \eta)$ be defined by

$$
\begin{aligned}
k_{1}(v)= & \gamma^{\text {AUT }}-\hat{C}_{0}(v)-\frac{C_{1}^{\text {AUT }}}{1+r}-G+\eta v \\
& +\sum_{t=1}^{\infty} \frac{1}{(1+r)^{t}}\left(Y^{\text {AUT }}-C_{0}^{\text {AUT }}-\frac{1}{1+r} C_{1}^{\text {AUT }}-G+\eta v^{\text {AUT }}\right)
\end{aligned}
$$

Then, $k_{1}(v ; \eta) \leqslant k(v ; \eta)$ - since the constructed allocations satisfy all the sustainability constraint from $t=1$ onwards. In addition, let $k_{2}(v ; \eta)$ be defined by

$$
k_{2}(v ; \eta)=\max \sum_{t=0}^{\infty} \frac{1}{(1+r)^{t}}\left[Y_{t}-C_{t, 0}-\frac{1}{1+r} C_{t, 1}-G+\eta v_{t}\right]
$$

subject to

$$
\log C_{t, 0}+\psi \log \left(1-Y_{t}\right)-(1+\psi+\beta) H\left(Y_{t}\right)+\beta \log C_{t, 1}=v_{t}
$$


Then $k(v ; \eta) \leqslant k_{2}(v ; \eta)$. Note that $\frac{\partial}{\partial v} k_{2}(v ; \eta) \rightarrow-\infty$ as $v \rightarrow \infty-$ this is because $\frac{\partial}{\partial v} k_{2}(v ; \eta)=$ $-C_{0}$ and $C_{0}$ converges to $\infty$ as $v$ tends to $\infty$. Therefore, we must also have $k_{v}(v ; \eta) \rightarrow-\infty$ as $v$ tends $\infty$. Additionally, $\frac{\partial}{\partial v} k_{2}(v ; \eta), \frac{\partial}{\partial v} k_{1}(v ; \eta) \rightarrow \eta$ as $v \rightarrow-\infty$. This implies that the same must hold for $k_{v}(v ; \eta)$.

The above lemma implies that the function $k(v ; \eta)$ is hump-shaped in $v$. Therefore, it must be maximized at some value $v^{*}$. Now, suppose that the sustainability constraint is binding. A binding sustainability constraint implies that $v^{\prime}=\underline{V}-\omega\left[\log C_{1}-H(Y)\right]$. In addition, the FOC with respect to $v^{\prime}$ implies that $k_{v}<0$. Replacing the sustainability constraint in the optimization in (P4), we have the following first order conditions

$$
\begin{aligned}
-1+\frac{\lambda}{C_{0}} & =0 \\
-\frac{1}{1+r}\left[1+k_{v} \cdot \frac{\omega}{C_{1}}\right]+\frac{\lambda \beta}{C_{1}} & =0 \\
1+\frac{1}{1+r} k_{v} \cdot \omega H^{\prime}(Y)-\lambda\left[\frac{\psi}{1-Y}+(1+\psi+\beta) H^{\prime}(Y)\right] & =0
\end{aligned}
$$

Using extensive algebra and the implicit function theorem, we can show that

$$
\frac{\mathrm{d} Y}{\mathrm{~d} \lambda}=\frac{\beta \mathrm{H}^{\prime} \frac{1}{1-\omega^{2} \mathrm{k}_{v v} / \mathrm{C}_{1}}+\left[\frac{\psi}{1-Y}+(1+\psi+\beta) \mathrm{H}^{\prime}(\mathrm{Y})\right]}{-\lambda\left[\frac{\psi}{(1-Y)^{2}}+(1+\psi+\beta) \mathrm{H}^{\prime \prime}(\mathrm{Y})\right]+\frac{\omega^{2}}{1+\mathrm{r}^{*}} \frac{1}{1-\omega^{2} \mathrm{P}^{\prime \prime} / \mathrm{C}_{1}}\left(\mathrm{H}^{\prime}\right)^{2} \mathrm{k}_{v v}+\frac{\omega}{1+\mathrm{r}^{*}} \mathrm{k}_{\nu} \mathrm{H}^{\prime \prime}}
$$

The numerator of the above expression is positive, since $\mathrm{k}_{v v}<0$ and $\mathrm{H}^{\prime}>0$, while its denominator is negative, since $k_{v}<0$. Thus the above expression is negative. As in the proof of Theorem 1, this implies that

$$
\frac{\mathrm{d} v^{\prime}}{\mathrm{d} \lambda}=\frac{-\omega \beta\left(1+\mathrm{r}^{*}\right) \frac{1}{\mathrm{C}_{1}}+\omega \mathrm{H}^{\prime} \frac{\mathrm{d} \gamma}{\mathrm{d} \lambda}}{1-\omega^{2} \mathrm{k}_{v v} / \mathrm{C}_{1}}<0
$$

That the policy function $v^{\prime}(v ; \eta)$ is decreasing follows from concavity of the value function $k(v ; \eta)$.

It remains to characterize the dynamics of $v$ over time. This dynamics mainly depends on the value of $v^{*}$ and whether the sustainability constraint is binding at this value or not. 
Note that if the sustainability constraint is slack at $v^{*}$, we must have that

$$
\begin{aligned}
k_{v}\left(v^{*} ; \eta\right) & =0=\eta-\lambda \\
\frac{\lambda}{\mathrm{C}_{0}} & =1 \\
\frac{\beta \lambda}{\mathrm{C}_{1}} & =\frac{1}{1+\mathrm{r}} \\
\lambda\left[\frac{1}{1-\mathrm{Y}}+(1+\psi+\beta) \mathrm{H}^{\prime}(\mathrm{Y})\right] & =1 \\
v^{\prime *} & =\log \mathrm{C}_{0}+\beta \log \mathrm{C}_{1}+\psi \log (1-\mathrm{Y})-(1+\psi+\beta) \mathrm{H}(\mathrm{Y})
\end{aligned}
$$

The above define $v^{*}$ as a function of $\eta$ together with the allocations $C_{0}, C_{1}$, and $Y$. Given these values, the left hand side of the sustainability constraint is an increasing function of $\eta$ and therefore, if $\eta$ is low enough, the sustainability constraint must be binding. Next, we turn to determination $\eta$. The optimization in (P3) can be written as

$K\left(\left\{a_{-1}^{i}\right\}_{i=1}^{N}, V_{0}\right)=\min _{\eta} \max _{P_{0}, v_{1}}-P_{0}-\sum_{i} \mu^{i} a_{-1}^{i}+k\left(v_{0} ; \eta\right)+\eta \frac{\beta}{\hat{\beta}} \sum \alpha^{i} \mu^{i} \log \left(a_{-1}^{i}+P_{0}\right)-\eta V_{0}$

subject to

$$
\omega \sum \alpha^{i} \mu^{i} \log \left(a_{-1}^{i}+P_{0}\right)+v_{0} \geqslant \underline{V}
$$

Since the objective is concave and the constraint set is convex, the function $K\left(\left\{a_{-1}\right\}^{i}, V_{0}\right)$ is concave. By envelope theorem

$$
K_{V}=-\eta
$$

Therefore, $\eta$ increases with $V_{0}$. In addition, the value $K\left(\left\{a_{-1}^{i}\right\}, V_{0}\right)$ is equal to debt $B_{0}$ and is decreasing in $V_{0}$. Thus for high values of initial debt, $V_{0}$ is low and so is $\eta$. The same argument holds for inequality - dispersion of $a_{-1}^{i}$ 's. This concludes the proof.

Q.E.D.

\subsection{Proof of Proposition 4}

To prove the claim in the Proposition, we start by showing some preliminary results for the optimization in $\left(\mathrm{P}^{\prime}\right)$.

Claim 1. $w(\hat{\mathrm{B}})$ is strictly decreasing, concave and differentiable.

Proof. We are going to use techniques similar to Abreu et al. (1990). The operator implicitly defined by the right hand side of $\left(\mathrm{P}^{\prime}\right)$ is monotone. Then, we can show along the lines of Theorem 5 in Abreu et al. (1990) that if we start iterating on it from $w_{0} \geqslant w$ then the sequence $\left\{w_{n}\right\}$ converges to $w$. 
Moreover, note that if $w_{n}$ is concave then $w_{n+1}$ is concave as well because the constraint set in $\left(\mathrm{P}^{\prime}\right)$ is convex and the objective function is concave. Then the limit must be concave as well. A similar argument can be applied to show that $w$ is decreasing. Differentiability follows from Benveniste-Scheinkman's theorem.

Claim 2. The political sustainability constraint is always binding.

Proof. Suppose by way of contradiction that the current government chooses a policy $\left(\mathrm{C}_{0}, \mathrm{Y}, \mathrm{C}_{1}, \hat{\mathrm{B}}^{\prime}\right)$ such that (24) is slack. Then the government can increase the value of current generation by increasing external debt by a small amount (still respecting incentive of next period government not to default) and increasing consumption of young agents. This variation clearly increases the value, a contradiction. Hence the sustainability is always binding.

Now, we turn to prove the claim in the Proposition by analyzing the problem in $\left(\mathrm{P}^{\prime}\right)$. Letting $\lambda$ and $\eta$ be the multipliers on (23) and (24), the FOCs are

$$
\begin{aligned}
\frac{1}{\mathrm{C}_{0}}-\lambda & =0 \\
-\Omega^{\prime}(\mathrm{Y})-\eta \omega \mathrm{H}^{\prime}(\mathrm{Y})+\lambda & =0 \\
\beta \frac{1}{\mathrm{C}_{1}}+\eta\left[\frac{\omega}{\mathrm{C}_{1}}+w^{\prime}\left(\hat{\mathrm{B}}^{\prime}\right)\right] & =0 \\
\frac{\lambda}{1+r}+\eta w^{\prime}\left(\hat{\mathrm{B}}^{\prime}\right) & =0
\end{aligned}
$$

where we define $\Omega(Y)=-\psi \log (1-Y)+(1+\psi+\beta) H(Y)$ and the envelope condition is $w^{\prime}(B)=-\lambda$. Using (50) in (53) to substitute for $\lambda$ we can express the multiplier $\eta$ as

$$
\eta=-\frac{C_{0}}{1+r} \frac{1}{w^{\prime}\left(\hat{B}^{\prime}\right)}
$$

Moreover, using (54) in (51) to substitute for $\eta$ and rearranging we obtain

$$
\beta C_{1}\left(\frac{1}{C_{0}}-\frac{1}{1+r}\right)-\frac{\omega}{1+r} \frac{1}{w^{\prime}\left(\hat{B}^{\prime}\right)}=0
$$

We first show that $C_{0}$ is decreasing in $\hat{B}$. The fact that $C_{0}$ is decreasing in $\hat{B}$ follows from combining (50) with the envelope condition and using concavity of $w$.

We now turn to show that $\hat{B}^{\prime}$ is decreasing in $\hat{B}$. Suppose by way of contradiction that $\hat{B}^{\prime}$ is increasing in $\hat{B}$ for some $\hat{B}$ and so $d \hat{B}^{\prime} / d \hat{B}>0$ for some $\hat{B}$. Totally differentiating (55) we obtain

$$
\beta\left(\frac{1}{C_{0}}-\frac{1}{1+r}\right) \frac{d C_{1}}{d \hat{B}}=\beta \frac{C_{1}}{C_{0}^{2}} \frac{d C_{0}}{d \hat{B}}+\frac{\omega}{1+r} \frac{w^{\prime \prime}\left(\hat{B}^{\prime}\right)}{\left(w^{\prime}\left(\hat{B}^{\prime}\right)\right)^{2}} \frac{d B^{\prime}}{d \hat{B}}
$$


Because of concavity of $w$, the fact that $\mathrm{C}_{0}$ is decreasing, and the contradiction hypothesis that $\hat{B}^{\prime}$ is decreasing, the expression above implies that $C_{1}$ must be decreasing in $\hat{B}$. Using this fact and the contradiction hypothesis that $\hat{B}^{\prime}$ is increasing in the sustainability constraint - which is binding by Claim 2 above - it follows that $Y$ must be decreasing in $\hat{\mathrm{B}}^{\prime}$. But totally differentiating the first order condition for output (51) we obtain

$$
\left[\Omega^{\prime \prime}+\eta \omega H^{\prime \prime}\right] \frac{d Y}{d \hat{B}}=-\omega H^{\prime} \frac{d \eta}{d \hat{B}}+\frac{d \lambda}{d \hat{B}}
$$

Totally differentiating (54) we obtain

$$
\frac{d \eta}{d \hat{B}}=-\frac{1}{1+r} \frac{1}{w^{\prime}\left(\hat{B}^{\prime}\right)} \frac{d C_{0}}{d \hat{B}}+\frac{C_{0}}{1+r} \frac{w^{\prime \prime}\left(\hat{B}^{\prime}\right)}{\left(w^{\prime}\left(\hat{B}^{\prime}\right)\right)^{2}} \frac{d \hat{B}^{\prime}}{d \hat{B}}<0
$$

Using this into (56) and noticing that $\mathrm{H}^{\prime}>0, \mathrm{~d} \lambda / \mathrm{d} \hat{\mathrm{B}}>0$, and the term in square brackets is positive because of convexity of $\Omega$ and $\mathrm{H}$ imply that $d \mathrm{Y} / \mathrm{d} \hat{\mathrm{B}}>0$. This is a contradiction. Hence it must be that $\hat{B}^{\prime}$ is decreasing.

\subsection{Proof of Proposition 5}

As in the proof of Proposition 1, we consider the dual of the problem solved by the government. A proof similar to the one in section 8.2 establishes that these two problems are equivalent. With shocks this dual problem is given by

$$
\hat{\mathrm{B}}(\mathrm{V})=\max _{\mathrm{Y}, \mathrm{C}_{0}, \mathrm{C}_{1}, \mathrm{~V}^{\prime}\left(\mathrm{s}^{\prime}\right)} \mathrm{Y}-\mathrm{C}_{0}-\mathrm{C}_{1}+\frac{1}{1+\mathrm{r}} \sum_{\mathrm{s}^{\prime}} \pi\left(\mathrm{s}^{\prime}\right) \hat{\mathrm{B}}\left(\mathrm{V}^{\prime}\left(\mathrm{s}^{\prime}\right)\right)
$$

subject to

$$
\begin{aligned}
\frac{\beta}{\hat{\beta}} \log C_{1}+\left[\log C_{0}+\psi \log (1-Y)-(1+\psi+\beta) H(Y)\right]+\hat{\beta} \sum_{s^{\prime}} \pi\left(s^{\prime}\right) V^{\prime}\left(s^{\prime}\right) & =V \\
V^{\prime}\left(s^{\prime}\right)-\frac{\beta}{\hat{\beta}} H(Y) & \geqslant \underline{W}\left(s^{\prime}\right)
\end{aligned}
$$

where note that $s$ is not part of the state because the term $G(s)$ is additive. Then foreign debt is $\hat{B}(V)-\left[G(s)+\frac{E G\left(s^{\prime}\right)}{r}\right]$.

We first show the following Lemma:

Lemma 4. The solution to the functional equation (P5) satisfies the following:

A unique $\hat{\mathrm{B}}(\mathrm{V})$ exists that satisfies (P5). Furthermore, $\hat{\mathrm{B}}(\mathrm{V})$ is strictly decreasing, strictly concave and differentiable.

The policy function $\mathrm{V}^{\prime}(\mathrm{V}, \mathrm{s})$ is increasing in $\mathrm{s}$. 
Proof. Properties of the Value Function. The proof follows closely that of Proposition 1 and Lemma 2. Specifically since the function $H(Y)$ is concave in $Y$, the constraint set is convex and as a result the value function is strictly concave. The rest of the claim can be proven using standard techniques from Stokey et al. (1989).

Properties of the Policy Function. Here, we show that $V^{\prime}(V, s)$ is increasing in $s$. Note that for any s, we must have that

$$
\frac{\beta}{\hat{\beta} C_{1}(s)}=-\frac{1}{\hat{B}^{\prime}\left(V^{\prime}(s)\right)}
$$

This implies that if $C_{1}(s)>C_{1}\left(s^{\prime}\right)$, then $V^{\prime}(s)>V^{\prime}\left(s^{\prime}\right)$, since $\hat{B}(\cdot)$ is decreasing and concave. Consider the set of states $S_{1} \subset S$ for which the sustainability constraint is slack. Then, the first order conditions associated with (P5) imply that

$$
\forall s, s^{\prime} \in S_{1}, C_{1}(s)=C_{1}\left(s^{\prime}\right), V^{\prime}(s)=V^{\prime}\left(s^{\prime}\right)
$$

Consider a state $s \in S-S_{1}$. We show that $\min S-S_{1}>\max S_{1}$. Suppose not. Let $\hat{s}=\max S_{1}>\tilde{s}=\min S-S_{1}$. Then, it must be that

$$
\begin{aligned}
& \frac{\beta}{\hat{\beta}} \log C_{1}(\hat{s})+V^{\prime}(\hat{s})>\underline{W}(\hat{s})+\frac{\beta}{\hat{\beta}} H(Y) \\
& \frac{\beta}{\hat{\beta}} \log C_{1}(\tilde{s})+V^{\prime}(\tilde{s})=\underline{W}(\tilde{s})+\frac{\beta}{\hat{\beta}} H(Y)
\end{aligned}
$$

Since $\underline{W}(s)$ is increasing in $s$, simply because government spending decreases with $s$, we must have $\underline{W}(\hat{\mathbf{s}})>\underline{W}(\tilde{s})$. Hence, the above inequality and equality imply that $V^{\prime}(\hat{\mathbf{s}})>V^{\prime}(\tilde{\mathbf{s}})$. We show that if this is the case, there is a perturbation that increases the objective and hence we have a contradiction. Consider a small increase in $V^{\prime}(\tilde{s})$ by $\varepsilon>0$ and a small decrease in $V^{\prime}(\hat{s})$ by $\frac{\pi(\tilde{s})}{\pi(\hat{s})} \varepsilon$. This perturbation does not change the value that the current government receives from the allocation and hence the promise keeping constraint is satisfied. Furthermore, since $\varepsilon$ is small and (57) is strict inequality, sustainability constraints are satisfied. However, the difference between the value of the objective for this perturbation to the original objective is given by

$$
\pi(\tilde{\mathrm{s}}) \hat{\mathrm{B}}\left(\mathrm{V}^{\prime}(\tilde{\mathrm{s}})+\varepsilon\right)+\pi(\hat{\mathrm{s}}) \hat{\mathrm{B}}\left(\mathrm{V}^{\prime}(\hat{\mathrm{s}})-\frac{\pi(\tilde{\mathrm{s}})}{\pi(\hat{\mathrm{s}})} \varepsilon\right)-\pi(\tilde{\mathrm{s}}) \hat{\mathrm{B}}\left(\mathrm{V}^{\prime}(\tilde{\mathrm{s}})\right)-\pi(\hat{\mathrm{s}}) \hat{\mathrm{B}}\left(\mathrm{V}^{\prime}(\hat{\mathrm{s}})\right)
$$

The derivative of the above expression at $\varepsilon=0$ is given by

$$
-\pi(\tilde{s}) \hat{\mathrm{B}}^{\prime}\left(\mathrm{V}^{\prime}(\tilde{\mathrm{s}})\right)-\pi(\tilde{\mathrm{s}}) \hat{\mathrm{B}}^{\prime}\left(\mathrm{V}^{\prime}(\hat{\mathrm{s}})\right)=\pi(\tilde{\mathrm{s}})\left[\hat{\mathrm{B}}^{\prime}\left(\mathrm{V}^{\prime}(\tilde{\mathrm{s}})\right)-\hat{\mathrm{B}}^{\prime}\left(\mathrm{V}^{\prime}(\hat{\mathrm{s}})\right)\right]>0
$$


where the last inequality follows from strict concavity of $\hat{B}$. This means that for $\varepsilon>0$ and small enough this perturbation increases the value of the objective in (P1) and hence we have a contradiction. Therefore, it must be that $\min S-S_{1}>\max S_{1}$. Hence, if we let $s^{*}=\max S_{1}$, we must have

$$
\begin{aligned}
& \frac{\beta}{\hat{\beta}} \log C_{1}(s)+V^{\prime}(s)=\underline{W}(s)+\frac{\beta}{\hat{\beta}} H(Y), \forall s>s^{*}, \\
& \frac{\beta}{\hat{\beta}} \log C_{1}(s)+V^{\prime}(s)>\underline{W}(s)+\frac{\beta}{\hat{\beta}} H(Y), \forall s \leqslant s^{*}
\end{aligned}
$$

The first set of equalities above imply that $V^{\prime}(s)$ must be increasing in s. Furthermore, a similar argument to the perturbation above can be used to show that $V^{\prime}\left(s^{\prime}\right)=V^{\prime}\left(s^{*}\right)<$ $V^{\prime}(s)$, for all $s>s^{*} \geqslant s^{\prime}$. This implies that $V^{\prime}(s)$ is weakly decreasing.

Next, we prove the claims in Proposition 5.

Proof of 1 .

As the proof in Lemma 4 shows, for each $V$ there is a state $s^{*}$ so that for all $s \leqslant s^{*}$, the sustainability constraint is slack while for all $s>s^{*}$, the sustainability constraint is binding. By continuity of the policy function, it must be that this property holds for an interval including $V$. We can then use the binding sustainability constraints to solve for $\mathrm{V}^{\prime}(\mathrm{s})$ and write the promise keeping constraint as

$$
\begin{aligned}
\log C_{0}+ & \psi \log (1-Y)-(1+\psi) H(Y) \\
& +\sum_{s \leqslant s^{*}} \pi(s)\left[-\beta H(Y)+\beta \log C_{1}(s)+\hat{\beta} V^{\prime}(s)\right]+\hat{\beta} \sum_{s>s^{*}} \pi(s) \underline{W}(s)=V
\end{aligned}
$$

while the value of the objective is given by

$$
\begin{aligned}
& \mathrm{Y}-\mathrm{C}_{0}+\frac{1}{1+\mathrm{r}} \sum_{s \leqslant s^{*}}\left[-\mathrm{C}_{1}(\mathrm{~s})+\hat{\mathrm{B}}\left(\mathrm{V}^{\prime}(\mathrm{s})\right)\right] \\
& +\frac{1}{1+\mathrm{r}} \sum_{\mathrm{s}>\mathrm{s}^{*}} \pi(\mathrm{s})\left[-\mathrm{C}_{1}(\mathrm{~s})+\mathrm{B}\left(\underline{\mathrm{W}}(\mathrm{s})-\frac{\beta}{\hat{\beta}}\left(\log \mathrm{C}_{1}(\mathrm{~s})-\mathrm{H}(\mathrm{Y})\right)\right)\right]
\end{aligned}
$$

Hence, the FOC associated with $\mathrm{Y}$ as well as that of $\left\{\mathrm{C}_{1}(\mathrm{~s})\right\}_{\mathrm{s}>\mathrm{s}^{*}}$ are given by

$$
\begin{array}{r}
1+\sum_{s>s^{*}} \pi(s) \frac{\beta}{\hat{\beta}(1+r)} \hat{B}^{\prime}\left(V^{\prime}(s)\right) H^{\prime}(Y)-\lambda\left[\frac{\psi}{1-Y}+\left(1+\psi+\beta \sum_{s \leqslant s^{*}} \pi(s)\right) H^{\prime}(Y)\right]=(58) \\
1+\hat{B}^{\prime}\left(V^{\prime}(s)\right) \frac{\beta}{\hat{\beta} C_{1}(s)}=0
\end{array}
$$

Note that as before, the envelope condition implies that $\hat{B}^{\prime}(V)=-\lambda$ and in order to show 
that $Y(V)$ is decreasing in $V$, it is sufficient to show that as $\lambda$ rises, $Y$ decreases. Taking total derivative from the above equations:

$$
\begin{aligned}
\mathrm{dC}_{1}(\mathrm{~s}) & =-\frac{\beta}{\hat{\beta}} \hat{\mathrm{B}}^{\prime \prime}\left(\mathrm{V}^{\prime}(\mathrm{s})\right) \mathrm{d} \mathrm{V}^{\prime}(\mathrm{s}) \\
\mathrm{d} \mathrm{V}^{\prime}(\mathrm{s}) & =-\frac{\beta}{\hat{\beta}}\left[\frac{1}{\mathrm{C}_{1}(\mathrm{~s})} \mathrm{dC}_{1}(\mathrm{~s})-\mathrm{H}^{\prime}(\mathrm{Y}) \mathrm{d} \mathrm{T}\right]
\end{aligned}
$$

The above imply that

$$
\begin{aligned}
\mathrm{d} \mathrm{V}^{\prime}(\mathrm{s}) & =-\frac{\beta}{\hat{\beta}}\left[-\frac{\hat{\beta}}{\beta \hat{\mathrm{B}}^{\prime}\left(\mathrm{V}^{\prime}(\mathrm{s})\right)} \mathrm{dC}_{1}(\mathrm{~s})-\mathrm{H}^{\prime}(\mathrm{Y}) \mathrm{d} \mathrm{Y}\right] \\
& =-\frac{\beta}{\hat{\beta}}\left[\frac{\hat{\beta}}{\beta \hat{\mathrm{B}}^{\prime}\left(\mathrm{V}^{\prime}(\mathrm{s})\right)} \frac{\beta}{\hat{\beta}} \hat{\mathrm{B}}^{\prime \prime}\left(\mathrm{V}^{\prime}(\mathrm{s})\right) \mathrm{d} \mathrm{V}^{\prime}(\mathrm{s})-\mathrm{H}^{\prime}(\mathrm{Y}) \mathrm{d} \mathrm{Y}\right] \\
\mathrm{d} \mathrm{V}^{\prime}(\mathrm{s}) & =\frac{\frac{\beta}{\hat{\beta}} \mathrm{H}^{\prime}(\mathrm{Y}) \mathrm{d} \mathrm{d}}{1+\frac{\beta}{\hat{\beta}} \hat{\mathrm{B}}^{\prime \prime}\left(\mathrm{V}^{\prime}(\mathrm{s})\right)}
\end{aligned}
$$

Taking a total derivative from (58) and by extensively using the implicit function theorem we have

$$
\frac{\mathrm{d} Y}{\mathrm{~d} \lambda}=\frac{-\frac{\psi}{1-Y}-\left(1+\psi+\beta \sum_{s \leqslant s^{*}} \pi(s)\right) \mathrm{H}^{\prime}}{\lambda\left[\frac{\psi}{(1-Y)^{2}}+\left(1+\psi+\beta \sum_{s \leqslant s^{*}} \pi(s)\right) \mathrm{H}^{\prime \prime}\right]+\frac{\beta}{\hat{\beta}(1+r)} \sum_{s>s^{*}} \pi(s)\left[\mathrm{B}^{\prime \prime}(s) \frac{-\frac{\beta}{\beta}\left(H^{\prime}\right)^{2}}{1+\frac{\beta}{B^{\prime \prime}} \frac{B^{\prime \prime}(s)}{B^{\prime}(s)}}-B^{\prime}(s) H^{\prime \prime}\right]}
$$

The denominator of the above expression is positive while the denominator is negative. This is because $\mathrm{H}^{\prime}>0, \mathrm{H}^{\prime \prime}>0, \hat{\mathrm{B}}^{\prime}<0$, and $\hat{\mathrm{B}}^{\prime \prime}<0$. Therefore, $\frac{\mathrm{dY}}{\mathrm{d} \lambda}<0$. This proves the first claim.

Proof of 2.

Given the first claim that $Y(V)$ is decreasing, whenever the sustainability constraint is binding, we must have

$$
\frac{\beta}{\hat{\beta}}\left[\log C_{1}(s)-H(Y)\right]+V^{\prime}(s)=\underline{W}(s)
$$

Since $Y$ is decreasing in $V$, we must have that

$$
\frac{\beta}{\hat{\beta}} \log C_{1}(s)+V^{\prime}(s)=\underline{W}(s)+\frac{\beta}{\hat{\beta}} H(Y)
$$


and since $H$ is decreasing, $\frac{\beta}{\hat{\beta}} \log C_{1}(s)+V^{\prime}(s)$ must be decreasing in $V$ as well. Since

$$
\frac{\beta}{\hat{\beta} C_{1}(s)}=-\frac{1}{B^{\prime}\left(V^{\prime}(s)\right)}
$$

$C_{1}(s)$ and $V^{\prime}(s)$ must move together and hence, $C_{1}(s)$ and $V^{\prime}(s)$ are decreasing whenever the sustainability constraint is binding.

It remains to show that there must exist $\mathrm{V}^{*}$ (s) so that for all values of $\mathrm{V}<\mathrm{V}^{*}(\mathrm{~s})$, the sustainability constraint for state $s$ is binding and vice versa. Suppose this does not hold. That is, suppose that $V_{1}$ exists such that for a neighborhood of values of $V$ below $V_{1}$, the sustainability constraint is slack while for a neighborhood of values of $V$ above $V_{1}$, the sustainability constraint is binding. Then by continuity of the policy function from the theorem of the maximum, it must be that at $V_{1}$ the sustainability constraint is binding. Note that since for values of $V \in\left(V_{1}-\varepsilon, V_{1}\right)$ for a small $\varepsilon>0$, the sustainability constraint is slack, and we must have

$$
\begin{aligned}
\frac{1}{1+r} \hat{B}^{\prime}\left(V^{\prime}(V, s)\right)-\hat{\beta} \hat{B}^{\prime}(V) & =0 \\
-\frac{1}{1+r}-\beta \hat{B}^{\prime}(V) \frac{1}{C_{1}(V, s)} & =0
\end{aligned}
$$

where we have used the FOCs associated with $C_{1}$ and $V^{\prime}$ and the envelope condition. From concavity of the value function, the above imply that $V^{\prime}(V, s)$ and $C_{1}(V, s)$ are both increasing in V. Hence, it must be that

$$
\begin{aligned}
& \mathrm{V}^{\prime}\left(\mathrm{V}_{1}, \mathrm{~s}\right) \geqslant \mathrm{V}^{\prime}(\mathrm{V}, \mathrm{s}), \forall \mathrm{V} \in\left(\mathrm{V}_{1}-\varepsilon, \mathrm{V}_{1}\right) \\
& \mathrm{C}_{1}\left(\mathrm{~V}_{1}, \mathrm{~s}\right) \geqslant \mathrm{C}_{1}(\mathrm{~V}, \mathrm{~s}), \forall \mathrm{V} \in\left(\mathrm{V}_{1}-\varepsilon, \mathrm{V}_{1}\right)
\end{aligned}
$$

From part 1 , we know that $Y\left(V_{1}\right) \leqslant Y(V), \forall V \in\left(V_{1}-\varepsilon, V_{1}\right)$. Therefore, for $V \in\left(V_{1}-\varepsilon, V_{1}\right)$

$$
\begin{aligned}
\frac{\beta}{\hat{\beta}}\left[\log C_{1}\left(V_{1}, s\right)-H\left(Y\left(V_{1}\right)\right)\right]+V^{\prime}\left(V_{1}, s\right) & \geqslant \frac{\beta}{\hat{\beta}}\left[\log C_{1}(V, s)-H(Y(V))\right]+V^{\prime}(V, s) \\
& >\underline{W}(s)
\end{aligned}
$$

Which is a contradiction. This completes the proof.

\section{Proof of 3.}

Suppose not. That is, there exists $i, i+1$ such that $V^{*}(s(i))>V^{*}(s(i+1))$. This implies that for values of $V \in\left(V^{*}(s(i+1)), V^{*}(s(i))\right)$, the sustainability constraint for $s(i)$ is binding but that of $s(i+1)$ is slack. We know from Lemma 4 that $V^{\prime}(s(i+1))>$ $V^{\prime}(s)$. Hence a perturbation of the form $\hat{V}^{\prime}(s(i+1))=V^{\prime}(s(i+1))-\varepsilon$ and $\hat{V}^{\prime}(s(i))=$ $V^{\prime}(s(i))+\varepsilon \frac{\pi(s(i+1))}{\pi(s(i))}$ increases the objective and satisfies the all the constraints. This con- 
cludes the proof.

Q.E.D

\subsection{Proof of Existence of Invariant Distribution}

Here, we show the existence of a invariant distribution in our stochastic economy. Given a solution to the above functional equation, $\hat{B}(V)$ and its associated policy function for continuation values, $V^{\prime}(V, s)$, the ergodic set associated with this dynamic system is given by $\mathbf{V} \subset \mathbb{R}$ where

$$
V^{\prime}(\mathbf{V}, S)=\mathbf{V}
$$

Furthermore, the invariant distribution associated with $V^{\prime}(V, s)$ is given by $\mu$ which is a probability measure on $(\mathbf{V}, \mathcal{V})$ where $\mathcal{V}$ is the set of all Borel subsets of $\mathbf{V}$ and must satisfy

$$
\mu(A)=\int_{V} \sum_{s \in S} \pi(s) \mathbf{1}\left[V^{\prime}(V, s) \in A\right] d \mu(V)
$$

Lemma 5. The dynamic system implied by the policy function $\mathrm{V}^{\prime}(\mathrm{V}, \mathrm{s})$ has a compact ergodic set $\mathbf{V} \subset \mathbb{R}$. Furthermore, a probability measure $\mu$ exists that satisfies (60).

Proof. We first show that there exists an ergodic set $\mathbf{V}$ that is a subset of a bounded interval. Namely, let $\underline{V}=\mathrm{V}^{\prime}\left(\mathrm{V}^{*}(\mathrm{~s}(1)), \mathrm{s}(1)\right)$ and $\overline{\mathrm{V}}=\mathrm{V}^{\prime}(\underline{\mathrm{V}}, \mathrm{s}(\mathrm{K}))$. We show that for any $\mathrm{V} \in[\underline{\mathrm{V}}, \overline{\mathrm{V}}]$ and $\forall s \in S$, then $\mathrm{V}^{\prime}(\mathrm{V}, \mathrm{s}) \in[\underline{\mathrm{V}}, \overline{\mathrm{V}}]$. Note that for any $\mathrm{V}>\mathrm{V}^{*}(\mathrm{~s}(1))$, $\mathrm{V}^{\prime}(\mathrm{V}, \mathrm{s}(1)) \geqslant \mathrm{V}^{\prime}\left(\mathrm{V}^{*}(\mathrm{~s}(1)), \mathrm{s}(1)\right)=\underline{\mathrm{V}}$. Furthermore, from lemma 4, we have that

$$
\mathrm{V}^{\prime}(\mathrm{V}, \mathrm{s}(\mathfrak{i}))>\mathrm{V}^{\prime}(\mathrm{V}, \mathrm{s}(1)) \geqslant \underline{\mathrm{V}}, \forall 1 \leqslant i \leqslant K
$$

Now suppose that $\mathrm{V}<\mathrm{V}^{*}(\mathrm{~s}(1))$, then from proposition 5 we have that

$$
\mathrm{V}^{\prime}(\mathrm{V}, \mathrm{s}(\mathrm{i})) \geqslant \mathrm{V}^{\prime}(\mathrm{V}, \mathrm{s}(1)) \geqslant \mathrm{V}^{\prime}\left(\mathrm{V}^{*}(\mathrm{~s}(1)), \mathrm{s}(1)\right)=\underline{\mathrm{V}}
$$

Hence, for all $\mathrm{V}$, we must have that $\mathrm{V}^{\prime}(\mathrm{V}, \mathrm{s}) \geqslant \underline{\mathrm{V}}$.

Now, suppose that $V \in[\underline{V}, \bar{V}]$. Then either sustainability constraint for $s(K)$ is binding or slack. If it is slack, then we must have

$$
\hat{\mathrm{B}}^{\prime}\left(\mathrm{V}^{\prime}(\mathrm{V}, \mathrm{s}(\mathrm{K}))\right)=(1+\mathrm{r}) \hat{\beta} \hat{\mathrm{B}}^{\prime}(\mathrm{V})
$$

since $\hat{\beta}(1+r)<1$ and $\hat{B}^{\prime}<0$,

$$
\hat{\mathrm{B}}^{\prime}(\mathrm{V})<\hat{\mathrm{B}}^{\prime}\left(\mathrm{V}^{\prime}(\mathrm{V}, \mathrm{s}(\mathrm{K}))\right)
$$


and concavity of $\hat{B}(\cdot)$ implies that $V>V^{\prime}(V, s(K))$. Hence,

$$
\bar{V} \geqslant V>V^{\prime}(V, s(K)) \geqslant V^{\prime}(V, s(i)), \forall i
$$

If the sustainability constraint is binding,

$$
\underline{\mathrm{V}}<\mathrm{V} \rightarrow \mathrm{V}^{\prime}(\mathrm{V}, \mathrm{s}(\mathrm{K}))<\mathrm{V}^{\prime}(\underline{\mathrm{V}}, \mathrm{s}(\mathrm{K}))=\overline{\mathrm{V}}
$$

and furthermore

$$
\mathrm{V}^{\prime}(\mathrm{V}, \mathrm{s}(\mathfrak{i}))<\mathrm{V}^{\prime}(\mathrm{V}, \mathrm{s}(\mathrm{K}))=\overline{\mathrm{V}} \text {. }
$$

This establishes that any ergodic set $\mathbf{V}$ must be a subset of $[\underline{\mathrm{V}}, \overline{\mathrm{V}}]$.

Next, we show that a stationary distribution $\mu$ exists. Since $[\underline{V}, \bar{V}]$ is a compact subset of $\mathbb{R}$, then by Riesz Representation Theorem (Dunford and Schwartz (1958), IV.6.3), the space of regular measures on $[\underline{V}, \bar{V}]$ is isomorphic to the space $C^{*}([\underline{V}, \bar{V}])$, the dual of the space of bounded continuous functions on $[\underline{\mathrm{V}}, \overline{\mathrm{V}}]$. Moreover, by Banach-Alaoglu Theorem (Rudin (1991), Theorem 3.15), the set $\left\{f \in C^{*}([\underline{V}, \bar{V}]) ;\|f\| \leqslant k\right\}$ is a compact set in the weak-* topology for any $k>0$. Equivalently, the set of regular measures, $\psi$, with $\|\psi\| \leqslant 1$, is compact. Since non-negativity and full measure on $[\underline{V}, \overline{\mathrm{V}}]$ are closed properties, we must have the set

$$
\mathcal{M}([\underline{\mathrm{V}}, \overline{\mathrm{V}}])=\{\psi ; \psi \text { a regular measure on }[\underline{\mathrm{V}}, \overline{\mathrm{V}}], \psi([\underline{\mathrm{V}}, \overline{\mathrm{V}}])=1, \psi \geqslant 0\}
$$

is compact in weak-* topology. Since any ergodic set $\mathbf{V}$ is a subset of $[\underline{\mathrm{V}}, \overline{\mathrm{V}}]$, the transformation $\mathrm{T}$ on $\mathcal{M}([\underline{\mathrm{V}}, \overline{\mathrm{V}}])$ given by

$$
\mathrm{T}(\psi)(\mathrm{A})=\int_{[\underline{\mathrm{V}}, \bar{V}]} \sum_{s \in S} \pi(\mathrm{s}) \mathbf{1}\left[\mathrm{V}^{\prime}(\mathrm{V}, \mathrm{s}) \in \mathrm{A}\right] \mathrm{d} \psi(\mathrm{V})
$$

maps $\mathcal{M}([\underline{\mathrm{V}}, \overline{\mathrm{V}}])$ into itself. Since from theorem of maximum, $\mathrm{V}^{\prime}(\mathrm{V}, \mathrm{s})$ is continuous in $\mathrm{V}$, the above mapping is continuous. Thus by Schauder-Tychonoff Theorem (Dunford and Schwartz (1958), V.10.5), T has a fixed point $\mu$. This concludes the proof. Q.E.D.

\section{Policy Game}

In this section, we describe the policy game underlying the analysis in section 3 . The game is a dynamic game whose state variable is the distribution of government debt $\left(B_{t},\left\{a_{t}^{i}\right\}_{i=1}^{N}\right)$ where $B_{t}$ is external government debt and $a_{t}^{i}$ is the government debt held 
by old agents of type $i$. In any period, $t$, and given the state of the game, the timing of the actions is as follows:

- The government chooses it policy, $\pi_{t}=\left(B_{t+1}, B_{t+1}^{d}, \tau_{l, t}, \tau_{a, t}, T_{t}, P_{t}, \delta_{t}\right) \in \Pi$. The government policy $\pi_{t}$ must be consistent with the government budget constraint.

- After the government chooses its policy, private agents act. Old agents consumes their savings and pension payments, young agents choose their consumption, labor supply and savings, $c_{0 t}^{i}, l_{t}^{i}, a_{t+1}^{i}$, subject to their budget constraint, and foreign lenders choose their holdings of government bonds $B_{t+1}$ facing prices $q_{t+1}$.

Let

$$
h^{t}=\left(h^{t-1}, \pi_{t},\left\{c_{1 t}^{i}\right\}_{i=1}^{N},\left\{c_{0 t}^{i}, l_{t}^{i}, a_{t+1}^{i}\right\}_{i=1}^{N}, q_{t}, q_{t}^{d}\right)
$$

be the public history at the end of period t. Additionally, let the interim history $h_{p}^{t}=$ $\left(h^{t-1}, \pi_{t}\right)$ be the history following government's announcement of policies. Let $H^{t}$ and $\mathrm{H}_{\mathrm{p}}^{\mathrm{t}}$ be the space of such histories. The strategies of all set of agents is denoted as follows: government's strategy is denoted by $\sigma_{\mathrm{t}}: \mathrm{H}^{\mathrm{t}-1} \rightarrow \Pi$, young households' strategy is denoted by $\sigma_{0 t}^{i}: H_{p}^{t} \rightarrow \mathbb{R}_{+}^{3}$, old households' strategy is denoted by $\sigma_{1 t}^{i}: H_{p}^{t} \rightarrow \mathbb{R}_{+}$, and foreign creditors' strategy is denoted $\sigma_{t}^{*}: H_{p}^{t} \rightarrow \mathbb{R}_{+}$. Finally, let the pricing rule for government debt be given by $q_{t+1}, q_{t+1}^{d}: H_{p}^{t} \rightarrow \mathbb{R}_{+}$.

We can then define a sustainable equilibrium. A set of strategies $\left(\sigma_{\pi}, \sigma_{y}, \sigma_{0}, \sigma^{*}\right)$ is a sustainable equilibrium if: i) For all $\mathrm{h}^{\mathrm{t}-1}$ the government strategy maximizes social welfare as described in section 3 , and ii) for all $h_{p}^{t}$ the equilibrium strategies induce government policies $\left\{B_{t}, B_{t}^{d}, \tau_{l, t}, \tau_{a, t}, T_{t}, P_{t}, \delta_{t}\right\}_{t=0}^{\infty}$, allocations $\left\{c_{t, 0}^{i}, c_{t, 1}^{i}, y_{t}^{i}, a_{t}^{i}\right\}_{t=0}^{\infty}$ and prices $\left\{q_{t}, q_{t}^{d}\right\}_{t=0}^{\infty}$ that are competitive equilibrium with taxes.

Given this policy game, it is immediate that autarky is an equilibrium. Given that households do not save and foreign creditors do not lend to the government, the government's best response is to find labor income taxes to finance transfers to the young and pensions for the old - this value is found by maximizing social welfare. They can also set asset taxes at $100 \%$. In response to this policy, households find it optimal to not to save. In addition, knowing that future governments will be in autarky, the current government does not want to deviate from such policy. Hence, autarky is an equilibrium.

Since autarky is an equilibrium and we can construct allocations by triggering to autarky following deviations by the government, any allocation that results from such an equilibrium must at least deliver a value higher than autarky. Thus the sustainability constraint (14) must be satisfied. 


\section{Optimal Policies with Commitment}

In this section, we describe policies when the government can commit. The optimal policy with commitment (the Ramsey outcome) is associated with the competitive equilibrium with taxes that attains the highest social welfare as described in section 3. We characterize the optimal policy using the primal approach. Using the characterization of competitive equilibrium outcomes in Lemma 1, optimal allocations must solve the following programming problem:

$$
\begin{aligned}
\max _{\left\{\mathrm{C}_{0, \mathrm{t}}, \mathrm{C}_{1, \mathrm{t}}, Y_{\mathrm{t}}\right\}} & \frac{\beta}{\hat{\beta}} \sum_{i} \mu^{i} \alpha^{i} \log \left(\mathrm{a}_{-1}^{i}+\mathrm{P}_{0}\right) \\
& +\sum_{\mathrm{t}=0}^{\infty} \hat{\beta}^{\mathrm{t}}\left[\log \mathrm{C}_{0 \mathrm{t}}+\psi \log \left(1-\mathrm{Y}_{\mathrm{t}}\right)+\beta \log \mathrm{C}_{1, \mathrm{t}+1}+(1+\psi+\beta) H\left(\mathrm{Y}_{\mathrm{t}}\right)\right]
\end{aligned}
$$

subject to

$$
\begin{array}{r}
\sum_{\mathrm{t}=0}^{\infty}\left(\frac{1}{1+r}\right)^{\mathrm{t}}\left[Z Y_{\mathrm{t}}-\mathrm{C}_{0, \mathrm{t}}-\mathrm{C}_{1, \mathrm{t}}-\mathrm{G}_{\mathrm{t}}\right] \\
\left\{\mathrm{a}_{-1}^{\mathrm{i}}\right\}_{\mathrm{i}=1}^{\mathrm{N}}, \mathrm{B}: \text { given }
\end{array}
$$

The first order conditions for the problem for $t \geqslant 0$ are given by

$$
\begin{aligned}
\hat{\beta}^{\mathrm{t}} \frac{1}{\mathrm{C}_{0, \mathrm{t}}} & =\lambda\left(\frac{1}{1+\mathrm{r}}\right)^{\mathrm{t}} \\
\hat{\beta}^{\mathrm{t}} \frac{\beta}{\mathrm{C}_{0, t+1}} & =\lambda\left(\frac{1}{1+\mathrm{r}}\right)^{\mathrm{t}+1} \\
\hat{\beta}^{\mathrm{t}}\left(\frac{\psi}{1-Y_{\mathrm{t}}}-(1+\psi+\beta) \mathrm{H}^{\prime}\left(Y_{\mathrm{t}}\right)\right) & =\lambda\left(\frac{1}{1+\mathrm{r}}\right)^{\mathrm{t}+1} \mathrm{Z}
\end{aligned}
$$

where $\lambda$ is the multiplier on the consolidated budget constraint for the country. The above can be written as

$$
C_{0, t}=\frac{\hat{\beta}^{\mathrm{t}}(1+r)^{\mathrm{t}}}{\lambda}, C_{0, t+1}=\beta \frac{\hat{\beta}^{\mathrm{t}}(1+r)^{\mathrm{t}}}{\lambda}, 1-Y_{\mathrm{t}}=\frac{\hat{\beta}^{\mathrm{t}}(1+r)^{\mathrm{t}}}{\lambda}\left[\psi-(1+\psi+\beta) H^{\prime}\left(Y_{\mathrm{t}}\right)\left(1-Y_{\mathrm{t}}\right)\right] .
$$

It is then clear that if $\hat{\beta}^{t}(1+r)<1$ then $\left\{C_{0, t}, C_{1, t+1}, 1-Y_{t}\right\}_{t=0}^{\infty}$ have a downward trend converging to zero. Instead if $\hat{\beta}^{\mathrm{t}}(1+r)=1$ then all the allocations are constant over time. 


\section{Characterization of SPE Outcomes in the Political Econ- omy Model}

We start our analysis by characterizing the set of SPE of the political economy game. As in the baseline case, we focus on symmetric equilibria that can be supported by triggering to autarky following deviations by the government. The following lemma characterizes the set of allocations that can be implemented as a SPE of the political economy game with reversion to autarky.

Lemma 6. Given the international interest rate $\mathrm{r}$, initial external debt, $\mathrm{B}_{0}$, and an initial distribution of assets for the initial old, $\left\{\mathrm{a}_{-1}^{\mathrm{i}}\right\}$, government policies $\left\{\mathrm{B}_{\mathrm{t}}, \mathrm{B}_{\mathrm{t}}^{\mathrm{d}}, \tau_{\mathrm{l}, \mathrm{t}}, \tau_{\mathrm{a}, \mathrm{t}}, \mathrm{T}_{\mathrm{t}}, \mathrm{P}_{\mathrm{t}}, \delta_{\mathrm{t}}\right\}_{\mathrm{t}=0^{\prime}}^{\infty}$

allocations $\left\{c_{\mathrm{t}, 0}^{\mathrm{i}}, \mathrm{c}_{\mathrm{t}, 1}^{\mathrm{i}}, \mathrm{y}_{\mathrm{t}}^{\mathrm{i}}, \mathrm{a}_{\mathrm{t}}^{\mathrm{i}}\right\}_{\mathrm{t}=0}^{\infty}$ and prices $\left\{\mathrm{q}_{\mathrm{t}}, \mathrm{q}_{\mathrm{t}}^{\mathrm{d}}\right\}_{\mathrm{t}=0}^{\infty}$ are a SPE outcome if and only if:

1. The allocations, prices and government policies are a competitive equilibrium with taxes;

2. The allocations satisfy the following political sustainability constraint for all $\mathrm{t} \geqslant 0$

$$
\omega \sum_{i} \alpha^{i} \mu^{i} u_{t-1,1}^{i}+\sum_{i} \alpha^{i} \mu^{i} u_{t, 0}^{i} \geqslant \underline{v}
$$

where $\underline{\mathrm{V}}$ is the value of the autarkic equilibrium and it is given by the following programming problem:

$$
\begin{aligned}
\underline{\mathrm{V}}=\max _{c_{0_{0}^{i}, c_{1}, y^{i}, \tau_{l}, T}} & \omega \sum_{i} \alpha^{i} \mu^{i} u\left(c_{1}\right)+\sum_{i} \alpha^{i} \mu^{i} u\left(c_{0}^{i}, y^{i} ; \theta^{i}\right) \\
\text { s.t. } & \sum_{i} \mu^{i} c_{0}^{i}+c_{1}+G=Z \sum \mu^{i} y^{i} \\
& \theta^{i}\left(1-\tau_{l}\right) u_{c, 0}^{i}+u_{y}^{i}=0 \\
& c_{0}^{i}=\left(1-\tau_{l}\right) Z y^{i}+T
\end{aligned}
$$

The proof for this lemma is omitted because the argument is essentially the same as in Chari and Kehoe (1990) and Abreu (1988).

\subsection{Best SPE Outcome}

Under our preference specification, aggregate welfare can be written solely in terms of aggregate allocations and initial pension payments as

$$
\beta / \hat{\beta} \sum_{i} \mu^{i} \alpha^{i} \log \left(\left(1-\tau_{a, 0}\right) a_{0}^{i}+P_{0}\right)+\sum_{t=0}^{\infty} \hat{\beta}^{t}\left[\log C_{0 t}-\Omega\left(Y_{t}\right)+\beta \log C_{1 t+1}\right],
$$


where we define $\Omega(Y)=-\psi \log (1-Y)+(1+\psi+\beta) H(Y)$. The problem for the planner at $t=0$ is then to choose an aggregate allocation $\left\{C_{0 t}, C_{1 t}, Y_{t}\right\}_{t=0}^{\infty}$ and time zero policies $\left\{P_{0}, \tau_{a, 0}, \delta_{0}\right\}$ that maximize (62) subject to the present value version of the consolidated budget constraint for the country

$$
\sum_{t}\left(\frac{1}{1+r}\right)^{t}\left[Z Y_{t}-C_{0 t}-C_{1 t}-G\right] \geqslant B \delta_{0}
$$

and the sequence of political sustainability constraints from $t=1$ and onward,

$$
\omega\left[\log C_{1 t}-H\left(Y_{t-1}\right)\right]+\left[\log C_{0 t}-\Omega\left(Y_{t}\right)+\beta \log C_{1 t+1}\right] \geqslant \underline{v},
$$

and for $t=0$,

$$
\omega \sum_{i} \mu^{i} \alpha^{i} \log \left(\left(1-\tau_{a, 0}\right) a_{0}^{i}+P_{0}\right)+\left[\log C_{0 t}-\Omega\left(Y_{t}\right)+\beta \log C_{1 t+1}\right] \geqslant \underline{V} .
$$

\subsection{EG Political Equilibrium}

Setup. We make our selection operational by setting up the equilibrium recursively. ${ }^{18}$ The state variable is $(\mathbb{B}, z)$ where $\mathbb{B}=\left(B,\left\{a^{i}\right\}, P^{e}\right), P^{e}$ are pension payments promised by the previous government, and $z \in\{0,1\}$ is a variable that records if previous governments defaulted. We adopt the convention that $z=1$ if previous governments defaulted in the past and zero otherwise. Given our selection, if $z=1$ then value for the current government is $\underline{\mathrm{V}}$ for all $\mathbb{B}, \mathrm{V}(\mathbb{B}, 0)=\underline{\mathrm{V}}$. Taking as given the decision of the future governments, denoted by a bar, the value function for the government that inherited a state $(\mathbb{B}, 0)$ is given by

$$
\mathrm{V}(\mathbb{B}, 0)=\max \{v(\mathbb{B}), \underline{V}\}
$$

where the value $v$ is the value associated with honoring all debt obligations and it can be expressed in primal form as

$v(\mathbb{B})=\max _{\pi=\left(\mathrm{P}, \mathrm{C}_{0}, Y, \mathbb{B}^{\prime}\right)} \omega \sum_{i} \mu^{i} \alpha^{i} \log \left(a^{i}+P\right)+\log C_{0}-\hat{\Omega}(Y)+\beta \sum_{i} \mu^{i} \alpha^{i} \log \left(a^{i /}+\bar{P}\left(\mathbb{B}^{\prime}\right)\right)$

\footnotetext{
${ }^{18}$ This is equivalent on assigning a Pareto weight of 1 to the first generation and a Pareto weight of zero to each generation thereafter.
} 
subject to

$$
\begin{aligned}
\sum_{i} \mu^{i}\left(a^{i}+P\right)+C_{0}+B+G & \leqslant Y+\frac{1}{1+r} B \\
P & \geqslant P^{e} \\
\bar{v}\left(\mathbb{B}^{\prime}\right) & \geqslant \underline{V} \\
a^{i \prime}+\bar{P}\left(\mathbb{B}^{\prime}\right) & =\varphi^{i}(Y)\left(\sum_{i} \mu^{i} a^{i \prime}+\bar{P}\left(\mathbb{B}^{\prime}\right)\right)
\end{aligned}
$$

where $\hat{\Omega}(\mathrm{Y})=-\log (1-\mathrm{Y})+(1+\psi+\beta) \mathrm{H}(\mathrm{Y})=\Omega(\mathrm{Y})+\beta \mathrm{H}(\mathrm{Y}), \overline{\mathrm{P}}$ and $\bar{v}$ are the policy rule and the value function used by future government. Recall that $\varphi^{i}(Y)$ is the consumption share for type $i$ household given by (10).

The constraint (68) is the consolidated budget constraint for the country in sequential form. Constraint (69) requires that the pension payments by the current government, $\mathrm{P}$, are at least what promised by the previous government, $\mathrm{P}^{e}$. The constraint $(70)$, guarantees that next period government has no incentive to default. The current government leaves a state to next period government such that it finds not optimal to default. Finally, constraint (71) ensures that assets holdings $\left\{a^{i /}\right\}$ are consistent with optimality of the households saving decisions. With log-preferences, this amount to assume that next period consumption share of type $i$ agent is equal to current consumption share $\varphi^{i}(Y)$.

Notice that requiring that the current government passes a state to the future government such that it does not have a strict incentive to default is without loss of generality. In fact, suppose to the contrary that the current government chooses $\mathbb{B}^{\prime}$ such that $v\left(\mathbb{B}^{\prime}\right)<\underline{V}$. Then it follows that the price of external debt equals zero and so no resources can be raised from foreign creditors. Moreover, since there is a default next period, private agents optimality implies that $a^{i \prime}=0$ for all $i$. Hence, the current government is better off defaulting today, strictly if external debt is strictly positive or there is domestic asset inequality, contradicting optimality for the current government.

A Markov equilibrium are policy rules $\overline{\mathrm{P}}, \overline{\mathrm{C}}_{0}, \overline{\mathrm{Y}}, \overline{\mathrm{B}}^{\prime}$ and value functions $\overline{\mathrm{V}}$ and $\bar{v}$ such that they satisfy

$$
\begin{aligned}
\mathrm{P}(\mathbb{B} \mid \overline{\mathrm{P}}, \bar{v}) & =\overline{\mathrm{P}}(\mathbb{B}), \mathrm{C}_{0}(\mathbb{B} \mid \overline{\mathrm{P}}, \bar{v})=\overline{\mathrm{C}}_{0}(\mathbb{B}), \mathrm{Y}(\mathbb{B} \mid \overline{\mathrm{P}}, \bar{v})=\overline{\mathrm{Y}}(\mathbb{B}), \\
\mathbb{B}^{\prime}(\mathbb{B} \mid \overline{\mathrm{P}}, \bar{v}) & =\overline{\mathbb{B}}^{\prime}(\mathbb{B}), \text { and } v(\mathbb{B} \mid \overline{\mathrm{P}}, \bar{v})=\bar{v}(\mathbb{B})
\end{aligned}
$$

for all $\mathbb{B}$ such that $\bar{v}(\mathbb{B}) \geqslant \underline{V}$ where $P, C_{0}, Y, \mathbb{B}^{\prime}, V$, and $v$ are the policy rule and the value associated with the problem in (66) and (67) given $\bar{P}$ and $\bar{v}$.

Characterization. We now turn to show that outcomes obtained from the policy rules 
associated with $\left(\mathrm{P}^{\prime}\right)$ and its associated time zero problem

$$
w_{0}\left(B,\left\{a^{i}\right\}, P^{e}\right)=\max \left\{\underline{V} \max _{P>P^{e}} \sum_{i} \mu^{i} \alpha^{i} \log \left(a^{i}+P\right)+w\left(\sum_{i} \mu^{i} a^{i}+P+B\right)\right\}
$$

are a Markov equilibrium outcome. To this end, let $\left(\mathrm{C}_{0}^{w}, \mathrm{Y}^{w}, \mathrm{C}_{1}^{\prime w}, \mathrm{~B}^{\prime w}\right)$ be the policy functions associated with the problem $\left(\mathrm{P}^{\prime}\right)$ and $\mathrm{P}^{w 0}$ be the optimal pension policy associated with the time zero problem (72).

Lemma 7. Given an initial condition $(\mathbb{B}, 0)$ such that it is not optimal to default in period zero, the outcome obtained for all $\mathrm{t} \geqslant 0$ as

$$
\left(C_{0 t}, Y_{t}, C_{1 t+1}, B\right)=\left(C_{0}^{w}, Y^{w}, C_{1}^{\prime w}, B\right)\left(C_{1 t}+B\right)
$$

where $\mathrm{C}_{1,0}=\sum_{i} \mu^{i} \log \left(\mathrm{a}^{\mathrm{i}}+\mathrm{P}^{w 0}(\mathbb{B})\right)$ is a Markov equilibrium outcome of the political economy game.

Proof. Consider the largest $w$ that solves the functional equation defined by the right hand side of $\left(\mathrm{P}^{\prime}\right)$. For all $\mathbb{B}$ such that $w_{0}(\mathbb{B}) \geqslant V_{A U T}$, let $\mathrm{P}^{w 0}(\mathbb{B})$ be the decision rule associated with problem (72). We can construct the other equilibrium objects for a Markov equilibrium as follows:

$$
\begin{aligned}
\overline{\mathrm{P}}(\mathbb{B}) & =\mathrm{P}^{w 0}(\mathbb{B}) \\
\overline{\mathrm{C}}_{0}(\mathbb{B}) & =\mathrm{C}_{0}^{w}(x(\mathbb{B})), \quad \overline{\mathrm{Y}}(\mathbb{B})=\mathrm{Y}^{w}(x(\mathbb{B})), \quad \mathrm{B}^{\prime}(\mathbb{B})=\mathrm{B}^{w \prime}(x(\mathbb{B})), \\
\overline{\mathrm{P}}^{e}(\mathbb{B}) & =\varphi^{1}\left(\mathrm{Y}^{w}(x(\mathbb{B}))\right) \mathrm{C}_{1}^{w}(x(\mathbb{B})), \quad \overline{\mathrm{a}}^{i}(\mathbb{B})=\varphi^{i}\left(Y^{w}(x(\mathbb{B}))\right) C_{1}^{w}(x(\mathbb{B}))-\overline{\mathrm{P}}^{e}(\mathbb{B}),
\end{aligned}
$$

and $\bar{v}(\mathbb{B})=\mathcal{w}_{0}(\mathbb{B})$ where we define $x(\mathbb{B})$ as

$$
x(\mathbb{B}) \equiv B+\sum_{i} \mu^{i} a^{i}+P^{w 0}(\mathbb{B}) .
$$

To show that our constructed policy rules and values constitute a Markov equilibrium, we have to show that for all $\mathbb{B}$ such that $\mathcal{w}_{0}(\mathbb{B}) \geqslant \underline{V}$ we have that $\mathrm{P}(\mathbb{B} \mid \overline{\mathrm{P}}(\cdot), \bar{v}(\cdot))=\mathrm{P}^{w 0}(\mathbb{B})$ and $v\left(\mathbb{B} \mid \mathrm{P}^{w 0}(\cdot), \mathcal{w}_{0}(\cdot)\right)=\mathcal{w}_{0}(\mathbb{B})$.

First, notice that we can combine problems $\left(\mathrm{P}^{\prime}\right)$ and $(72)$ to obtain

$$
w_{0}(B)=\max _{\left(P, C_{0}, Y, C_{1}^{\prime}, B^{\prime}\right)} \omega \sum_{i} \mu^{i} \alpha^{i} \log \left(b^{i}+P\right)+\log C_{0}-\Omega(Y)+\beta\left[-H(Y)+\log \left(C_{1}^{\prime}\right)\right]
$$


subject to

$$
\begin{aligned}
\sum_{i} \mu^{i}\left(b^{i}+P\right)+C_{0}+B+G & \leqslant Z Y+\frac{B^{\prime}}{1+r} \\
\omega\left[-H(Y)+\log C_{1}\right]+w\left(B^{\prime}+C_{1}\right) & \geqslant \underline{V}
\end{aligned}
$$

Second, since the sustainability constraint is always binding, it is without loss of generality to replace the constraint (75) with

$$
w_{0}\left(\mathbb{B}^{\prime}\right) \geqslant \underline{\mathrm{V}}
$$

where $\mathbb{B}^{\prime}=\left(B^{\prime},\left\{\varphi^{i}(Y) C_{1}-P^{e}\right\}, P^{e}\right)$. In fact, we know that in general

$$
w_{0}\left(\mathbb{B}^{\prime}\right) \geqslant \omega\left[-H(Y)+\log C_{1}\right]+w\left(B^{\prime}+C_{1}\right)
$$

but at the optimum in $\left(\mathrm{P}^{\prime}\right)$ the above is an equality. To see this, suppose by way of contradiction that

$$
w_{0}\left(\mathbb{B}^{\prime}\right)>w\left[-H(Y)+\log C_{1}\right]+w\left(B^{\prime}+C_{1}\right)=\underline{V}
$$

Note that for this to be the case we must have that $\mathrm{P}^{\prime}>\mathrm{P}^{e}$ otherwise we have an equality. So the next period government wants to redistribute resources toward the old. Hence we can equivalently write

$$
\begin{aligned}
\omega\left[-\mathrm{H}(\mathrm{Y})+\log \mathrm{C}_{1}\right]+w\left(\mathrm{~B}^{\prime}+\mathrm{C}_{1}\right) & =\omega \sum_{i} \mu^{i} \alpha^{i} \log \left(\hat{\varphi}^{i}(\mathrm{Y}) \mathrm{C}_{1}\right)+w\left(\mathrm{~B}^{\prime}+\mathrm{C}_{1}\right)< \\
& <\max _{\Delta \geqslant 0} \omega \sum_{i} \mu^{i} \alpha^{i} \log \left(\hat{\varphi}^{i}(\mathrm{Y}) \mathrm{C}_{1}+\Delta\right)+w\left(\mathrm{~B}^{\prime}+\mathrm{C}_{1}-\Delta\right)
\end{aligned}
$$

where $\Delta \geqslant 0$ are the additional pension payments provided by the future government. Given concavity of $w$ established in Claim 1 , the optimal $\Delta^{*}$ is greater than zero if and only if

$$
\Theta \frac{\omega}{C_{1}}>-w^{\prime}\left(\hat{B}^{\prime}\right)
$$

where $\Theta \equiv \sum_{i} \mu^{i} \alpha^{i} / \hat{\varphi}^{i}(Y)>1$. Consider now the following variation that increases pensions by $\varepsilon$, decreases output by $\varepsilon_{y}$ and increases external debt by $\varepsilon^{*}$. The variation is feasible in $\left(\mathrm{P}^{\prime}\right)$ if

$$
\begin{aligned}
\omega H^{\prime} \varepsilon_{y}+\frac{\omega}{C_{1}} \varepsilon & =\Theta \frac{\omega}{C_{1}} \varepsilon \Rightarrow \varepsilon_{y}=\frac{(\Theta-1) \frac{\omega}{C_{1}}}{\omega H^{\prime}} \varepsilon>0 \\
{\left[\Theta \frac{\omega}{C_{1}}+w^{\prime}\left(\hat{B}^{\prime}\right)\right] \varepsilon+w^{\prime}\left(\hat{B}^{\prime}\right) \varepsilon^{*} } & =0 \Rightarrow \varepsilon^{*}=\frac{\left[\Theta \frac{\omega}{C_{1}}+w^{\prime}\left(\hat{B}^{\prime}\right)\right]}{-w^{\prime}\left(\hat{B}^{\prime}\right)} \varepsilon
\end{aligned}
$$


where $\varepsilon^{*}>0$ given (76). If the original allocation is optimal, it must be that this variation does not increase the objective value so

$$
\begin{aligned}
\Delta \text { obj } & =\frac{1}{C_{0}}\left(\frac{\varepsilon^{*}}{1+r}-\varepsilon_{y}\right)+\frac{\beta}{C_{1}} \varepsilon+\left[\frac{\psi}{1-Y}+(1+\psi+\beta) H^{\prime}(Y)\right] \varepsilon_{y} \leqslant 0 \\
& \Rightarrow \frac{\Delta o b j}{\varepsilon}=\frac{1}{C_{0}} \frac{\left[\Theta \frac{\omega}{C_{1}}+w^{\prime}\left(\hat{B}^{\prime}\right)\right]}{-w^{\prime}\left(\hat{B}^{\prime}\right)(1+r)}+\frac{\beta}{C_{1}}+\left[\frac{\psi}{1-Y}+(1+\psi+\beta) H^{\prime}(Y)-\frac{1}{C_{0}}\right] \frac{(\Theta-1) \frac{\omega}{C_{1}}}{-\omega H^{\prime}} \leqslant 0
\end{aligned}
$$

Note that under (76), the first term is positive, the second is positive. For the right hand side to be negative it is necessary that the last term is negative. From (51), we know that

$$
\eta=\frac{\frac{\psi}{1-Y}+(1+\psi+\beta) H^{\prime}(Y)-\frac{1}{C_{0}}}{\omega H^{\prime}(Y)}>0
$$

and so also the last term is positive. Hence at the optimum (76) cannot hold. Then it must be that future government does not want to redistribute toward the old by increasing pension payments beyond what promised by the previous government. Hence we can rewrite (73) as

$$
w_{0}(B)=\max _{\left(\mathrm{P}, \mathrm{C}_{0}, \mathrm{Y}^{\prime} \mathrm{C}_{1}^{\prime}, \mathrm{B}^{\prime \prime}, \mathrm{Pe}\right)} \omega \sum_{i} \mu^{i} \alpha^{i} \log \left(\mathrm{b}^{\mathrm{i}}+\mathrm{P}\right)+\log \mathrm{C}_{0}-\Omega(\mathrm{Y})+\beta\left[-\mathrm{H}(\mathrm{Y})+\log \left(\mathrm{C}_{1}^{\prime}\right)\right]
$$

subject to

$$
\begin{aligned}
\sum_{i} \mu^{i}\left(b^{i}+P\right)+C_{0}+B+G & \leqslant Y+\frac{B^{\prime}}{1+r} \\
w_{0}\left(\mathbb{B}^{\prime}\right) & \geqslant \underline{V} \\
\mathbb{B}^{\prime} & =\left(B^{\prime},\left\{\hat{\varphi}^{i}(Y) C_{1}-P^{e}\right\}, P^{e}\right)
\end{aligned}
$$

It is then evident that (77) is equivalent to $(67)$ and so $\mathrm{P}(\mathbb{B} \mid \overline{\mathrm{P}}(\cdot), \bar{v}(\cdot))=\mathrm{P}^{w 0}(\mathbb{B})$ and $v\left(\mathbb{B} \mid \mathrm{P}^{w 0}(\cdot), w^{0}(\cdot)\right)=w_{0}(\mathbb{B})$.

\section{A Model of The World Economy}

In this section, we describe a world economy consisted of identical countries who experience i.i.d. shocks to government spending. We show that in the steady state of such economy, the world interest rate is constant and satisfies the relationship $\hat{\beta}(1+r)<1$.

The world consists of a continuum of countries that are as described in section 5 . The initial state of each country is defined by its initial inequality $\Phi_{-1}$, external debt B and government spending represented by $s_{0}$. We let $x=\left(\Phi_{-1}, B, s_{0}\right)$ and $\psi_{0}$ be the initial 
distribution of $x$ across countries. In particular, let $X$ be the set of all possible $x$. Then, from market clearing $\psi_{0}$ must satisfy

$$
\int_{x} B(x) d \psi_{0}(x)=0
$$

Allocations for each country can be identified by its history of shocks and its initial state $x$. These allocations are given by $\left\{C_{t, 0}\left(s^{t}, x\right), C_{t-1,1}\left(s^{t}, x\right), Y_{t}\left(s^{t}, x\right), \Phi_{t}\left(s^{t}, x\right)\right\}$, where $s^{t}=\left(s_{1}, \cdots, s_{t}\right)$.

Hence, the world planning problem that treats each country symmetrically can be written as

$$
\begin{aligned}
\max & \int_{x}\left\{\frac{\beta}{\hat{\beta}} \mathrm{u}_{1}^{\mathrm{p}}\left(\mathrm{C}_{-1,1}(\mathrm{x}) ; \Phi_{-1}(\mathrm{x})\right)+\right. \\
& \left.\sum_{\mathrm{t}=0}^{\infty} \sum_{\mathrm{s}^{\mathrm{t}}} \hat{\beta}^{\mathrm{t}} \pi\left(\mathrm{s}^{\mathrm{t}}\right) \mathrm{U}^{\mathrm{p}}\left(\mathrm{C}_{\mathrm{t}, 0}\left(\mathrm{~s}^{\mathrm{t}}, \mathrm{x}\right), \mathrm{C}_{\mathrm{t}, 1}\left(\mathrm{~s}^{\mathrm{t}+1}, \mathrm{x}\right), \mathrm{Y}_{\mathrm{t}}\left(\mathrm{s}^{\mathrm{t}}, \mathrm{x}\right) ; \Phi_{\mathrm{t}}\left(\mathrm{s}^{\mathrm{t}}, \mathrm{x}\right)\right)\right\} \mathrm{d} \Psi_{0}(\mathrm{x})
\end{aligned}
$$

subject to

$$
\begin{aligned}
& \int_{x} \sum_{s^{t}} \pi\left(s^{t}\right)\left[C_{t, 0}\left(s^{t}, x\right)+C_{t-1}\left(s^{t}, x\right)+G\left(s_{t}\right)-Z Y_{t}\left(s^{t}, x\right)\right] d \psi_{0}(x)=0 \\
& \frac{\beta}{\hat{\beta}} \mathrm{u}_{1}^{\mathrm{p}}\left(\mathrm{C}_{\mathrm{t}-1,1}\left(\mathrm{~s}^{\mathrm{t}}, \mathrm{x}\right) ; \Phi_{\mathrm{t}-1}\left(\mathrm{~s}^{\mathrm{t}}, \mathrm{x}\right)\right)+ \\
& \sum_{\tau=t}^{\infty} \sum_{s^{\tau} \succsim s^{t}} \pi\left(s^{\tau} \mid s^{t}\right) \hat{\beta}^{\tau-t} U^{p}\left(C_{\tau, 0}\left(s^{\tau}, x\right), C_{\tau, 1}\left(s^{\tau+1}, x\right), Y_{\tau}\left(s^{\tau}, x\right) ; \Phi_{\tau}\left(s^{\tau}, x\right)\right) \geqslant \underline{W}\left(s_{t}\right)
\end{aligned}
$$

Note that at each point in time, the state of the economy can be characterized by the the distribution of external debt, inequality and government spending given by $\psi_{t}$ appropriately defined. Let $\lambda_{t}$ be the Lagrange multiplier associated with aggregate resource constraint (82). Then it must be that in a steady state where $\psi_{t}=\psi_{t+1}, \lambda_{t+1} / \lambda_{t}=q$ is constant. The ratio $q$ is equal to $\frac{1}{1+r}$ where $r$ is the international interest rate considered in section 5. In particular, it can be shown that the state of each country can be represented by promised utility $V_{t}$ as defined in section 3 . Then, it can be shown that each individual country's problem at each point in time is equivalent to the recursive formulation in (P5).

Note that first order conditions of the above problem with respect to consumption 
imply that

$$
\begin{array}{r}
{\left[\hat{\beta}^{\mathrm{t}}+\sum_{s^{\tau} \precsim s^{\mathrm{t}}} \hat{\beta}^{\mathrm{t}-\tau} \mu_{\tau}\left(s^{\tau}, x\right)\right] \frac{1}{\mathrm{C}_{\mathrm{t}, 0}\left(s^{\mathrm{t}}, x\right)}=\lambda_{\mathrm{t}}} \\
{\left[\hat{\beta}^{\mathrm{t}-1}+\sum_{s^{\tau} \precsim s^{\mathrm{t}}} \hat{\beta}^{\mathrm{t}-1-\tau} \mu_{\tau}\left(s^{\tau}, x\right)\right] \frac{\beta}{\mathrm{C}_{\mathrm{t}-1,1}\left(\mathrm{~s}^{\mathrm{t}}, x\right)}=\lambda_{\mathrm{t}}}
\end{array}
$$

Hence,

$$
\begin{aligned}
\frac{C_{t+1,0}\left(s^{t+1}, x\right)}{C_{t, 0}\left(s^{t}, x\right)}=\frac{\lambda_{t}}{\lambda_{t+1}} \frac{\hat{\beta}^{t+1}+\sum_{s^{\tau} \precsim s^{t+1}} \hat{\beta}^{t+1-\tau} \mu_{\tau}\left(s^{\tau}, x\right)}{\hat{\beta}^{t}+\sum_{s^{\tau} \precsim s^{t}} \hat{\beta}^{t-\tau} \mu_{\tau}\left(s^{\tau}, x\right)}=\frac{\lambda_{t}}{\lambda_{t+1}}\left(\hat{\beta}+\frac{\mu_{t+1}\left(s^{t+1}, x\right)}{\hat{\beta}^{t}+\sum_{s^{\tau} \precsim s^{t}} \hat{\beta}^{t-\tau} \mu_{\tau}\left(s^{\tau}, x\right)}\right) \\
\frac{C_{t, 1}\left(s^{t+1}, x\right)}{C_{t-1,1}\left(s^{t}, x\right)}=\frac{\lambda_{t}}{\lambda_{t+1}} \frac{\hat{\beta}^{t+1}+\sum_{s^{\tau} \precsim s^{t+1}} \hat{\beta}^{t+1-\tau} \mu_{\tau}\left(s^{\tau}, x\right)}{\hat{\beta}^{t}+\sum_{s^{\tau} \precsim s^{t}} \hat{\beta}^{t-\tau} \mu_{\tau}\left(s^{\tau}, x\right)}=\frac{\lambda_{t}}{\lambda_{t+1}}\left(\hat{\beta}+\frac{\mu_{t+1}\left(s^{t+1}, x\right)}{\hat{\beta}^{t}+\sum_{s^{\tau} \precsim s^{t}} \hat{\beta}^{t-\tau} \mu_{\tau}\left(s^{\tau}, x\right)}\right)
\end{aligned}
$$

Note that the above equations imply that

$$
\begin{gathered}
\frac{C_{t+1,0}\left(s^{t+1}, x\right)}{C_{t, 0}\left(s^{t}, x\right)} \geqslant \frac{\hat{\beta}}{q} \\
\frac{C_{t, 1}\left(s^{t+1}, x\right)}{C_{t-1,1}\left(s^{t}, x\right)} \geqslant \frac{\hat{\beta}}{q}
\end{gathered}
$$

with strict inequality if the sustainability constraint binds for $\left(s^{t+1}, x\right)$. This implies that we must have that in a steady state $\frac{\hat{\beta}}{q} \leqslant 1$, otherwise aggregate consumption increases without bounds. Additionally, if the sustainability constraint binds with positive probability, we must have that $\frac{\beta}{q}<1$. Hence, we have the following proposition:

Proposition 6. Consider a steady state of the planning problem in (81) where $\lambda_{\mathrm{t}+1} / \lambda_{\mathrm{t}}=\mathrm{q}$ is the ratio of the multiplier on (82). Then it must be that $\hat{\beta} / q \leqslant 1$. Furthermore, if in steady state, the sustainability constraint (83) binds with positive probability, then $\hat{\beta} / q<1$.

\section{Other Preferences}

In this section, we show that our basic insight extends to other preferences. To this end, we first state a generalization of Lemma 1 for general preferences:

Lemma 8. Given initial asset distribution for the initial old, $\left\{a_{0}^{i}\right\}_{i=1, \ldots, N}$, and an initial foreign government debt, $\mathrm{B}_{0}$, an allocation $\left\{\left\{\mathrm{c}_{\mathrm{t}, 0}^{\mathrm{i}}, \mathrm{c}_{1 \mathrm{t}-1}^{\mathrm{i}}, \mathrm{y}_{\mathrm{t}}^{\mathrm{i}}, \mathrm{a}_{\mathrm{t}}^{\mathrm{i}}\right\}_{\mathrm{i} \in\{1, \cdots, \mathrm{N}\}}\right\}_{\mathrm{t}=0}^{\infty}$ can be supported as a competitive equilibrium with taxes if and only if it satisfies the following: 
1. There exist a vector of market weights $\left\{\Phi_{\mathrm{t}}=\left(\varphi_{\mathrm{t}}^{\mathrm{i}}\right)_{\mathrm{i} \in\{1, \cdots, \mathrm{N}\}}\right\}_{\mathrm{t}=0}^{\infty}$ where $\sum_{\mathrm{i}} \mu^{\mathrm{i}} \varphi_{\mathrm{t}}^{\mathrm{i}}=1$ such that $\left\{\mathrm{c}_{\mathrm{t}, 0}^{\mathrm{i}}, \mathrm{y}_{\mathrm{t}}^{\mathrm{i}}\right\}_{\mathrm{i} \in\{1, \cdots, \mathrm{N}\}}$ solves

$$
\mathrm{u}_{0}^{\mathrm{M}}\left(\mathrm{C}_{\mathrm{t}, 0}, \mathrm{Y}_{\mathrm{t}} ; \Phi_{\mathrm{t}}\right)=\max _{\mathrm{c}_{0}^{i}, y^{i}} \sum_{i=1}^{\mathrm{N}} \varphi^{i} \mu^{i} \mathrm{u}\left(\mathrm{c}_{0}^{i}, 1-y^{i} / \theta^{i}\right)
$$

subject to

$$
\sum_{i=1}^{N} \mu^{i} c_{0}^{i}=C_{t, 0} \text { and } \sum_{i=1}^{N} \mu^{i} y^{i}=Y_{t}
$$

and $\left\{\mathrm{c}_{\mathrm{t}, 1}^{\mathrm{i}}\right\}_{\mathrm{i} \in\{1, \cdots, \mathrm{N}\}}$ solves

$$
\mathrm{u}_{1}^{\mathrm{M}}\left(\mathrm{C}_{\mathrm{t}, 1} ; \Phi_{\mathrm{t}}\right)=\max _{\mathrm{c}_{1}^{i}} \sum_{i=1}^{\mathrm{N}} \varphi^{i} \mu^{i} u\left(c_{1}^{i}\right)
$$

subject to

$$
\sum_{i=1}^{N} \mu^{i} c_{1}^{i}=C_{t, 1}
$$

where $C_{t, 0}, Y_{t}$, and $C_{t, 1}$ are the aggregate consumption of the young, aggregate effective hours worked, and aggregate consumption of the old born at $\mathrm{t}$, respectively. The solution to the above optimization problems is represented by the policy functions $\hat{c}_{0}^{i}\left(C_{t, 0}, Y_{t} ; \Phi_{t}\right), \hat{y}^{i}\left(C_{t, 0}, Y_{t} ; \Phi_{t}\right)$, and $\hat{c}_{1}^{i}\left(C_{\mathrm{t}, 1} ; \Phi_{\mathrm{t}}\right)$.

2. The following implementability condition holds for all $\mathrm{t} \geqslant 0$

$$
\begin{aligned}
& \mathrm{u}_{0, \mathrm{C}}^{\mathrm{M}}\left(\mathrm{C}_{\mathrm{t}, 0}, \mathrm{Y}_{\mathrm{t}} ; \Phi_{\mathrm{t}}\right) \hat{c}_{0}^{i}\left(\mathrm{C}_{\mathrm{t}, 0}, Y_{\mathrm{t}} ; \Phi_{\mathrm{t}}\right)+\mathrm{U}_{0, \mathrm{Y}}^{\mathrm{M}}\left(\mathrm{C}_{\mathrm{t}, 0}, \mathrm{Y}_{\mathrm{t}} ; \Phi_{\mathrm{t}}\right) \hat{y}^{\mathrm{i}}\left(\mathrm{C}_{\mathrm{t}, 0}, \mathrm{Y}_{\mathrm{t}} ; \Phi_{\mathrm{t}}\right) \\
&+\beta \mathrm{u}_{1, \mathrm{C}}^{\mathrm{M}}\left(\mathrm{C}_{\mathrm{t}, 1} ; \Phi_{\mathrm{t}}\right) \hat{\mathrm{c}}_{1}^{\mathrm{i}}\left(\mathrm{C}_{\mathrm{t}, 1} ; \Phi_{\mathrm{t}}\right)=\hat{\mathrm{T}}_{\mathrm{t}}
\end{aligned}
$$

for some constant $\hat{T}_{t}$, where $\mathrm{U}_{0, C}^{M}, \mathrm{U}_{0, Y}^{M}, \mathrm{U}_{1, \mathrm{C}}^{\mathrm{M}}$ are respectively partial derivatives of $\mathrm{U}_{0}^{\mathrm{M}}$ and $\mathrm{U}_{1}^{\mathrm{M}}$ with respect to $\mathrm{C}_{0}, \mathrm{Y}$, and $\mathrm{C}_{1}$.

3. Aggregate allocations satisfy present value version of the consolidated budget constraint

$$
\mathrm{B}_{0}+\sum_{\mathrm{t}=0}^{\infty} \frac{1}{\left(1+\mathrm{r}^{*}\right)^{\mathrm{t}}}\left[\mathrm{C}_{\mathrm{t}, 0}+\mathrm{C}_{\mathrm{t}-1,1}+\mathrm{G}\right] \leqslant \sum_{\mathrm{t}=0}^{\infty} \frac{1}{\left(1+\mathrm{r}^{*}\right)^{\mathrm{t}}} \mathrm{Y}_{\mathrm{t}}
$$

Proof. The proof closely follows that of Werning (2007). We first show that any competitive equilibrium with taxes must satisfy conditions $1-3$. The first order conditions 
associated with the households' maximization problem are given by

$$
\begin{aligned}
\left(1-\tau_{l, t}\right) u_{c}\left(c_{t, 0}^{i}, y_{t}^{i} ; \theta^{i}\right) & =-u_{y}\left(c_{t}^{i}, y_{t}^{i} ; \theta^{i}\right) \\
q_{t}^{d} u_{c}\left(c_{t, 0}^{i}, y_{t}^{i} ; \theta^{i}\right) & =\beta\left(1-\tau_{a, t+1}\right) u_{t, 1}^{\prime i}
\end{aligned}
$$

This implies that for all $i, j \in\{1, \cdots, N\}$,

$$
\begin{aligned}
& \frac{u_{c}\left(c_{t, 0}^{i}, y_{t}^{i} ; \theta^{i}\right)}{u_{c}\left(c_{t, 0}^{j}, y_{t}^{j} ; \theta^{j}\right)}=\frac{u_{y}\left(c_{t}^{i}, y_{t}^{i} ; \theta^{i}\right)}{u_{y}\left(c_{t}^{j}, y_{t}^{j} ; \theta^{j}\right)} \\
& \frac{u_{c}\left(c_{t, 0}^{i}, y_{t}^{i} ; \theta^{i}\right)}{u_{c}\left(c_{t, 0}^{j}, y_{t}^{j} ; \theta^{j}\right)}=\frac{u_{t, 1}^{i j}}{u_{t, 1}^{\prime j}}
\end{aligned}
$$

Hence, $\varphi^{i \prime}$ s must exists so that

$$
\frac{u_{c}\left(c_{t, 0}^{i}, y_{t}^{i} ; \theta^{i}\right)}{u_{c}\left(c_{t, 0}^{j}, y_{t}^{j} ; \theta^{j}\right)}=\frac{u_{y}\left(c_{t}^{i}, y_{t}^{i} ; \theta^{i}\right)}{u_{y}\left(c_{t}^{j}, y_{t}^{j} ; \theta^{j}\right)}=\frac{u_{t, 1}^{\prime i}}{u_{t, 1}^{\prime j}}=\frac{\varphi^{j}}{\varphi^{i}}
$$

Furthermore, the value of $\sum_{i} \mu^{i} \varphi^{i}$ is indeterminate and can be normalized to 1 . The above equations coincide with the FOC's associated with planning problems (84) and (85). This implies that $\left\{c_{\mathrm{t}, 0}^{\mathrm{i}}, c_{\mathrm{t}, 1}^{\mathrm{i}}, y_{\mathrm{t}}^{\mathrm{i}}\right\}_{\mathrm{i} \in\{1, \cdots, \mathrm{N}\}}$ must be solutions to the planning problems (84) and (85). This proves condition 1 .

Furthermore, the envelope conditions associated with (84) and (85) imply that

$$
\begin{aligned}
\frac{\left(1-\tau_{\mathrm{l}, \mathrm{t}}\right) \mathrm{U}_{0, \mathrm{Yt}}^{\mathrm{M}}}{\mathrm{u}_{0, \mathrm{Ct}}^{\mathrm{M}}}+1 & =0 \\
\frac{\mathrm{q}_{\mathrm{t}}^{\mathrm{d}}}{\left(1-\tau_{\mathrm{a}, \mathrm{t}+1}\right)} & =\frac{\beta \mathrm{u}_{1, \mathrm{Ct}}^{\mathrm{M}}}{\mathrm{u}_{0, \mathrm{Ct}}^{\mathrm{M}}}
\end{aligned}
$$

The inter-temporal budget constraint for the household is given by

$$
c_{t, 0}^{i}-y_{t}^{i}\left(1-\tau_{l, t}\right)+\frac{q_{t}^{d}}{\left(1-\tau_{a, t+1}\right)} c_{t, 1}^{i}=T
$$

Using the envelope relationships above, we can replace for taxes into the budget constraint to obtain

$$
c_{\mathrm{t}, 0}^{\mathrm{i}}+\frac{\mathrm{U}_{0, \mathrm{Yt}}^{\mathrm{M}}}{\mathrm{U}_{0, \mathrm{Ct}}^{\mathrm{M}}} y_{\mathrm{t}}^{\mathrm{i}}+\frac{\beta \mathrm{U}_{1, \mathrm{Ct}}^{\mathrm{M}}}{\mathrm{U}_{0, \mathrm{Ct}}^{\mathrm{M}}} c_{\mathrm{t}, 1}^{\mathrm{i}}=\mathrm{T}
$$

Multiplying by $\mathrm{U}_{0, \mathrm{Ct}}^{\mathrm{M}}$ gives condition 2 . Condition 3 simply follows by summing up all the budget constraints.

To show the reverse, it suffices to construct taxes from (89) and (90) while government 
transfers and government debt are not pinned down due to Ricardian equivalence. The value of foreign debt can be simply determined by the present value of the difference between aggregate consumption and aggregate output. This completes the proof.

\subsection{GHH Preferences}

When preferences are GHH of the form $\log \left(c_{0}-\psi l^{\gamma} / \gamma\right)+\beta \log c_{1}$ we can show that our main result holds. For these preferences, the problem of determining allocations given market weights $\varphi^{i}$ or the market utility problem is given by

$$
\mathrm{U}_{0}^{\mathrm{M}}(\mathrm{C}, \mathrm{Y} ; \Phi)=\max \sum \varphi^{i} \mu^{i} \log \left(\mathrm{c}^{\mathrm{i}}-\psi\left(\mathrm{l}^{\mathrm{i}}\right)^{\gamma} / \gamma\right)
$$

subject to

$$
\sum \mu^{i} c^{i}=C, \sum \mu^{i} \theta^{i} l^{i}=Y
$$

Then FOCs are given by

$$
\begin{aligned}
\frac{\varphi^{i}}{c^{i}-\psi\left(l^{i}\right)^{\gamma} / \gamma} & =\lambda_{C} \\
\frac{\varphi^{i}}{c^{i}-\psi\left(l^{i}\right)^{\gamma} / \gamma} \psi\left(l^{i}\right)^{\gamma-1} & =\lambda_{\gamma} \theta^{i}
\end{aligned}
$$

and we must have $\psi\left(l^{i}\right)^{\gamma-1}=\frac{\theta^{i} \lambda_{C}}{\lambda_{Y}}$. Then

$$
l^{i}=\left(\frac{\theta^{i} \lambda_{C}}{\psi \lambda_{Y}}\right)^{\varepsilon} \rightarrow \theta^{i} l^{i}=\left(\frac{\theta^{i}}{\theta^{j}}\right)^{1+\varepsilon} \theta^{j} l^{j} \rightarrow \theta^{i} l^{i}=\frac{\left(\theta^{i}\right)^{1+\varepsilon}}{\sum \mu^{j}\left(\theta^{j}\right)^{1+\varepsilon}} Y
$$

We define average productivity as

$$
\hat{\theta}^{1+\varepsilon}=\sum \mu^{j}\left(\theta^{j}\right)^{1+\varepsilon}
$$

Then,

$$
l^{i}=\frac{\left(\theta^{i}\right)^{\varepsilon}}{\hat{\theta}^{1+\varepsilon}} Y
$$




\section{Furthermore}

$$
\begin{aligned}
\frac{\varphi^{i}}{\lambda_{C}} & =c^{i}-\psi\left(l^{i}\right)^{\gamma} / \gamma \\
\frac{1}{\lambda_{C}} & =\sum \mu^{i} c^{i}-\psi \sum \mu^{i}\left(l^{i}\right)^{\gamma} / \gamma \\
& =C-\frac{\psi}{\gamma} \frac{\sum \mu^{i}\left(\theta^{i}\right)^{1+\varepsilon}}{\hat{\theta}^{(1+\varepsilon) \gamma}} \gamma^{\gamma} \\
& =C-\frac{\psi}{\gamma} \frac{\hat{\theta}^{(1+\varepsilon)}}{\hat{\theta}^{(1+\varepsilon) \gamma}} \gamma^{\gamma} \\
& =C-\frac{\psi}{\gamma} \hat{\theta}^{(1+\varepsilon)(1-\gamma)} \gamma^{\gamma} \\
& =C-\frac{\psi}{\gamma} \hat{\theta}^{-\gamma} \gamma \\
& =C-v(Y / \hat{\theta})
\end{aligned}
$$

Then,

$$
\begin{aligned}
c^{i} & =(\mathrm{C}-v(\mathrm{Y} / \hat{\theta})) \varphi^{i}+\frac{\psi}{\gamma}\left(\frac{\left(\theta^{i}\right)^{\varepsilon}}{\hat{\theta}^{1+\varepsilon}} \mathrm{Y}\right)^{\gamma} \\
& =\varphi^{i} \mathrm{C}-\varphi^{i} v(\mathrm{Y} / \hat{\theta})+\frac{\psi}{\gamma} \frac{\left(\theta^{i}\right)^{1+\varepsilon}}{\hat{\theta}^{(1+\varepsilon) \gamma}} \gamma^{\gamma} \\
& =\varphi^{i} \mathrm{C}-\varphi^{i} v(\mathrm{Y} / \hat{\theta})+\frac{\left(\theta^{i}\right)^{1+\varepsilon}}{\hat{\theta}^{1+\varepsilon}} \frac{\psi}{\gamma} \hat{\theta}^{(1+\varepsilon)(1-\gamma)} Y^{\gamma} \\
& =\varphi^{i} \mathrm{C}-v(\mathrm{Y} / \hat{\theta})\left(\varphi^{i}-\left(\frac{\theta^{i}}{\hat{\theta}}\right)^{1+\varepsilon}\right)
\end{aligned}
$$

Then the market utility can be written as

$$
\begin{aligned}
\mathrm{U}^{\mathrm{M}}(\mathrm{C}, \mathrm{Y} ; \Phi) & =\sum \mu^{i} \varphi^{i} \log \left((\mathrm{C}-v(\mathrm{Y} / \hat{\theta})) \varphi^{i}\right) \\
& =\log (\mathrm{C}-v(\mathrm{Y} / \hat{\theta}))+\sum \varphi^{i} \mu^{i} \log \varphi^{i}
\end{aligned}
$$

and so

$$
\begin{aligned}
u_{C} & =\frac{1}{C-v(Y / \hat{\theta})} \\
u_{Y} & =-\frac{1}{C-v(Y / \hat{\theta})} \frac{1}{\hat{\theta}} v^{\prime}\left(\frac{Y}{\hat{\theta}}\right)
\end{aligned}
$$


Hence, the budget constraint can be written as

$$
\begin{aligned}
\frac{1}{\mathrm{C}_{0}-v(\mathrm{Y} / \hat{\theta})}\left[\varphi^{i} \mathrm{C}_{0}-v(\mathrm{Y} / \hat{\theta})\left(\varphi^{i}-\left(\frac{\theta^{i}}{\hat{\theta}}\right)^{1+\varepsilon}\right)\right]-\frac{1}{\mathrm{C}_{0}-v(\mathrm{Y} / \hat{\theta})} \frac{1}{\hat{\theta}} v^{i}\left(\frac{Y}{\hat{\theta}}\right) \frac{\left(\theta^{i}\right)^{1+\varepsilon}+\beta \mathrm{U}_{\mathrm{C} 1} \mathrm{c}_{1}^{i}}{\hat{\theta}^{1+\varepsilon}}=\hat{\mathrm{T}}+\beta \varphi^{i} & =\hat{\mathrm{T}} \\
(1+\beta) \varphi^{i}-\frac{1}{\varepsilon} \frac{1}{\mathrm{C}_{0}-v(\mathrm{Y} / \hat{\theta})}\left(\frac{\theta^{i}}{\hat{\theta}}\right)^{1+\varepsilon} v(\mathrm{Y} / \hat{\theta}) & =\hat{\top} \\
1+\frac{1}{1+\beta} \frac{v(\mathrm{Y} / \hat{\theta})}{\mathrm{C}_{0}-v(\mathrm{Y} / \hat{\theta})} \frac{\left(\theta^{i}\right)^{1+\varepsilon}-\hat{\theta}^{1+\varepsilon}}{\hat{\theta}^{1+\varepsilon}} & =\varphi^{i}
\end{aligned}
$$

The objective for the government is

$$
(1+\beta) \sum \alpha^{i} \mu^{i} \log \varphi^{i}+\log \left(C_{0}-v(Y / \hat{\theta})\right)+\beta \log C_{1}
$$

So, we can write the recursive problem as

$$
\mathrm{B}(\mathrm{V})=\max \mathrm{Y}-\mathrm{C}_{0}-\frac{1}{1+\mathrm{r}} \mathrm{C}_{1}+\frac{1}{1+\mathrm{r}} \mathrm{B}\left(\mathrm{V}^{\prime}\right)
$$

subject to

$$
\begin{aligned}
(1+\beta) \sum \alpha^{i} \mu^{i} \log \varphi^{i}+\log \left(C_{0}-v(Y / \hat{\theta})\right)+\beta \log C_{1}+\hat{\beta} V^{\prime} & =V \\
\frac{\beta}{\hat{\beta}} \sum \alpha^{i} \mu^{i} \log \varphi^{i}+\log C_{1}+V^{\prime} & \geqslant \underline{W} \\
1+\frac{1}{1+\beta} \frac{v(1 / \hat{\theta})}{C_{0} Y^{-\gamma}-v(1 / \hat{\theta})} \frac{\left(\theta^{i}\right)^{1+\varepsilon}-\hat{\theta}^{1+\varepsilon}}{\hat{\theta}^{1+\varepsilon}} & =\varphi^{i}
\end{aligned}
$$

\section{Some preliminary results:}

Let $\mathrm{H}\left(\mathrm{Y}, \mathrm{C}_{0}\right)=\sum \alpha^{i} \mu^{i} \log \left(1+\frac{1}{1+\beta} \frac{v(1 / \hat{\theta})}{\mathrm{C}_{0} \gamma^{-\gamma}-v(1 / \hat{\theta})} \frac{\left(\theta^{i}\right)^{1+\varepsilon}-\hat{\theta}^{1+\varepsilon}}{\hat{\theta}^{1+\varepsilon}}\right)=\hat{\mathrm{H}}\left(\mathrm{C}_{0} \mathrm{Y}^{-\gamma}\right)$ where $\hat{\mathrm{H}}(\mathrm{x})=$ $\sum \alpha^{i} \mu^{i} \log \left(1+\frac{1}{1+\beta} \frac{v(1 / \hat{\theta})}{\chi-v(1 / \hat{\theta})} \frac{\left(\theta^{i}\right)^{1+\varepsilon}-\hat{\theta}^{1+\varepsilon}}{\hat{\theta}^{1+\varepsilon}}\right)$. Then we have:

Lemma 9. The function $\hat{\mathrm{H}}$ is strictly increasing and concave. Furthermore, the function $\mathrm{H}\left(\mathrm{Y}, \mathrm{C}_{0}\right)$ is decreasing in $\mathrm{Y}$ and increasing in $\mathrm{C}_{0}$ and if $\gamma \geqslant 2$, it is strictly concave in $\left(\mathrm{Y}, \mathrm{C}_{0}\right)$.

Proof. Extensive algebra - available upon request - shows that: 


$$
\begin{aligned}
& \hat{\mathrm{H}}^{\prime}(\mathrm{x})=-\sum \frac{\alpha^{i}}{\varphi^{i}} \mu^{i} \frac{1}{1+\beta} \frac{v(1 / \hat{\theta})}{(x-v(1 / \hat{\theta}))^{2}} \frac{\left(\theta^{i}\right)^{1+\varepsilon}-\hat{\theta}^{1+\varepsilon}}{\hat{\theta}^{1+\varepsilon}}>0 \\
& \hat{H}^{\prime \prime}(x)= 2 \sum \frac{\alpha^{i}}{\varphi^{i}} \mu^{i} \frac{1}{1+\beta} \frac{v(1 / \hat{\theta})}{(x-v(1 / \hat{\theta}))^{3}} \frac{\left(\theta^{i}\right)^{1+\varepsilon}-\hat{\theta}^{1+\varepsilon}}{\hat{\theta}^{1+\varepsilon}} \\
&-\sum \frac{\alpha^{i}}{\left(\varphi^{i}\right)^{2}} \mu^{i}\left(\frac{1}{1+\beta} \frac{v(1 / \hat{\theta})}{(x-v(1 / \hat{\theta}))^{2}} \frac{\left(\theta^{i}\right)^{1+\varepsilon}-\hat{\theta}^{1+\varepsilon}}{\hat{\theta}^{1+\varepsilon}}\right)^{2}<0 \\
&(\gamma+1) \hat{H}^{\prime}(x)+\gamma x \hat{H}^{\prime \prime}(x)= \frac{v(1 / \hat{\theta})}{(x-v(1 / \hat{\theta}))^{3}}[(\gamma+1) v(1 / \hat{\theta})+(\gamma-1) x] \sum \frac{\alpha^{i}}{\varphi^{i}} \mu^{i} \frac{1}{1+\beta} \frac{\left(\theta^{i}\right)^{1+\varepsilon}-\hat{\theta}^{1+\varepsilon}}{\hat{\theta}^{1+\varepsilon}} \\
&-\gamma \hat{H}^{\prime}(x)-\gamma x \hat{H}^{\prime \prime}(x)=-\frac{v(1 / \hat{\theta})}{(x-v(1 / \hat{\theta}))^{3}}[\gamma v(1 / \hat{\theta})+\gamma x] \sum \frac{\alpha^{i}}{\left(\varphi^{i}\right)^{2}} \mu^{i}\left(\frac{1}{1+\beta} \frac{v(1 / \hat{\theta})}{(x-v(1 / \hat{\theta}))^{2}} \frac{\left(\theta^{i}\right)^{1+\varepsilon}-\hat{\theta}^{1+\varepsilon}}{\hat{\theta}^{1+\varepsilon}}\right)^{2}<0 \\
&+\gamma x \sum \frac{\alpha^{i}}{1+\beta} \frac{\left(\theta^{i}\right)^{1+\varepsilon}-\hat{\theta}^{1+\varepsilon}}{\hat{\theta}^{1+\varepsilon}} \\
& \varphi^{i} \mu^{i}\left(\frac{1}{1+\beta} \frac{v(1 / \hat{\theta})}{(x-v(1 / \hat{\theta}))^{2}} \frac{\left(\theta^{i}\right)^{1+\varepsilon}-\hat{\theta}^{1+\varepsilon}}{\hat{\theta}^{1+\varepsilon}}\right)^{2}>0
\end{aligned}
$$

and

$$
\begin{aligned}
& \mathrm{H}_{\mathrm{C}}=\mathrm{Y}^{-\gamma} \hat{\mathrm{H}}^{\prime}\left(\mathrm{C}_{0} \mathrm{Y}^{-\gamma}\right)>0 \\
& \mathrm{H}_{\mathrm{Y}}=-\gamma \mathrm{C}_{0} \mathrm{Y}^{-\gamma-1} \hat{\mathrm{H}}^{\prime}\left(\mathrm{C}_{0} \mathrm{Y}^{-\gamma}\right)<0 \\
& \mathrm{H}_{\mathrm{CC}}=\mathrm{Y}^{-2 \gamma} \hat{\mathrm{H}}^{\prime \prime}\left(\mathrm{C}_{0} \mathrm{Y}^{-\gamma}\right)<0 \\
& \mathrm{H}_{Y \gamma}=\gamma \mathrm{C}_{0} \mathrm{Y}^{-\gamma-2}\left[(\gamma+1) \hat{\mathrm{H}}^{\prime}\left(\mathrm{C}_{0} \mathrm{Y}^{-\gamma}\right)+\gamma \mathrm{C}_{0} \mathrm{Y}^{-\gamma} \hat{\mathrm{H}}^{\prime \prime}\left(\mathrm{C}_{0} \mathrm{Y}^{-\gamma}\right)\right]<0 \\
& \mathrm{H}_{Y C}=-\gamma \gamma^{-\gamma-1} \hat{\mathrm{H}}^{\prime}\left(\mathrm{C}_{0} \mathrm{Y}^{-\gamma}\right)-\gamma \mathrm{Y}^{-2 \gamma-1} \mathrm{C}_{0} \hat{\mathrm{H}}^{\prime \prime}\left(\mathrm{C}_{0} \mathrm{Y}^{-\gamma}\right)>0 \\
& H_{Y \gamma} H_{C C}-\left(H_{Y C}\right)^{2}=-\gamma Y^{-2 \gamma-2} \hat{H}^{\prime}\left(\begin{array}{c}
{[(\gamma-2) x+\gamma \nu(1 / \hat{\theta})] \sum \frac{\alpha^{i}}{\varphi^{i}} \mu^{i} \frac{1}{1+\beta} \frac{v(1 / \hat{\theta})}{(x-v(1 / \hat{\theta}))^{3}} \frac{\left(\theta^{i}\right)^{1+\varepsilon}-\hat{\theta}^{1+\varepsilon}}{\hat{\theta}^{1+\varepsilon}}} \\
-(\gamma-1) \times \sum \frac{\alpha^{i}}{\left(\varphi^{i}\right)^{2}} \mu^{i}\left(\frac{1}{1+\beta} \frac{v(1 / \hat{\theta})}{(x-v(1 / \hat{\theta}))^{2}} \frac{\left(\theta^{i}\right)^{1+\varepsilon}-\hat{\theta}^{1+\varepsilon}}{\hat{\theta}^{1+\varepsilon}}\right)^{2}
\end{array}\right)
\end{aligned}
$$

The above expression is positive as long as $\gamma \geqslant 2$. This implies that the function $\mathrm{H}$ is concave, decreasing in $\mathrm{Y}$ and increasing in $\mathrm{C}$.

Let $\tilde{\beta}=\frac{\hat{\beta}}{\beta}$.

Note that with the above definition, we can write the problem

$$
B(V)=\max Y-C_{0}-\frac{1}{1+r} C_{1}+\frac{1}{1+r} B\left(V^{\prime}\right)
$$


subject to

$$
\begin{array}{r}
\log \left(C_{0}-v(Y / \hat{\theta})\right)+(1+\beta) H\left(C_{0}, Y\right)+\beta \log C_{1}+\hat{\beta} V^{\prime}=V \\
\tilde{\beta} \log C_{1}+\tilde{\beta} H\left(C_{0}, Y\right)+V^{\prime} \geqslant \underline{W}
\end{array}
$$

We analyze two cases:

Case 1. $\mathrm{V}$ is high so that the sustainability constraint is not binding. Then FOCs are given by

$$
\begin{aligned}
-1+\frac{\lambda}{C_{0}-v(Y / \hat{\theta})}+(1+\beta) \lambda H_{C}\left(C_{0}, Y\right) & =0 \\
-\frac{1}{1+r}+\frac{\beta \lambda}{C_{1}} & =0 \\
1-\frac{\lambda}{C_{0}-v(Y / \hat{\theta})} v^{\prime}(Y / \hat{\theta}) \frac{1}{\hat{\theta}}+(1+\beta) \lambda H_{Y}\left(C_{0}, Y\right) & =0 \\
\frac{1}{1+r} B^{\prime}\left(V^{\prime}\right)+\hat{\beta} \lambda & =0
\end{aligned}
$$

After rearranging, the first and third equations can be written as

$$
\begin{aligned}
\frac{1}{C_{0}-v(Y / \hat{\theta})}+(1+\beta) H_{C}\left(C_{0}, Y\right) & =\frac{1}{\lambda} \\
\frac{1}{C_{0}-v(Y / \hat{\theta})} v^{\prime}(Y / \hat{\theta}) \frac{1}{\hat{\theta}}-(1+\beta) H_{Y}\left(C_{0}, Y\right) & =\frac{1}{\lambda}
\end{aligned}
$$

or, using the definition of $\mathrm{H}_{C}$ and $\mathrm{H}_{Y}$ as

$$
\begin{aligned}
\frac{1}{C_{0}-v(Y / \hat{\theta})}+(1+\beta) Y^{-\gamma} \hat{H}^{\prime}\left(C_{0} Y^{-\gamma}\right) & =\frac{1}{\lambda} \\
\frac{1}{C_{0}-v(Y / \hat{\theta})} v^{\prime}(Y / \hat{\theta}) \frac{1}{\hat{\theta}}+(1+\beta) \gamma Y^{-\gamma-1} C_{0} \hat{H}^{\prime}\left(C_{0} Y^{-\gamma}\right) & =\frac{1}{\lambda}
\end{aligned}
$$

Multiplying the first equation by $C_{0}$ and the second equation by $\frac{Y}{\gamma}$ and subtracting the second from the first, we have

$$
1=\frac{\mathrm{C}_{0}-\mathrm{Y} / \gamma}{\lambda} \rightarrow \mathrm{C}_{0}=\lambda+\frac{\mathrm{Y}}{\gamma}
$$

So, the equation that governs $Y$ can be written as

$$
\frac{1}{\lambda+Y / \gamma-Y^{\gamma} \nu(1 / \hat{\theta})}+(1+\beta) Y^{-\gamma} \hat{H}^{\prime}\left((\lambda+Y / \gamma) Y^{-\gamma}\right)=\frac{1}{\lambda}
$$


We can rewrite the above equation as

$$
\frac{1}{(\lambda+Y / \gamma) Y^{-\gamma}-v(1 / \hat{\theta})}+(1+\beta) \hat{H}^{\prime}\left((\lambda+Y / \gamma) Y^{-\gamma}\right)=\frac{Y^{\gamma}}{\lambda}
$$

As we have noted above, inequality is governed by the variable $x=C_{0} Y^{-\gamma}=(\lambda+Y / \gamma) Y^{-\gamma}$ - As $x$ goes up inequality goes down. We want to characterize the behavior of various variables as a function of $\mathrm{V}$. Note that since the value function is concave - the constraint set is convex and the objective is linear, $\mathrm{B}^{\prime}(\mathrm{V})$ is a decreasing function of $\mathrm{V}$. Since by the envelope condition $B^{\prime}(V)=-\lambda$ and hence as $V$ increases $\lambda$ increases as well. So the characterization comes down to the behavior of various variables as a function of $\lambda$. We start with inequality $x$. Note that

$$
\begin{aligned}
\mathrm{dx} & =\mathrm{Y}^{-\gamma} \mathrm{d} \lambda+\left[-\gamma \mathrm{Y}^{-\gamma-1} \lambda+\frac{1-\gamma}{\gamma} \mathrm{Y}^{-\gamma}\right] \mathrm{d} Y \\
& =\mathrm{Y}^{-\gamma} \mathrm{d} \lambda-\mathrm{t} d \mathrm{Y} \\
\mathrm{d} Y & =\frac{\mathrm{dx}-\mathrm{Y}^{-\gamma} \mathrm{d} \lambda}{\mathrm{t}}
\end{aligned}
$$

where $t=\gamma Y^{-1-\gamma} \lambda+\frac{\gamma-1}{\gamma} Y^{-\gamma}>0$. Then we can write the above equation as

$$
\lambda\left[\frac{1}{x-\bar{v}}+(1+\beta) \hat{H}^{\prime}(x)\right]-\gamma^{\gamma}=0
$$

Taking derivatives

$$
\mathrm{d} \lambda\left[\frac{1}{x-\bar{v}}+(1+\beta) \hat{H}^{\prime}(x)\right]+\lambda\left[-\frac{1}{x-\bar{v}}+(1+\beta) \hat{H}^{\prime \prime}(x)\right] d x-\gamma Y^{\gamma-1} d Y=0
$$

or

$$
\mathrm{d} \lambda\left[\frac{\gamma \mathrm{Y}^{-1}}{\mathrm{t}}+\frac{1}{x-\bar{v}}+(1+\beta) \hat{\mathrm{H}}^{\prime}(x)\right]+\left[\left(-\frac{1}{x-\bar{v}}+(1+\beta) \hat{H}^{\prime \prime}(x)\right) \lambda-\frac{\gamma \gamma^{-1}}{t}\right] \mathrm{d} x=0
$$

As a result

$$
\frac{d x}{d \lambda}=-\frac{\frac{\gamma Y^{-1}}{t}+\frac{1}{x-\bar{v}}+(1+\beta) \hat{H}^{\prime}(x)}{\left(-\frac{1}{x-\bar{v}}+(1+\beta) \hat{H}^{\prime \prime}(x)\right) \lambda-\frac{\gamma \gamma^{\gamma-1}}{t}}>0
$$

and this is positive since the numerator is negative and denominator is positive. This implies that $x$ increases with $V$ and as a result inequality decreases as $V$ increases.

Case 2. Suppose that the constraint is binding. Then we can write the program as

$$
B(V)=\max Y-C_{0}-\frac{1}{1+r} C_{1}+\frac{1}{1+r} B\left(\underline{W}-\tilde{\beta}^{-1} \log C_{1}-\tilde{\beta}^{-1} H\left(C_{0}, Y\right)\right)
$$


subject to

$$
\log \left(C_{0}-v(Y / \hat{\theta})\right)+H\left(C_{0}, Y\right)+\hat{\beta} \underline{W}=V
$$

The FOCs are

$$
\begin{array}{r}
-1-\frac{\lambda}{C_{0}-v(Y / \hat{\theta})}-\frac{1}{\tilde{\beta}(1+r)} B^{\prime}\left(V^{\prime}\right) Y^{-\gamma} \hat{H}^{\prime}\left(C_{0} Y^{-\gamma}\right)+\lambda Y^{-\gamma} \hat{H}^{\prime}\left(C_{0} Y^{-\gamma}\right)=0 \\
-\frac{1}{1+r}-\frac{1}{\tilde{\beta}(1+r)} B^{\prime}\left(V^{\prime}\right) \frac{1}{C_{1}}=0 \\
1+\frac{1}{\tilde{\beta}(1+r)} \gamma Y^{-\gamma-1} \hat{H}^{\prime}\left(C_{0} Y^{-\gamma}\right) B^{\prime}\left(V^{\prime}\right)-\lambda \frac{v^{\prime}(Y / \hat{\theta}) / \hat{\theta}}{C_{0}-v(Y / \hat{\theta})}-\lambda \gamma Y^{-\gamma-1} \hat{H}^{\prime}\left(C_{0} Y^{-\gamma}\right)=0
\end{array}
$$

Note that as before

$$
\mathrm{C}_{0}=\lambda+\frac{\mathrm{Y}}{\gamma}
$$

So similar to what we had before, we can write

$$
\begin{aligned}
\mathrm{dx} & =\mathrm{Y}^{-\gamma} \mathrm{d} \lambda+\left[-\gamma \mathrm{Y}^{-\gamma-1} \lambda+\frac{1-\gamma}{\gamma} \mathrm{Y}^{-\gamma}\right] \mathrm{d} Y \\
& =\mathrm{Y}^{-\gamma} \mathrm{d} \lambda-\mathrm{t} \mathrm{d} Y \\
\mathrm{~d} Y & =\frac{\mathrm{d} x-\mathrm{Y}^{-\gamma} \mathrm{d} \lambda}{\mathrm{t}}
\end{aligned}
$$

We can write the first FOC as

$$
-Y^{\gamma}-\frac{\lambda}{C_{0} Y^{-\gamma}-v(1 / \hat{\theta})}-\frac{1}{\tilde{\beta}(1+r)} B^{\prime}\left(V^{\prime}\right) \hat{H}^{\prime}\left(C_{0} Y^{-\gamma}\right)+\lambda \hat{H}^{\prime}\left(C_{0} Y^{-\gamma}\right)=0
$$

or

$$
-Y^{\gamma}-\frac{\lambda}{x-\bar{v}}-\frac{1}{\tilde{\beta}(1+r)} B^{\prime}\left(V^{\prime}\right) \hat{H}^{\prime}(x)+\lambda \hat{H}^{\prime}(x)=0
$$

Taking derivative we can write

$$
\begin{aligned}
& -\gamma \gamma^{\gamma-1} d Y+\lambda\left(-\frac{1}{(x-\bar{v})^{2}}+\hat{H}^{\prime \prime}(x)\right) d x+\left(\frac{1}{x-\bar{v}}+\hat{H}^{\prime}(x)\right) d \lambda \\
& -\frac{1}{\tilde{\beta}(1+r)} B^{\prime}\left(V^{\prime}\right) \hat{H}^{\prime \prime}(x) d x-\frac{1}{\tilde{\beta}(1+r)} \hat{H}^{\prime}(x) B^{\prime \prime}\left(V^{\prime}\right) d V^{\prime}=0
\end{aligned}
$$


From the FOCs, we have

$$
\begin{aligned}
C_{1} & =-\frac{1}{\tilde{\beta}} B^{\prime}\left(V^{\prime}\right) \rightarrow d C_{1}=-\frac{1}{\tilde{\beta}} B^{\prime \prime}\left(V^{\prime}\right) d V^{\prime} \\
V^{\prime} & =\underline{W}-\tilde{\beta}^{-1} \log C_{1}-\tilde{\beta}-1 \hat{H}(x) \rightarrow d V^{\prime}=-\frac{1}{\tilde{\beta}} \frac{1}{C_{1}} d C_{1}-\frac{1}{\tilde{\beta}} \hat{H}^{\prime}(x) d x \\
d C_{1} & =-\frac{1}{\tilde{\beta}} B^{\prime \prime}\left(V^{\prime}\right)\left[-\frac{1}{\tilde{\beta}} \frac{1}{C_{1}} d C_{1}-\frac{1}{\tilde{\beta}} \hat{H}^{\prime}(x) d x\right] \\
& =-\frac{1}{\tilde{\beta}} B^{\prime \prime}\left(V^{\prime}\right)\left[\frac{1}{B^{\prime}\left(V^{\prime}\right)} d C_{1}-\frac{1}{\tilde{\beta}} \hat{H}^{\prime}(x) d x\right] \\
& =-\frac{1}{\tilde{\beta}} \frac{B^{\prime \prime}}{B^{\prime}} d C_{1}+\frac{1}{\tilde{\beta}^{2}} B^{\prime \prime} \hat{H}^{\prime} d x \\
d C_{1} & =\frac{\frac{1}{\tilde{\beta}^{2}} B^{\prime \prime} \hat{H}^{\prime}}{1+\frac{1}{\tilde{\beta}} \frac{B^{\prime \prime}}{B^{\prime}}} d x \\
d V^{\prime} & =-\frac{1}{B^{\prime \prime}} \tilde{\beta} d C_{1} \rightarrow d V^{\prime}=-\frac{\frac{1}{\tilde{\beta}} \hat{H}^{\prime}}{1+\frac{1}{\tilde{\beta}} \frac{B^{\prime \prime}}{B^{\prime}}} d x
\end{aligned}
$$

Note that $\frac{B^{\prime \prime}}{B^{\prime}}>0$. So we can rewrite

$$
\begin{array}{r}
-\gamma \gamma^{\gamma-1} \frac{d x-\gamma^{-\gamma} d \lambda}{t}+\lambda\left(-\frac{1}{(x-\bar{v})^{2}}+\hat{H}^{\prime \prime}(x)\right) d x+\left(\frac{1}{x-\bar{v}}+\hat{H}^{\prime}(x)\right) d \lambda \\
-\frac{1}{\tilde{\beta}(1+r)} B^{\prime}\left(V^{\prime}\right) \hat{H}^{\prime \prime}(x) d x+\frac{1}{\tilde{\beta}(1+r)} \hat{H}^{\prime}(x) B^{\prime \prime}\left(V^{\prime}\right) \frac{\frac{1}{\tilde{\beta}} \hat{H}^{\prime}}{1+\frac{1}{\tilde{\beta}} \frac{B^{\prime \prime}}{B^{\prime}}} d x=0
\end{array}
$$

and we can write

$$
\begin{aligned}
& \mathrm{d} x \quad\left[-\frac{\gamma \gamma^{\gamma-1}}{\mathrm{t}}+\lambda\left(-\frac{1}{(x-\bar{v})^{2}}+\hat{\mathrm{H}}^{\prime \prime}(\mathrm{x})\right)-\frac{1}{\tilde{\beta}(1+\mathrm{r})} \mathrm{B}^{\prime}\left(\mathrm{V}^{\prime}\right) \hat{\mathrm{H}}^{\prime \prime}(\mathrm{x})\right. \\
& \left.+\frac{1}{\tilde{\beta}(1+r)} \hat{H}^{\prime}(x) B^{\prime \prime}\left(V^{\prime}\right) \frac{\frac{1}{\tilde{\beta}} \hat{H}^{\prime}}{1+\frac{1}{\tilde{\beta}} \frac{B^{\prime \prime}}{B^{\prime}}}\right]= \\
& {\left[-\hat{\mathrm{H}}^{\prime}-\frac{1}{x-\bar{v}}-\frac{\gamma \mathrm{Y}^{-1}}{\mathrm{t}}\right] \mathrm{d} \lambda \rightarrow \frac{\mathrm{d} x}{\mathrm{~d} \lambda}>0} \\
& \frac{d V^{\prime}}{d \lambda}=-\frac{\frac{1}{\tilde{\beta}} \hat{H}^{\prime}}{1+\frac{1}{\tilde{\beta}} \frac{B^{\prime \prime}}{B^{\prime}}} \frac{d x}{d \lambda}<0
\end{aligned}
$$

This completes the proof that $\mathrm{V}^{\prime}$ is decreasing in $\lambda$ and as a result in $\mathrm{V}$. Hence, we have the following proposition:

Proposition 7. The continuation value for the policy function $\mathrm{V}^{\prime}(\mathrm{V})$ in (91) is $U$-shaped in $\mathrm{V}$. 


\subsection{BGP Preferences}

For generic time separable preferences $\mathrm{U}\left(\mathrm{C}_{0}, \mathrm{Y}\right)+\beta \mathrm{U}\left(\mathrm{C}_{1}, 0\right)$, we cannot write the planning problem recursively using external government debt as a state variable. However, there is an alternative formulation in which we use total debt $\hat{B}$ as a state variable and solve:

$$
V(\hat{B})=\max \sum_{i} \mu^{i} \alpha^{i}\left[U\left(c_{0}^{i}, y^{i}\right)+\beta U\left(c_{1}^{i}, 0\right)\right]+\hat{\beta} V\left(\frac{c_{1}^{i}}{1+r}+B^{\prime}\right)
$$

subject to

$$
\begin{aligned}
& \sum_{i} \mu^{i}\left[c_{0}^{i}+\frac{c_{1}^{i}}{1+r}\right]+G+\hat{B} \leqslant \sum_{i} \mu^{i} y^{i}+\frac{B^{\prime}}{1+r} \\
& \frac{\beta}{\hat{\beta}} \sum_{i} \mu^{i} \alpha^{i} U\left(c_{1}^{i}, 0\right)+V\left(\hat{B}^{\prime}\right) \geqslant \underline{W}
\end{aligned}
$$

Let preferences be BGP (Cobb-Douglass):

$$
\mathrm{u}(\mathrm{c}, \mathrm{l})=\frac{\left(\mathrm{c}^{1-\psi}(1-l)^{\psi}\right)^{1-\sigma}}{1-\sigma}
$$

Using the characterization of competitive equilibrium outcomes in Lemma 8, we can write the programming problem above solely in terms of aggregates. In fact, if the market weights are $\Phi=\left\{\varphi^{i}\right\}$ then from the FOCs for market utility problem we can express individual allocations as

$$
\begin{aligned}
c_{0 i} & =\frac{\varphi_{i}^{1 / \sigma} \theta_{i}^{\psi(\sigma-1) / \sigma}}{\sum_{j} \mu_{j}\left[\varphi_{j}^{1 / \sigma} \theta_{j}^{\psi(\sigma-1) / \sigma}\right]} C_{0}=s_{0}^{i}(\Phi) C_{0} \\
1-l_{i} & =\frac{\varphi_{i}^{1 / \sigma} \theta_{i}^{\psi(\sigma-1) / \sigma}}{\sum_{j} \mu_{j}\left[\varphi_{j}^{1 / \sigma} \theta_{j}^{\psi(\sigma-1) / \sigma}\right]} \frac{(1-Y)}{\theta_{i}}=s_{0}^{i}(\Phi) \frac{(1-Y)}{\theta_{i}} \\
c_{1 i} & =\frac{\varphi_{i}^{-1 /[(1-\psi)(1-\sigma)-1]}}{\sum_{j} \mu_{j} \varphi_{j}^{-1 /[(1-\psi)(1-\sigma)-1]}} C_{1}=s_{1}^{i}(\Phi) C_{1}
\end{aligned}
$$

so that

$$
\begin{aligned}
\sum_{i} \mu^{i} \alpha^{i} U\left(c_{0}^{i}, y^{i}\right) & =A_{0}(\Phi) U\left(C_{0}, Y\right) \\
\sum_{i} \mu^{i} \alpha^{i} U\left(c_{1}^{i}, 0\right) & =A_{1}(\Phi) U(C, 0)
\end{aligned}
$$


where

$$
\begin{aligned}
& A_{0}(\Phi)=\sum_{i} \mu^{i} \alpha^{i} s_{0}^{i}(\Phi)^{1-\sigma} \theta_{i}^{-\psi(1-\sigma)} \\
& A_{1}(\Phi)=\sum_{i} \mu^{i} \alpha^{i} s_{1}^{i}(\Phi)^{(1-\sigma)(1-\psi)}
\end{aligned}
$$

Moreover the implementability conditions are

$$
\hat{\mathrm{T}}=\mathrm{c}_{0}^{i}+\beta \frac{(1-\psi)\left(\mathrm{c}_{1}^{\mathfrak{i}}\right)^{(1-\psi)(1-\sigma)-1}}{(1-\psi)(1-\sigma) \mathrm{U}\left(\mathrm{c}_{0}^{\mathrm{i}}, l^{\mathrm{i}}\right) / \mathrm{c}_{0}^{\mathrm{i}}} \mathrm{c}_{1}^{\mathrm{i}}-\frac{\psi}{1-\psi} \frac{\mathrm{c}_{\mathfrak{i}}}{1-\mathrm{l}_{i}} \mathrm{l}_{\mathrm{i}}
$$

for some $\hat{T}$. Using (92), (93), and (94) in (99) implicitly defines $\Phi=\Phi\left(C_{0}, Y, C_{1}\right)$. We can then write the problem (in dual form) using only aggregates as

$$
\hat{B}(V)=\max Z Y-C_{0}-\frac{C_{1}}{1+r}-G+\frac{1}{1+r} \hat{B}\left(V^{\prime}\right)
$$

subject to

$$
\begin{aligned}
A_{0}\left(\Phi\left(C_{0}, Y, C_{1}\right)\right) U\left(C_{0}, Y\right)+\beta A_{1}\left(\Phi\left(C_{0}, Y, C_{1}\right)\right) U\left(C_{1}, 0\right)+\hat{\beta} V^{\prime} & =V \\
\frac{\beta}{\hat{\beta}} A_{1}\left(\Phi\left(C_{0}, Y, C_{1}\right)\right) U\left(C_{1}, 0\right)+V^{\prime} & \geqslant \underline{W}
\end{aligned}
$$

Figure 5 shows the policy functions associated with this problem. The result is that $V^{\prime}(V)$ is U-shaped (and so $\hat{B}^{\prime}$ and $B^{\prime}$ are hump-shaped).

\section{Three-Period OLG}

In this section, we argue that overshooting and the cyclical dynamics are robust features of the environment and not special to the two-period OLG structure considered in the text. To address this point, consider an economy where agents live for three periods an work only when young. The preferences are

$$
\log c_{0}+\psi \log (1-y / \theta)+\beta \log c_{1}+\beta^{2} \log c_{2}
$$

Using a similar logic to the one used for the baseline economy, we can solve for the best sustainable equilibrium recursively using foreign debt $B$ and past period output $Y_{-}$ as state variables:

$V\left(B, Y_{-}\right)=\max _{B^{\prime}, Y} \kappa \log \left(Y+\frac{B^{\prime}}{1+r}-B-G\right)+\psi \log (1-Y)-\left(1+\psi+\beta+\beta^{2}\right) H(Y)+\hat{\beta} V\left(B^{\prime}, Y\right)$ 

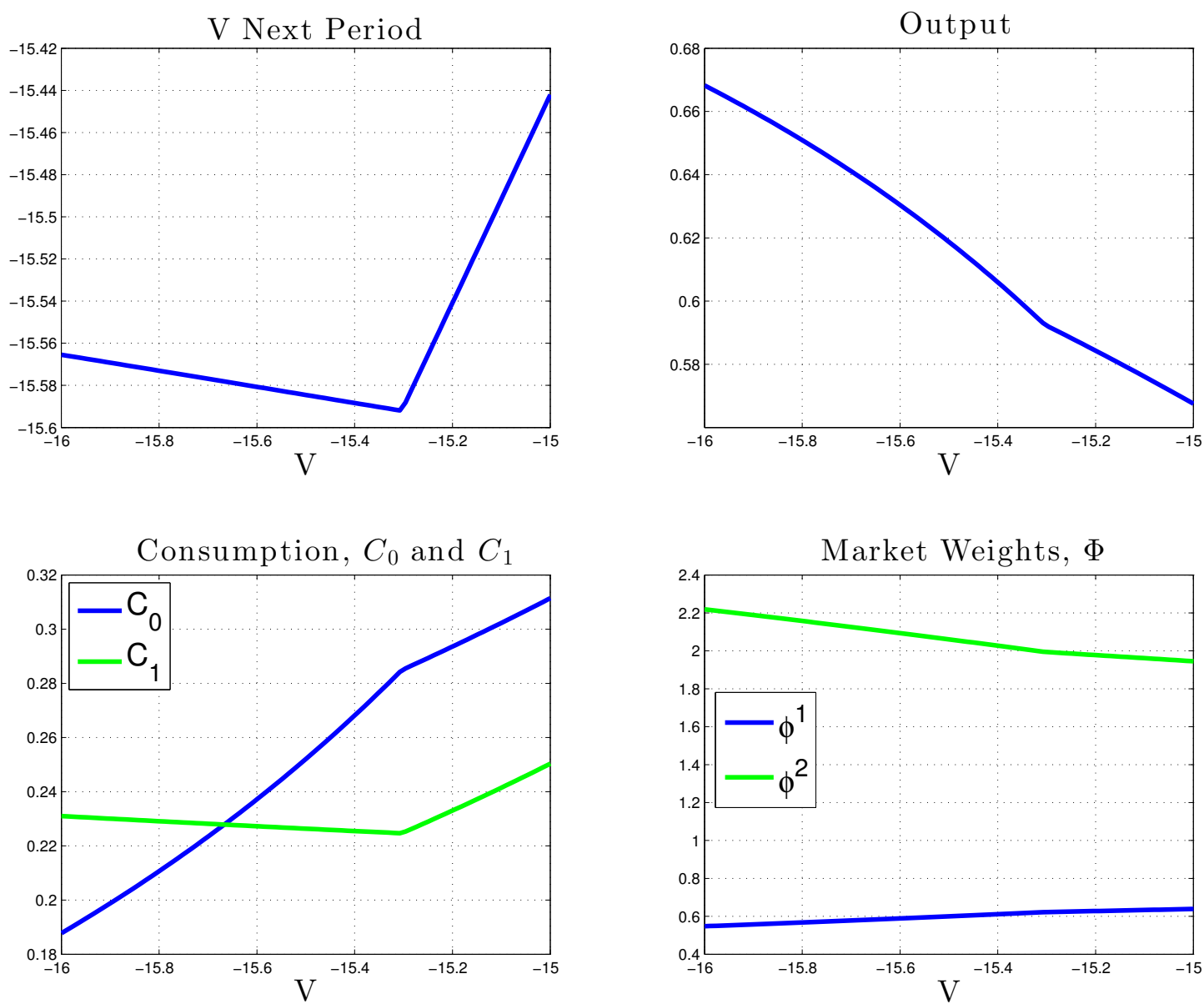

Figure 5: Policy functions with BGP preferences

subject to

$$
W\left(B, Y_{-}, Y\right)=-\left(\frac{\beta}{\hat{\beta}}\right)^{2} H\left(Y_{-}\right)-\frac{\left(\beta+\beta^{2}\right)}{\hat{\beta}} H(Y)+V\left(B^{\prime}, Y\right) \geqslant \underline{W}
$$

where $\mathrm{k}$ now is given by $1+\beta / \hat{\beta}+(\beta / \hat{\beta})^{2}$ and $\underline{W}$ is defined in a similar way to the analog in our baseline economy.

A complete analytical characterization of the dynamics is not available. However, we are still able to show that for any given $Y_{-}$the policy function for foreign debt $B^{\prime}\left(B, Y_{-}\right)$ is hump-shaped in $B$ as shown in Figure 6. That is, given $Y_{-}, B^{\prime}\left(B, Y_{-}\right)$is increasing in $B$ for low values of $B$ and when the sustainability constraint is not binding. Furthermore, it is decreasing in $B$ for high values of $B$ and when the sustainability constraint is binding. ${ }^{19}$

\footnotetext{
${ }^{19} \mathrm{~A}$ proof is available upon request.
} 

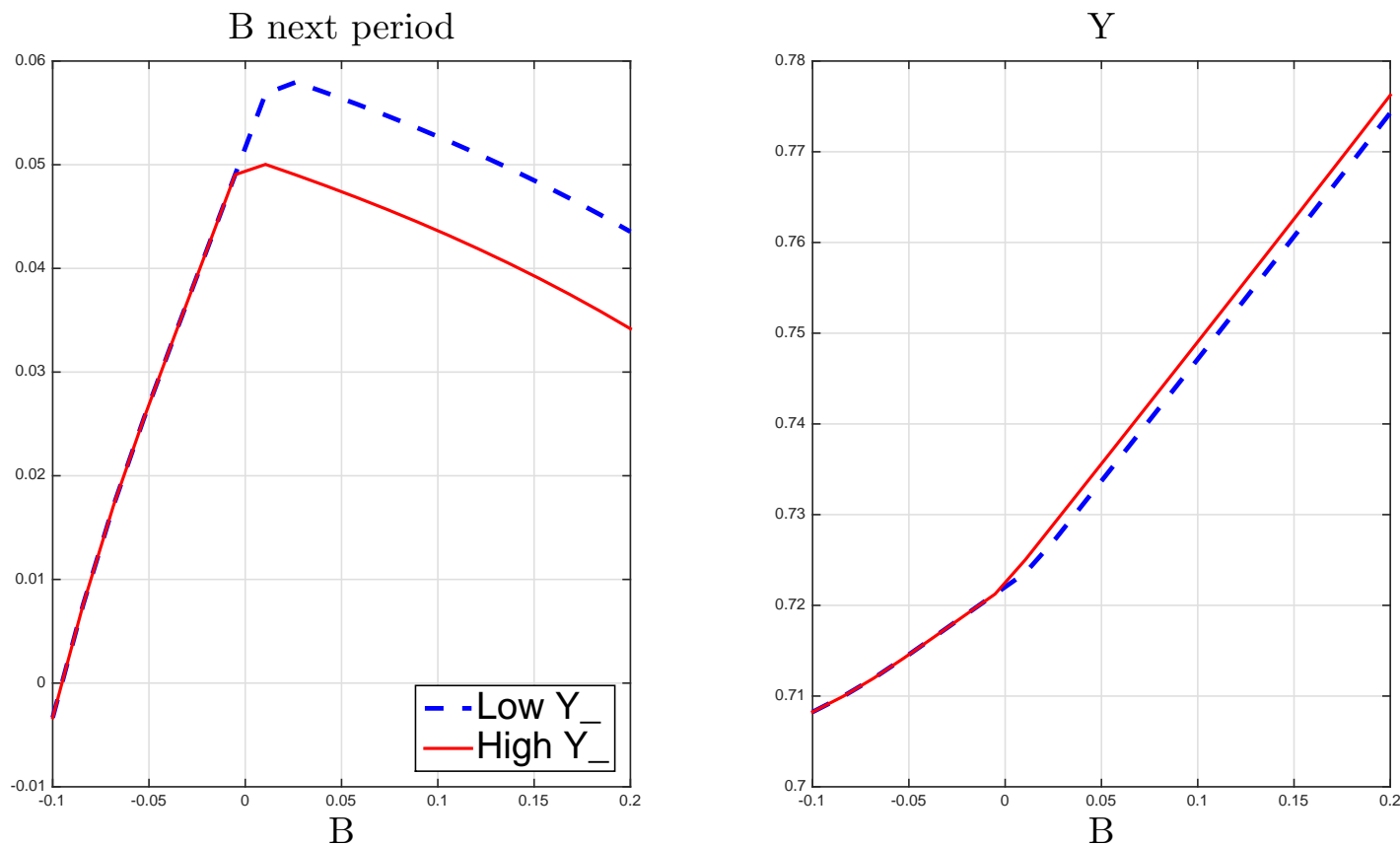

Figure 6: Policy Functions with three-period OLG

Hence this economy features overshooting as our baseline case.

The fact that $B^{\prime}$ is hump-shaped in $B$ is not enough to show that a sample path has an oscillatory dynamics if $\hat{\beta}(1+r)<1$. This is because the level of foreign debt issued also negatively depends on lagged output (current inequality among middle aged people) as shown in Figure 6. However, we can solve the model numerically and show that this economy still has a cyclical pattern. Figure 7 shows a typical outcome path. When the government inherits high foreign debt - above the steady state value - the convergence to the final steady state is cyclical. The difference here is that now the length of each cycle lasts two periods and not one. 


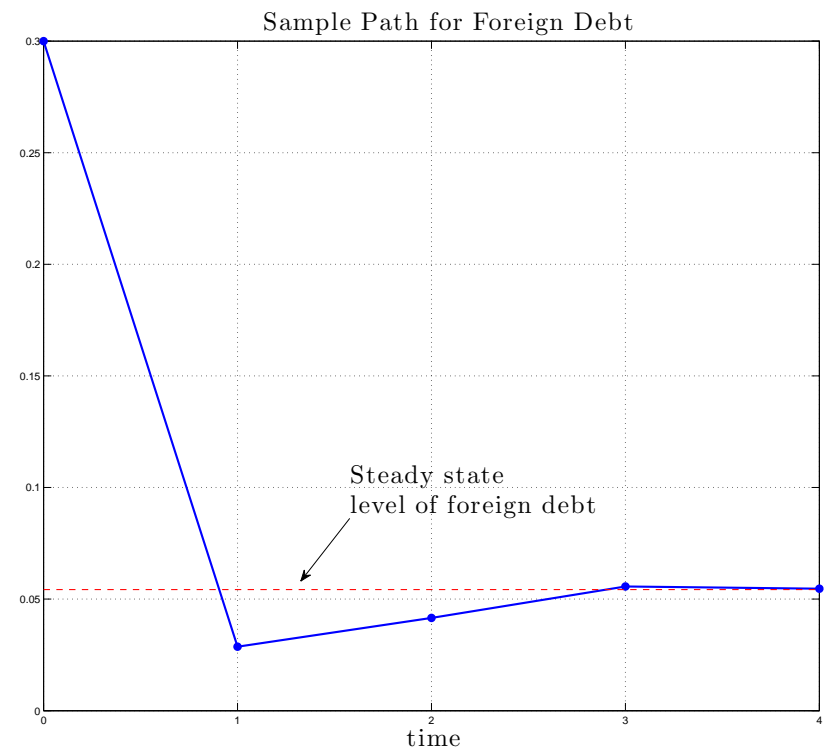

Figure 7: Overshooting and cycles with three-period OLG 